\title{
THESIS
}

\section{LATENT HEATING AND MIXING DUE TO ENTRAINMENT IN TROPICAL DEEP CONVECTION}

\author{
Submitted by \\ Clayton J. McGee \\ Department of Atmospheric Science
}

\author{
In partial fulfillment of the requirements \\ For the Degree of Master of Science \\ Colorado State University \\ Fort Collins, Colorado
}

Spring 2013

Master's Committee:

Advisor: Susan van den Heever

Eric Maloney

Richard Eykholt 


\section{ABSTRACT \\ LATENT HEATING AND MIXING DUE TO ENTRAINMENT IN TROPICAL DEEP CONVECTION}

Recent studies have noted the role of latent heating above the freezing level in reconciling Riehl and Malkus' Hot Tower Hypothesis (HTH) with evidence of diluted tropical deep convective cores. This study evaluates recent modifications to the HTH through Lagrangian trajectory analysis of deep convective cores in an idealized, high-resolution cloud-resolving model (CRM) simulation. A line of tropical convective cells develops within a high-resolution nested grid whose boundary conditions are obtained from a large-domain CRM simulation approaching radiative-convective equilibrium (RCE). Microphysical impacts on latent heating and equivalent potential temperature $\left(\theta_{\mathrm{e}}\right)$ are analyzed along trajectories ascending within convective regions of the high-resolution nested grid. Changes in $\theta_{\mathrm{e}}$ along backward trajectories are partitioned into contributions from latent heating due to ice processes and a residual term. This residual term is composed of radiation and mixing. Due to the small magnitude of radiative heating rates in the convective inflow regions and updrafts examined here, the residual term is treated as an approximate representation of mixing within these regions. The simulations demonstrate that mixing with dry air decreases $\theta_{\mathrm{e}}$ along ascending trajectories below the freezing level, while latent heating due to freezing and vapor deposition increase $\theta_{\mathrm{e}}$ above the freezing level. The latent heating contributions along trajectories from cloud nucleation, condensation, evaporation, freezing, deposition, and sublimation are also quantified. Finally, the source regions of trajectories reaching the upper troposphere are identified; it is found that two-thirds of backward trajectories with starting points within strong updrafts or downdrafts above $10 \mathrm{~km}$ 
have their origin at levels higher than $2 \mathrm{~km}$ AGL. The importance of both boundary layer and mid-level inflow in moist environments is underscored in this study. 


\section{ACKNOWLEDGEMENTS}

My sincere appreciation is extended to my advisor, Professor Sue van den Heever for her consistent and patient guidance in my development as a scientist, as well as for the positive and collaborative environment she helped foster within the research group. I am tremendously grateful for her leadership and the professional and personal development I experienced under her mentorship. Special thanks are extended to Matthew Igel for designing and running the original outer grid RCE simulation, which served as a platform for this study. I also thank Steve Saleeby for providing the microphysical budgeting code within RAMS, which was critical in diagnosing the latent heating budgets. Thank you to Natalie Tourville for excellent technical support of all computers and clusters. I would also like to express my gratitude to all past and current van den Heever research group members for many tremendously helpful scientific discussions along the way. Finally, I want to thank my parents for their consistent love and support.

This work was funded by NASA grant NNX10AM41G. 


\section{TABLE OF CONTENTS}

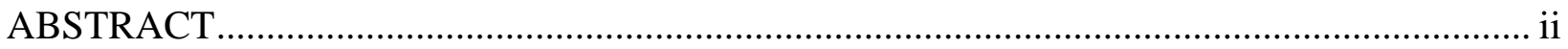

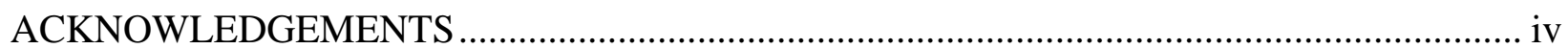

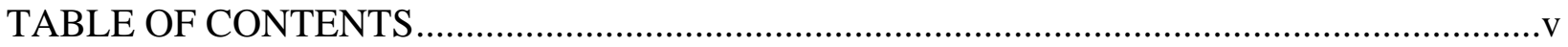

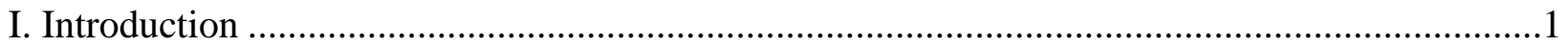

1.1. The Hot Tower Hypothesis ...................................................................................

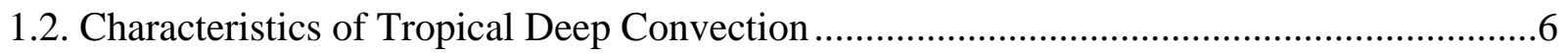

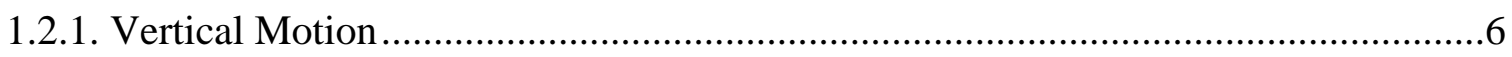

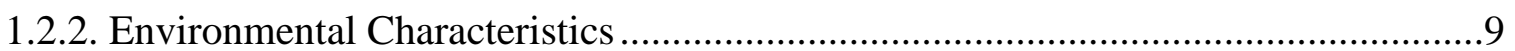

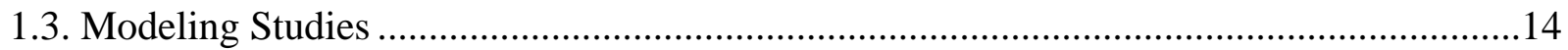

1.3.1. CRM Investigations ………………………….......................................14

1.3.2. The Role of Microphysical Schemes ................................................................ 17

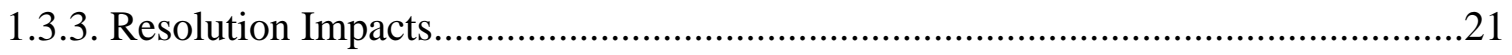

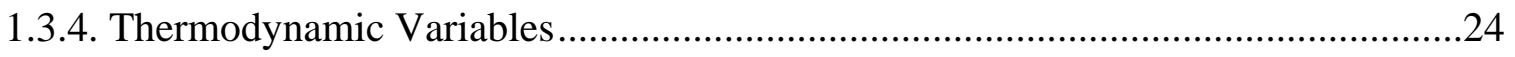

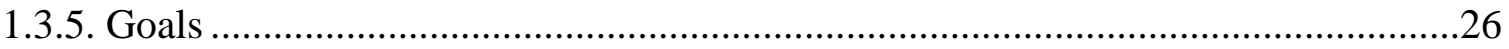

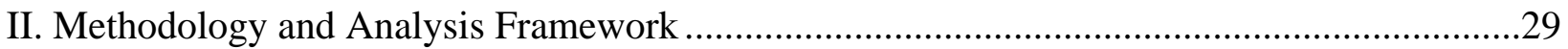

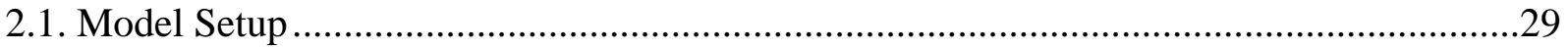

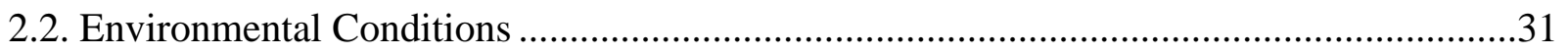

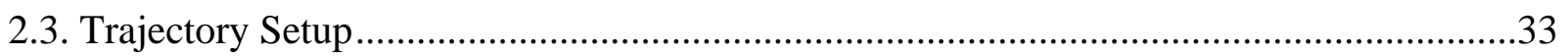

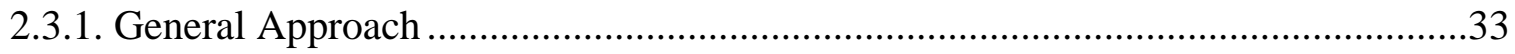

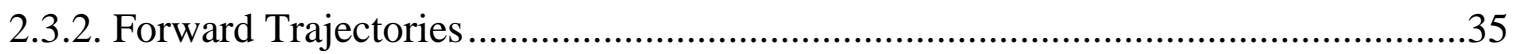

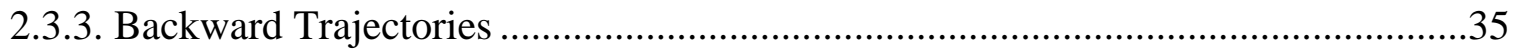

2.3.4. Interpolation and Ignored Trajectories..............................................................38

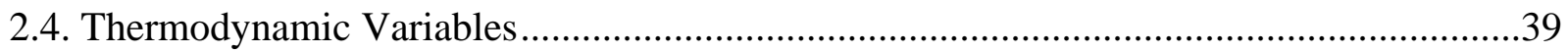

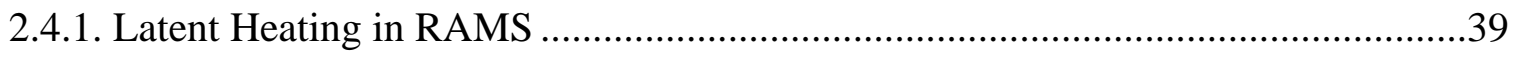

2.4.2. Equivalent Potential Temperature....................................................................... 40

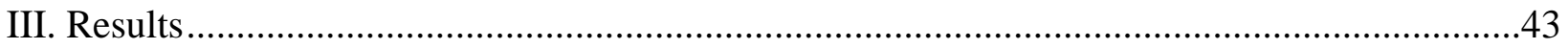

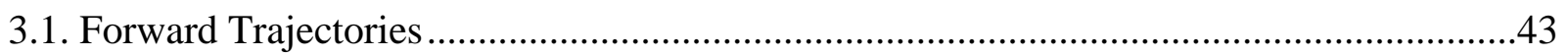

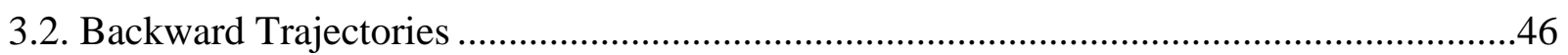

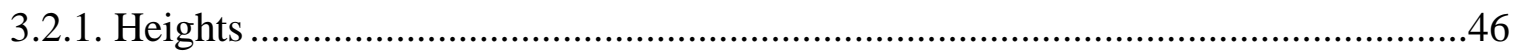

3.2.2. Latent Heating Changes .....................................................................................49

3.2.3. Equivalent Potential Temperature Changes........................................................55

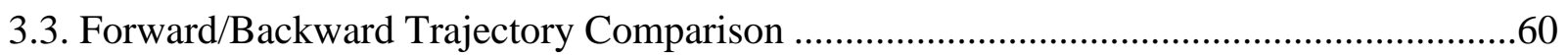

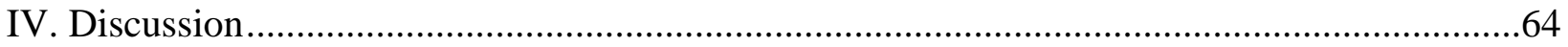




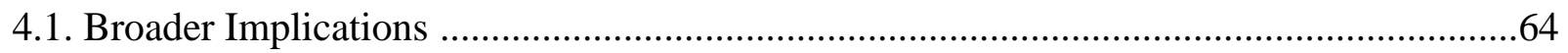

4.2. Consequences of the Pseudoadiabatic Assumption ..................................................65

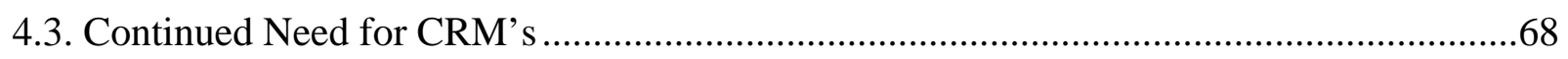

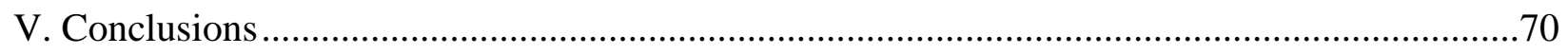

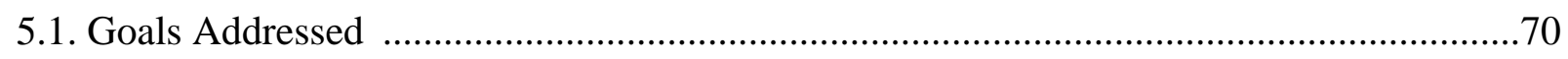

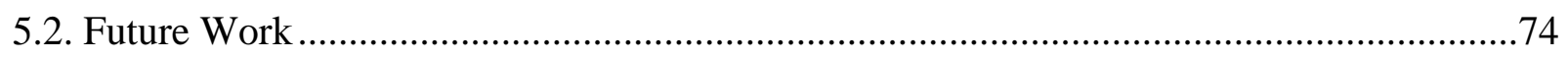

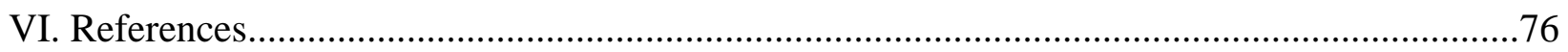




\section{Introduction}

\subsection{The Hot Tower Hypothesis}

Tropical deep convection is critically important to the atmospheric general circulation. Deep convection along the equatorial belt is the driving force behind the Hadley circulation, which is characterized by an ascending branch in equatorial latitudes and a descending branch in the subtropics. This relationship between deep moist convection and the Hadley circulation has been appreciated for some time, and was first emphasized by Riehl and Malkus (1958).

Observations of the tropical atmosphere following World War II confirmed the presence of a mid-tropospheric minimum in the mean vertical profile of moist static energy (MSE). MSE is the summation of air's sensible energy, latent energy, and potential energy. Figure 1.1 illustrates the mean vertical profiles of MSE in the tropical atmosphere. The increase of MSE above this midtropospheric minimum is what attracted the attention of Riehl and Malkus. In their groundbreaking 1958 study they reasoned that it would be impossible for a slow mass circulation to explain the observed MSE profile, since air traveling in the ascending branch of the Hadley cell would have to go against the mean gradient in MSE when moving from the middle to the upper troposphere.

In what would later become known as the "Hot Tower Hypothesis" (HTH), Riehl and Malkus (1958) proposed that undiluted deep convective cores (later known as "hot towers") were responsible for transporting air with high MSE from the boundary layer directly to the upper troposphere. Such cores are defined as "undiluted" when MSE is constant in the vertical through the core such that ascending parcels' MSE values are conserved. Conservation of MSE means that changes in water vapor that affect the latent energy must be compensated by the 


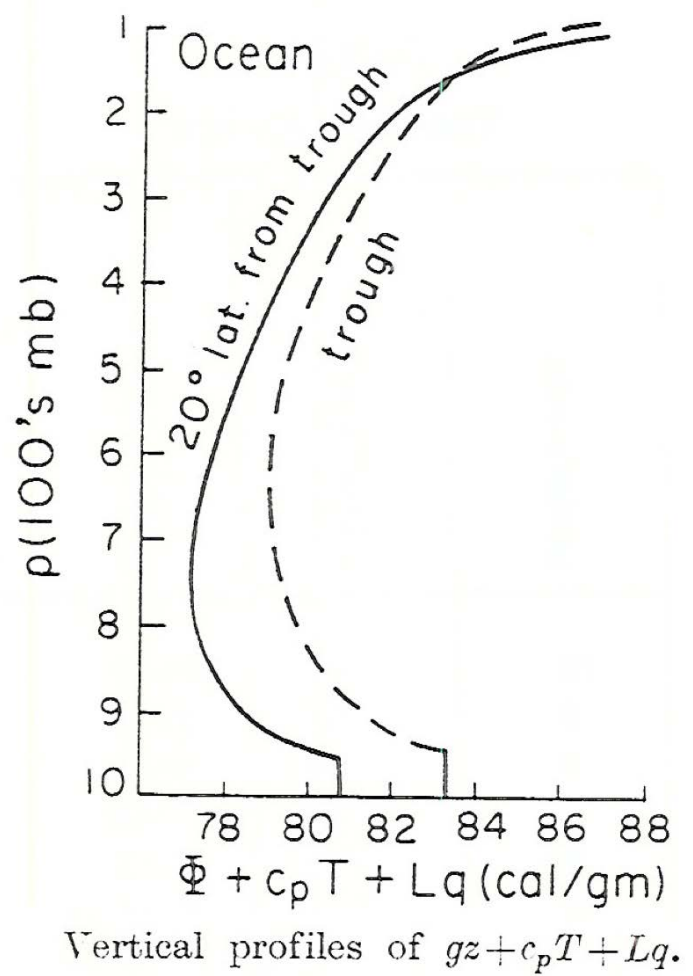

Fig. 1.1: Vertical profiles of moist static energy in the tropics (after Riehl and Malkus 1958).

corresponding realization of latent energy as sensible heat. From a MSE perspective, undiluted convection exists only when latent energy (which is a function of water vapor) following a parcel changes solely due to either condensation or evaporation. Thus, the undiluted convective cores Riehl and Malkus envisioned were fundamentally characterized by the absence of mixing with environmental air of different latent energy. Figure 1.2 shows a convective tower that, for the sake of illustration, is assumed to conform to the associated labels that fit the conceptual model of Riehl and Malkus. They calculated that it would take 1500 to 5000 active undiluted convective towers to accomplish the entire atmospheric mass transport observed within the Hadley circulation.

Field campaigns in the following decades allowed for detailed observations of tropical deep convection and an opportunity to test the HTH. Measurements of vertical velocity were made for a range of tropical convective systems. LeMone and Zipser (1980) and Zipser and 


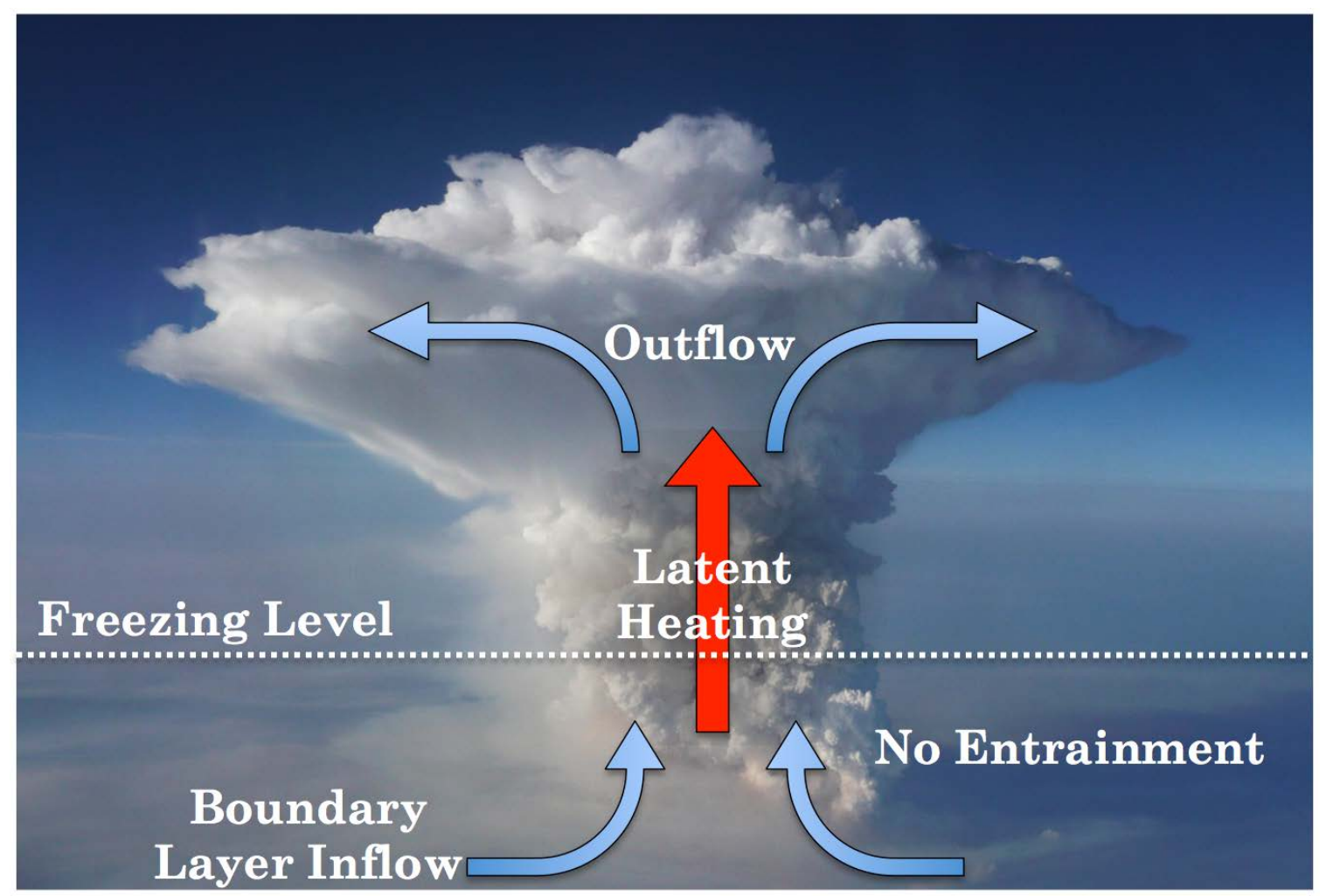

Fig. 1.2: Hot tower and associated labels that fit with the Hot Tower Hypothesis as proposed by Riehl and Malkus (1958). Background photo courtesy of Andrew Grosse.

LeMone (1980) compiled statistics on the intensities of convective updrafts intercepted by aircraft during the Global Atmospheric Research Program (GARP) Atlantic Tropical Experiment (GATE) in the eastern tropical Atlantic. Igau et al. (1999) performed a similar analysis of Electra data gathered during the Tropical Ocean Global Atmosphere Coupled Ocean Atmosphere Response Experiment (TOGA COARE) in the Western Pacific. Jorgensen et al. (1985) reported aircraft measurements of updrafts in the eyewall and rainbands of hurricanes. Radar wind profilers and dual-Doppler analysis also captured vertical velocity measurements of tropical convection (Balsley et al. 1988; Chilson et al. 1993; May and Rajopadhyaya 1996, Yuter and Houze 1995 a,b,c; Cifelli and Rutledge 1998). The weakness of observed updrafts compared to the updraft strengths that would be expected during undiluted ascent began to challenge the "undilute" requirement within the HTH. Although some aircraft measurements of vertical 
velocity were likely unable to capture the strongest updrafts due to flight safety considerations, it became increasingly clear that undiluted convection was far from ubiquitous.

In fact, in an assessment of the HTH fifty years after its inception, Zipser (2003) summarized accumulated observations by stating that "undiluted updraft cores are not found" in the tropical atmosphere. Zipser argued that since parcels ascending from the boundary layer experience significant amounts of dry air entrainment and water loading, these parcels require additional buoyancy provided by latent heating above the freezing level in order to reach the upper troposphere. To provide evidence for Zipser's argument, Fierro et al. (2009) performed a high-resolution modeling study of a tropical squall line and quantified changes in equivalent potential temperature $\left(\theta_{\mathrm{e}}\right)$ as a function of height along trajectories ascending from the boundary layer (Figure 1.3). Fierro et al. (2009) noted that $\theta_{\mathrm{e}}$ decreases in the lowest few kilometers due
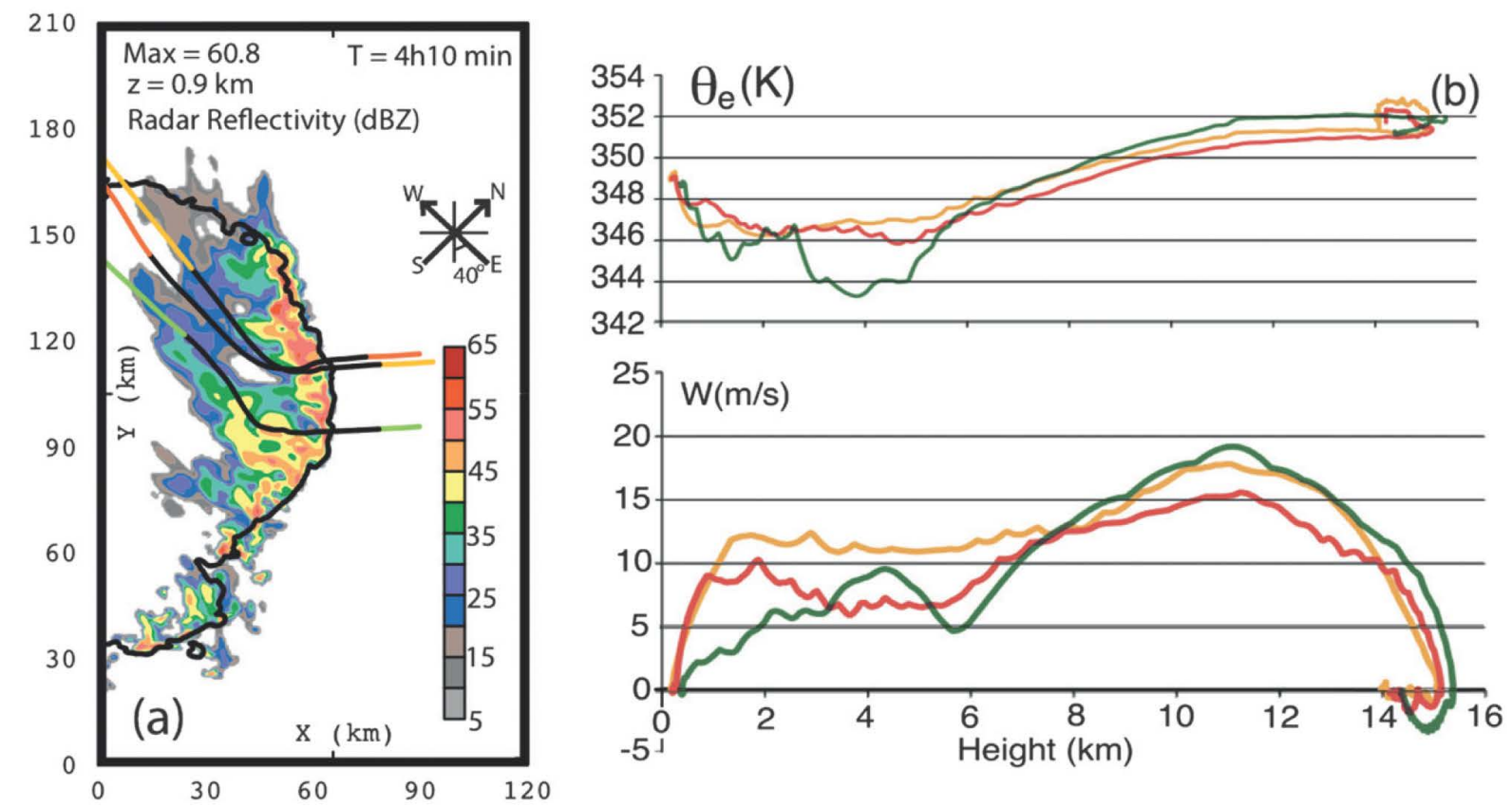

Fig. 1.3: (a) Radar reflectivity in the simulated squall line with sample parcel trajectories overlain as lines. (b) Vertical profiles of $\theta_{\mathrm{e}}$ and vertical velocity for these three trajectories (after Fierro et al. 2009). 
to the mixing of drier environmental air into the convection. They also highlighted an increase in $\theta_{\mathrm{e}}$ for many parcels above the freezing level. As a result, they presented a modified definition of hot towers as "any deep convective tower rooted on the boundary layer and topping in the upper troposphere", regardless of the degree of dilution. Figure 1.4 illustrates this modified definition of hot towers. A subsequent investigation by Fierro et al. (2012) began to quantify the specific latent heating processes that could lead to the vertical distribution of $\theta_{\mathrm{e}}$ reported in Fierro et al. (2009). Latent heating along a representative trajectory showed significant amounts of freezing and vapor deposition above the freezing level.

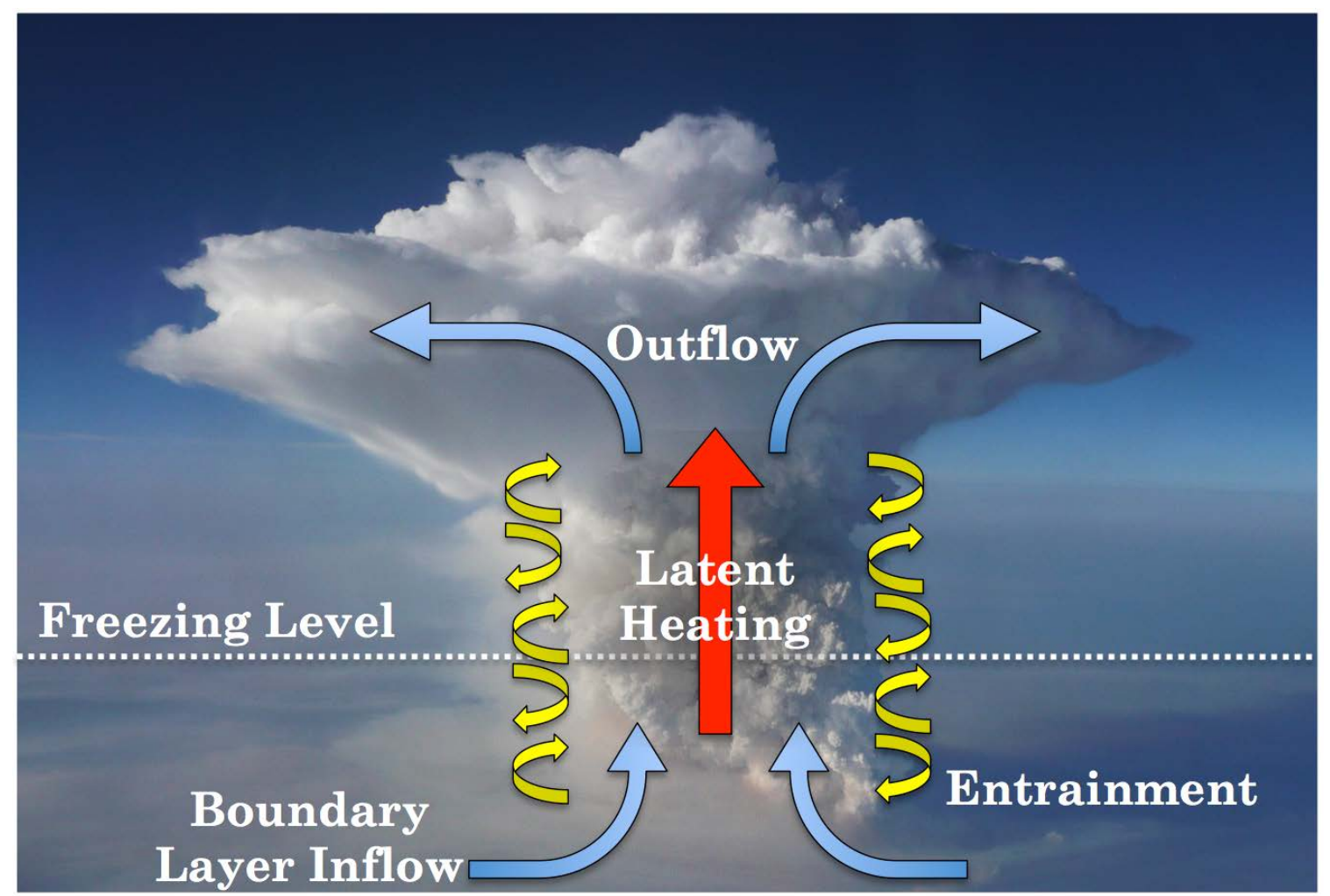

Fig. 1.4: Modified schematic of a hot tower based on the findings of Zipser (2003), Fierro et al. (2009), Fierro et al. (2012), and Romps and Kuang (2010). Yellow arrows indicate entrainment and red arrow indicates latent heating in the updraft that provides convective buoyancy for ascent. 
In summary, from the days of Riehl and Malkus (1958) through to the present day, tropical thunderstorms have been viewed as integral drivers of the atmospheric general circulation, but the role of dilution and ice processes have only been acknowledged more recently. The following sections in chapter I provide a more descriptive overview of the characteristics of tropical deep convection as interpreted from observations (Section 1.2) and model experiments (Section 1.3) through the past several decades. In section 1.2.1, observations of tropical deep convective motions are summarized in order to provide explanation for the evolution of the HTH since its inception. In sections 1.2.2 and 1.3.1, an overview of the environments favorable for deep convection in the tropics is provided and the processes that control the vertical distribution of energy within tropical convective systems are discussed. The consequences of choosing different microphysical schemes are discussed in section 1.3.2, and the impacts of varying model resolution are highlighted within previous studies in section 1.3.3. Section 1.3.4 provides information about conserved thermodynamic variables needed to accurately calculate the thermodynamic budget calculations introduced in Chapter II. Goals of the study are outlined in section 1.3.5.

\subsection{Characteristics of Tropical Deep Convection}

\subsubsection{Vertical Motion}

Observations of updraft intensity provide insight into whether convection is really undiluted, since dilution due to entrainment and/or momentum mixing reduces an updraft's buoyancy and thereby reduces its vertical velocity. Since the HTH posited that the Hadley circulation is driven by a population of undiluted convective updrafts, it is therefore useful to examine the characteristics of tropical convective vertical motion in order to assess whether 
tropical deep convection is actually undiluted. Updrafts analyzed by LeMone and Zipser (1980) exhibited a log-normal distribution in metrics of convective intensity such as vertical velocity and diameter, and stronger and larger updrafts were less common than weaker, smaller ones; only $10 \%$ of all cores were larger than $2 \mathrm{~km}$ in diameter, and $10 \%$ of all cores had vertical velocities stronger than $5 \mathrm{~m} \mathrm{~s}^{-1}$. Cores were defined as having vertical velocity greater than the absolute value of $1 \mathrm{~m} \mathrm{~s}^{-1}$ continuously for more than $0.5 \mathrm{~km}$ along a flight track. They also noted that downdrafts were typically weaker than updrafts except near cloud base. In a related analysis, Zipser and LeMone (1980) noted that convective cores in GATE were often embedded within larger mesoscale systems.

TOGA COARE provided another opportunity to make measurements of tropical updrafts. Similar to what was observed for GATE, Lucas et al. (1994) reported a log-normal distribution for mass flux, core diameter, and vertical velocity. Cores were observed to be weaker than what would be predicted from adiabatic parcel theory. Igau et al. (1999) showed that maritime COARE updrafts were generally weaker and smaller than continental tropical convection. Under the assumption of saturation, many downdrafts were calculated to be positively buoyant. The relative unlikelihood of positively buoyant downdrafts led them to conclude that many cores are actually unsaturated. This is not surprising given that evaporative cooling often accompanies downdrafts even in the lower troposphere where the lower levels are frequently quite moist.

Other field campaigns have been useful in documenting characteristics of tropical convective updrafts and downdrafts. Wind profiler data compiled by Cifelli and Rutledge (1998) showed local maxima in updraft intensities at $4 \mathrm{~km}$ and in the upper troposphere for convective cores observed within oceanic squall lines near Darwin, Australia. Anderson et al. (2005) observed similar updraft sizes and intensities between cores observed during the Tropical 
Rainfall Measuring Mission Large Scale Biosphere-Atmosphere (TRMM-LBA) experiment in the Amazon and the Kwajalein Experiment (KWAJEX) in the central Pacific Ocean (Figure 1.5). Heymsfield et al. (2010) compiled observations collected by the airborne high altitude nadirviewing ER-2 Doppler radar (EDOP). Using derived relationships for fall speed, vertical motion
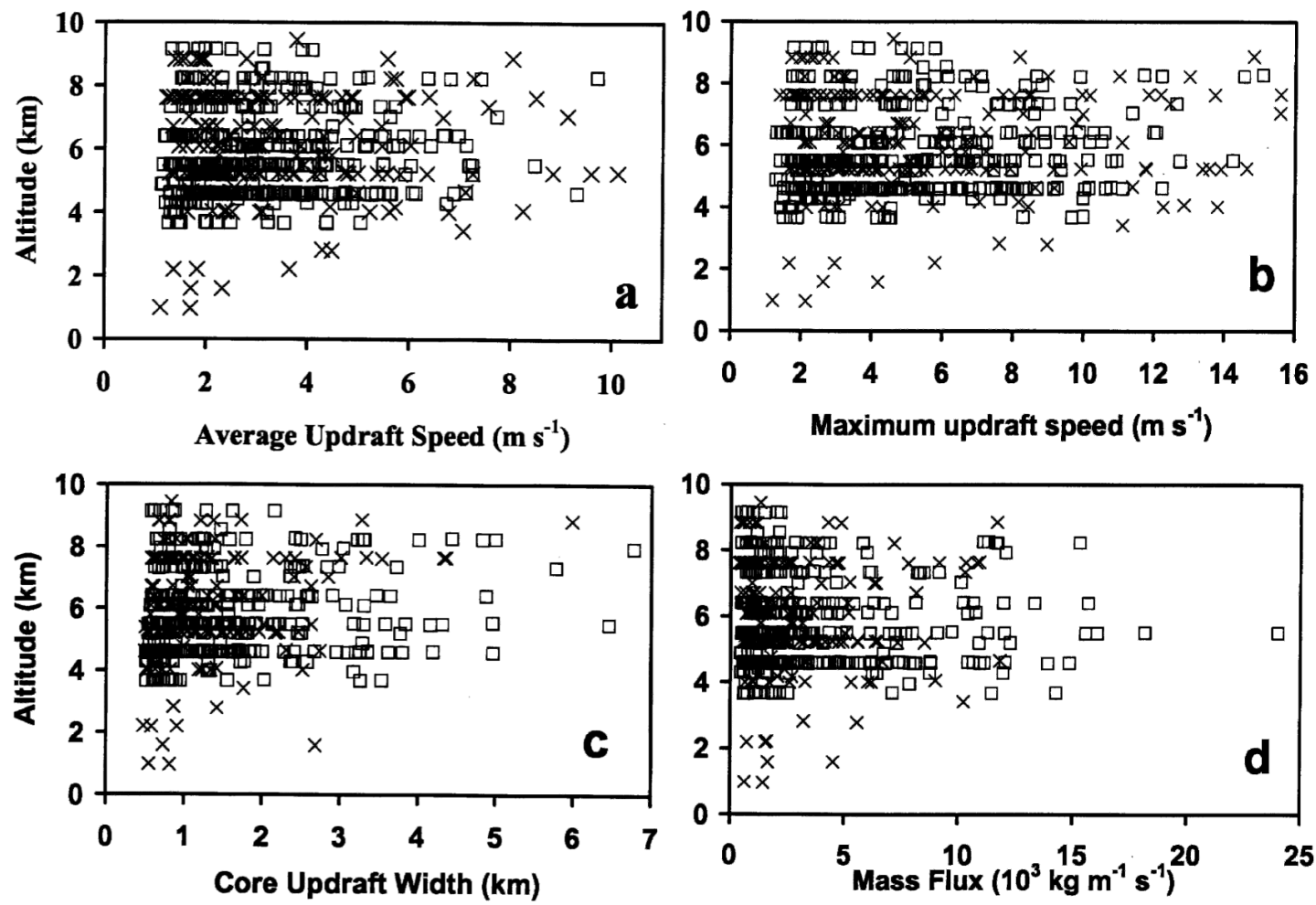

Fig. 1.5: Distribution of (a) average speed, (b) maximum speed, (c) width, and (d) mass flux of updraft cores sampled during TRMM-LBA (denoted by 'X's) and KWAJEX (denoted by outlined squares) (after Anderson et al. 2005).

was extracted from Doppler velocity retrievals. They found that both land-based and oceanic updraft cores in the tropics often had vertical velocities exceeding $15 \mathrm{~m} \mathrm{~s}^{-1}$. Peak updraft intensities were found to be located between 10 and $12 \mathrm{~km}$ AGL (Figure 1.6). The widest cores were observed within land-based and sea-breeze convection, while narrower cores were found within maritime convection and tropical cyclones. The results of Heymsfield et al. (2010) suggest that updrafts penetrated by aircraft in LeMone and Zipser (1980) may have been lowbiased due to flight safety concerns that often constrained measurements to below the freezing 
level. The higher velocities in Heymsfield et al. (2010) do not disprove the role of dry air entrainment in reducing convective buoyancy and vertical velocity, but they do suggest that velocities may be higher than previously thought. The following section provides additional background about the characteristics of tropical convective systems and the environments in which they exist.

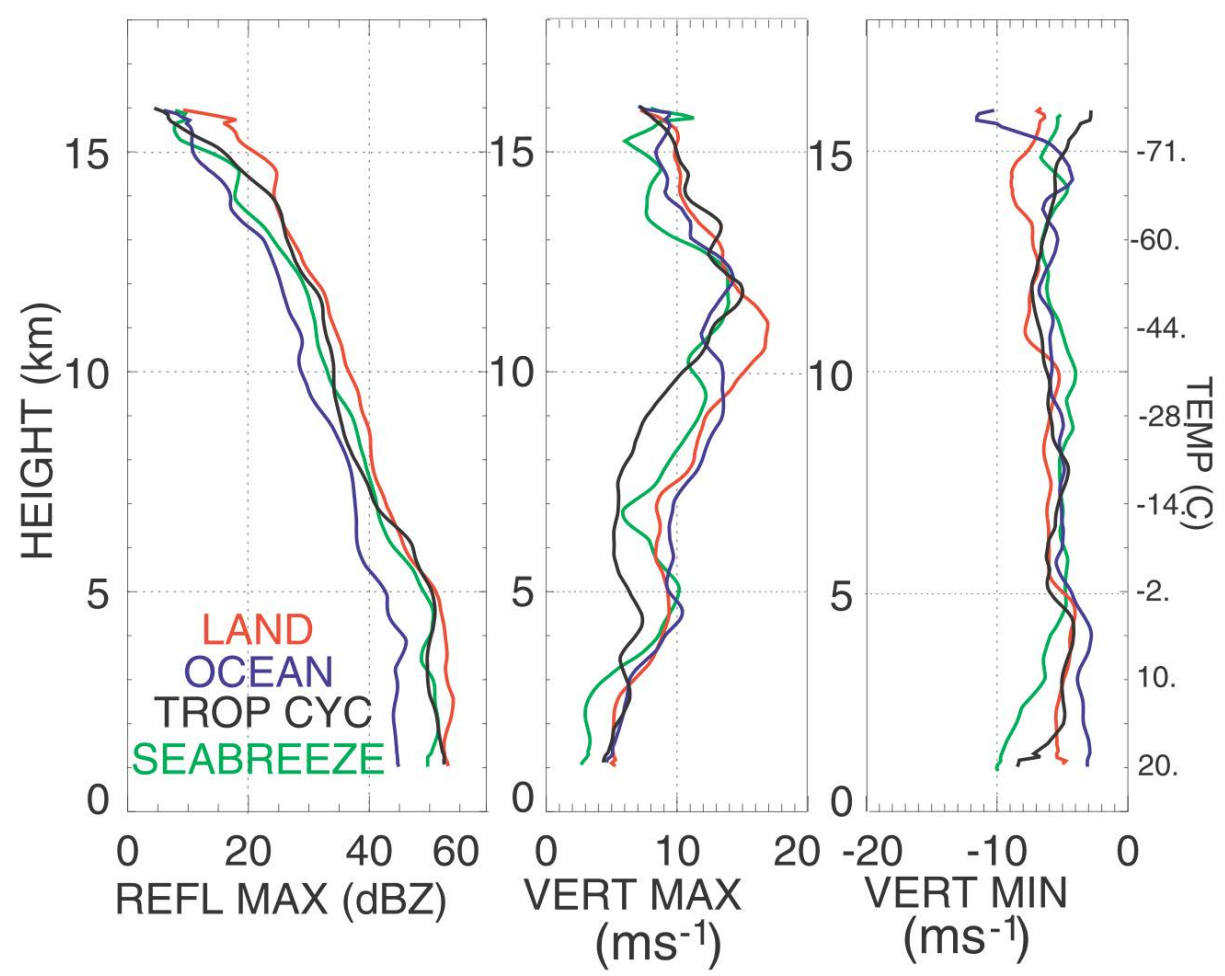

Fig. 1.6: Mean profiles for land, ocean, tropical cyclone, and sea-breeze convection from various field campaigns in the tropics. Temperature scale from the Jordan mean sounding is shown on the right side of the figure (after Heymsfield et al. 2010).

\subsubsection{Environmental Characteristics}

Soundings collected during TOGA COARE provide a detailed overview of the types of ambient environments favorable for tropical deep convective development. Lucas and Zipser (2000) used cluster analysis to obtain the dominant modes of observed thermodynamic and kinematic vertical structures from sounding data. Their derived composite soundings showed that deep convection occurred within environments of both weak and strong vertical wind shear. 
However, deep convection was distinctly more favored when $\theta_{\mathrm{e}}$ was higher due to enhanced moisture in the lower and middle troposphere. This fact is illustrated in Figure 1.7, which shows mean vertical soundings for composite soundings in active and fair weather time periods, respectively; the active periods have lower dewpoint depressions than the fair weather periods, and the average precipitation for active periods is $5.25 \mathrm{~mm}_{\text {day }}{ }^{-1}$ compared with $2.52 \mathrm{~mm}_{\text {day }}{ }^{-1}$ for the fair weather periods.
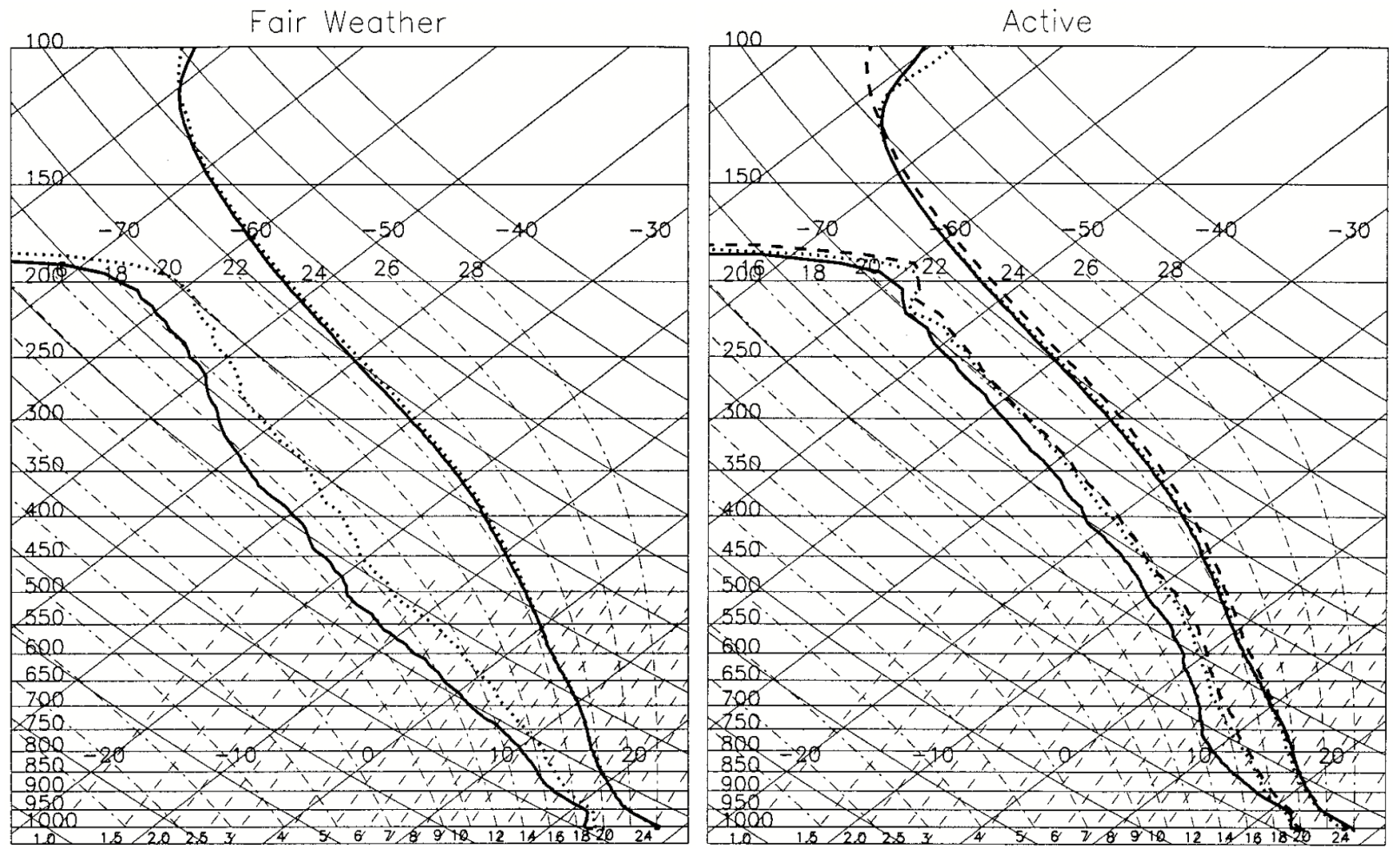

Fig. 1.7: Fair weather and active convective periods as defined by cluster analysis of soundings observed by Lucas and Zipser (2000) (adapted from Lucas and Zipser 2000).

Independent of the level of convective activity, nearly all observed temperature profiles in the study were close to the moist adiabatic lapse rate. Other studies have shown how stable layers play a significant role in the development of tropical deep convection. Johnson et al. (1999) and Posselt et al. (2008) highlighted the trade stable layer around $2 \mathrm{~km}$, the freezing level around $5 \mathrm{~km}$, and the tropopause around 15-16 km (Figure 1.8), and the associated large-scale 
circulations. Deep convection is not inhibited by the trade stable layer or the freezing level, but is limited by the height of the tropopause. The freezing level likely serves as a barrier against precipitation-laden congestus clouds with weak updrafts from becoming deep convection. The trade stable layer prevents many ordinary cumuli from becoming congestus, which may feed back to deep convective development.

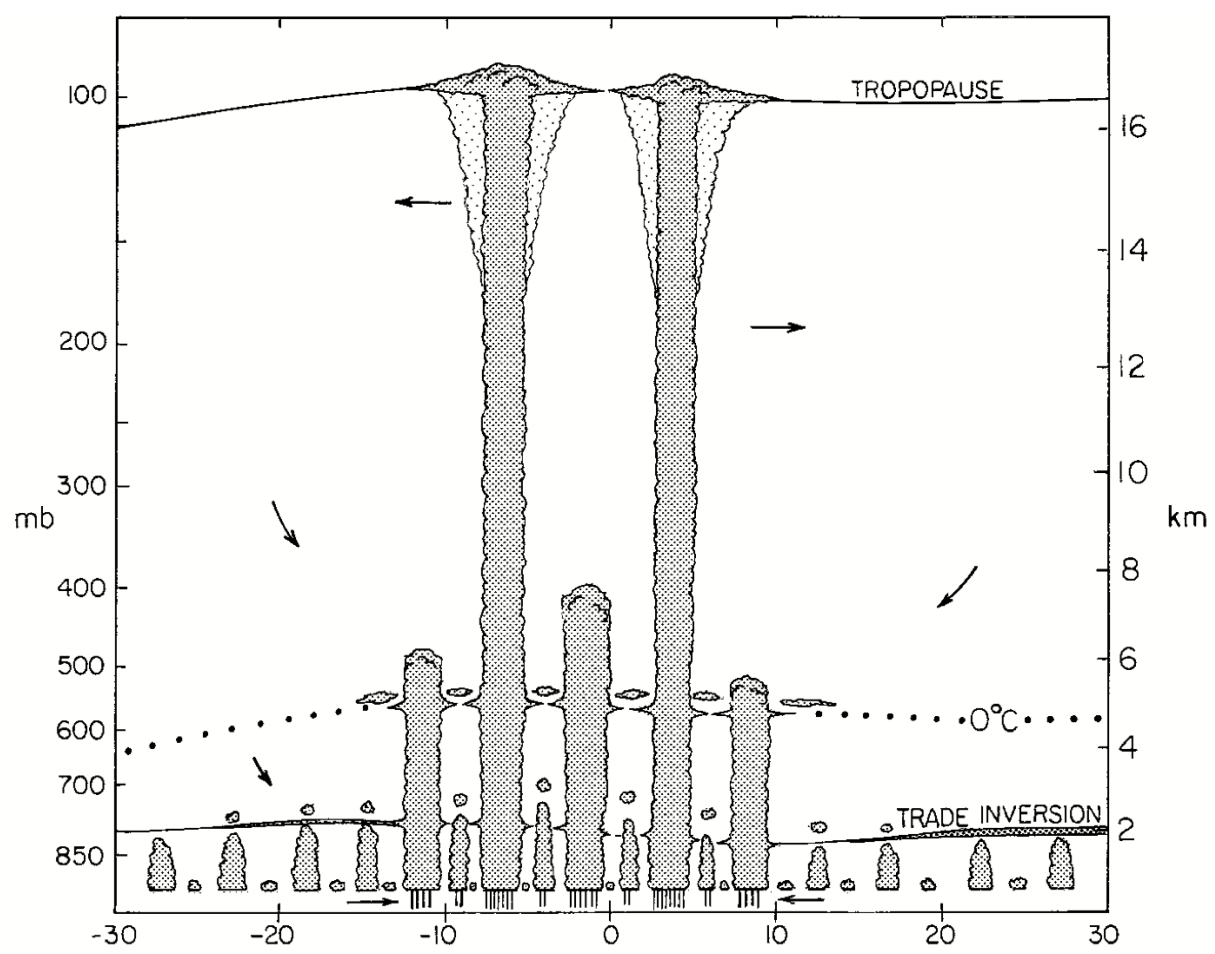

Fig. 1.8: Schematic of the tri-modal distribution of tropical convection between $30^{\circ} \mathrm{N}$ and $30^{\circ} \mathrm{S}$ (cloud modes are shallow cumulus, cumulus congestus, and cumulonimbus). Stable layers are labeled as "trade inversion", " $0{ }^{\circ} \mathrm{C}$ " (for freezing level), and "tropopause" (after Johnson et al. 1999).

The forward trajectories released in Fierro et al. (2009) were initialized within the boundary layer, but there may be reason to question the appropriateness of using only the boundary layer as the source region; the degree to which tropical deep convective clouds consist of air entrained from above the boundary layer is not entirely apparent. Efforts have been made to quantify the source regions of deep convective air. Betts (1976) and Zipser (1977) formulated a parcel model in which drier air originating from above the boundary layer would sink toward 
the rear inflow region upon encountering the convective region of a mesoscale convective system (MCS). Under this model, only boundary layer parcels were available to ascend to the upper troposphere. However, in an analysis of Doppler radar measurements made of deep convection during TOGA COARE, Kingsmill and Houze (1999) showed that deep layer inflows into updrafts are quite common. Observations and a modeling simulation by Bryan and Fritsch (2000) showed similar results. Mechem et al. (2002) investigated the importance of deep inflow by comparing two simulated convective systems from TOGA COARE that differed in terms of mid-level moisture. Parcel trajectory heights for these simulations are illustrated in Figure 1.9. Their simulations showed that the moister case had much deeper inflow than the drier case. Lucas and Zipser (2000) documented substantial variability in environmental moisture during TOGA COARE among active convective events. Thus, it is likely that the heights of convective inflow vary significantly across different environments.
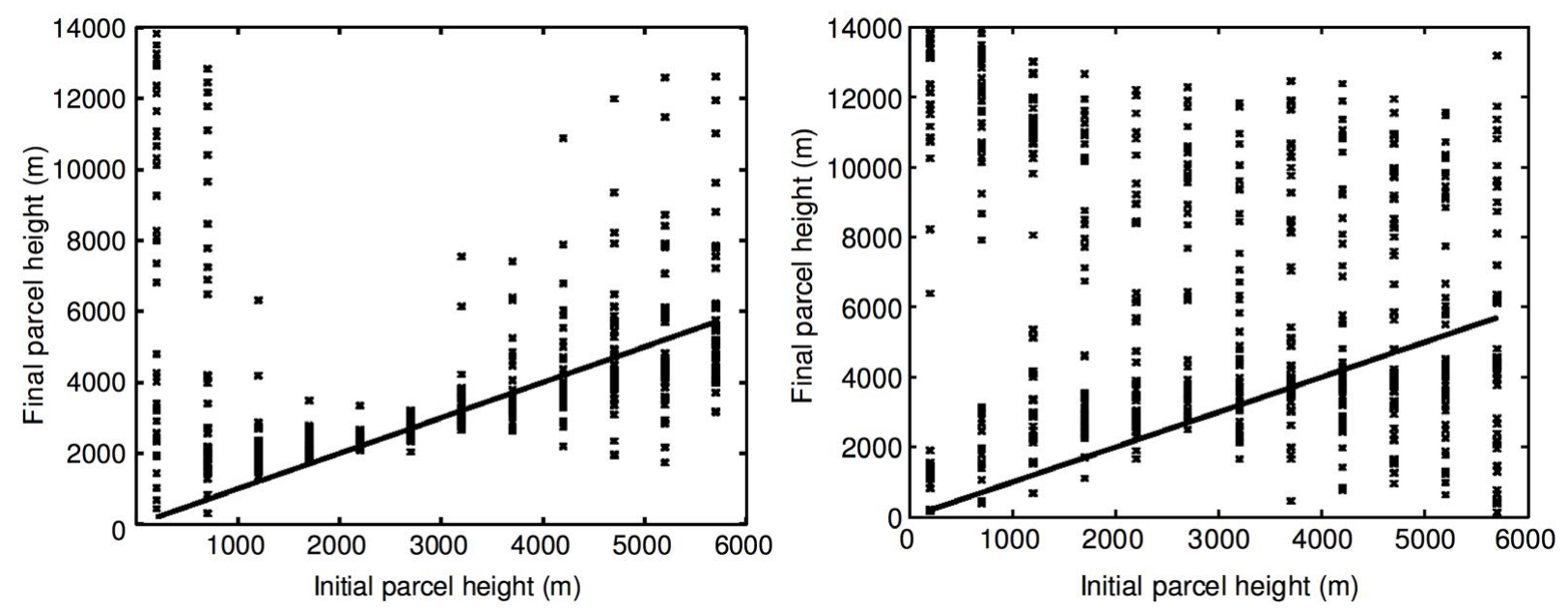

Fig. 1.9: Initial and final ending heights for trajectories in the dry control simulation (left) and the moist mid-level simulation (right) (adapted from Mechem et al. 2002).

Following the seminal work of Stommel (1947), which highlighted the role of entrainment in cumulus clouds, many investigations into convective entrainment have been implicitly interested in understanding the source regions of convective inflow. Paluch (1979) 
proposed that ascending cumulus clouds entrain air from well above their current level.

Raymond and Blyth (1986) and Blyth et al. (1988) showed that clouds entrain air from all levels. There have been different interpretations of what causes entrainment in ascending convection; Blyth et al. (1988) posited that downdrafts around a rising thermal mixed less buoyant air into the base of the thermal, while Grabowski (1995) argued more for shear instabilities causing entrainment at the edge of the cloud. Yeo and Romps (2013) showed that clouds entrain a mixture of environmental air and previously detrained air. They also demonstrated that deep convective clouds are heavily diluted and that the origin height of the convective air is well above cloud base.

Tropical deep convective systems also alter the thermodynamic structure of the environments in which they develop. Understanding the heating profiles of deep convection has been an area of intense focus for several decades. Yanai et al. (1973) used rawinsonde data to calculate heat and moisture budgets within a tropical cloud cluster that evolved in a cumulus ensemble. The GATE field campaign then provided the first of many opportunities to investigate the heating modes within observed tropical convective systems. Houze (1982) documented tropical clusters during the GATE and Monsoon Experiment (MONEX) and showed that heating rates within these clusters were determined by life stage; condensation dominated heating in the earlier convective stages of development, while evaporation and melting played an important role below the stratiform anvil in later stages. Frank and McBride (1989) observed heating rate changes in convective clusters during the Australian Monsoon Experiment (AMEX) but saw smaller variations in the vertical distribution of heating compared to GATE systems. These studies showed that convective and stratiform regions were composed of distinct heating profiles in the tropics. Houze (1988) documented the microphysical processes observed within the 
convective and stratiform regions. Supercooled water lofted by updrafts was found to add latent heating above the freezing level and falling ice particles were shown to contribute to cooling at the melting level in the stratiform region. Convective regions were characterized by positive latent heating at all levels and a maximum heating in the middle troposphere. Stratiform regions exhibited low-level cooling due to evaporation, and heating in the anvil. Idealized profiles of latent heating with convective and stratiform regions are shown in Figure 1.10 (Schumacher and Houze 2004). The following section transitions toward a review of modeling studies that have been useful in understanding the characteristics of tropical deep convection.

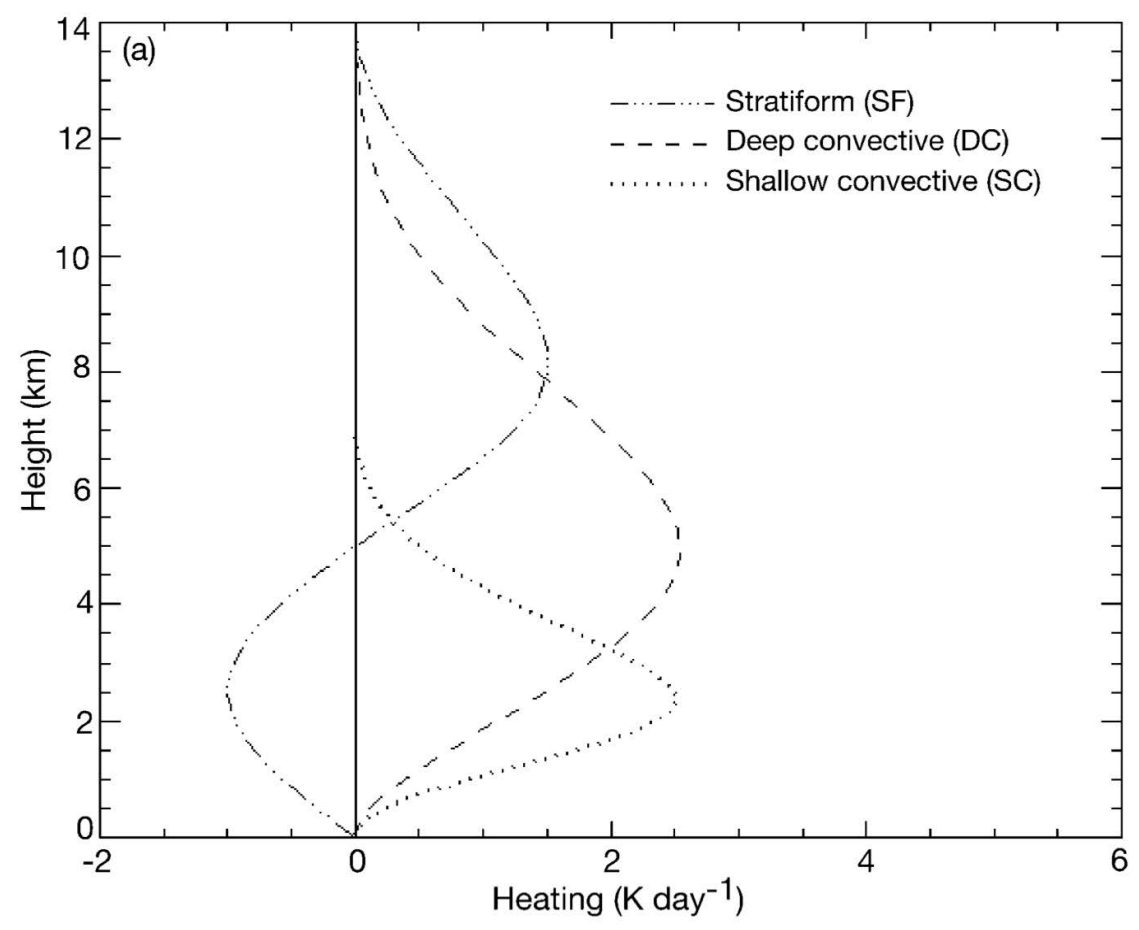

Fig. 1.10: Idealized vertical profiles of latent heating in stratiform, deep convective, and shallow convective regimes (adapted from Schumacher and Houze 2004).

\subsection{Modeling Studies}

\subsubsection{CRM Investigations}

Cloud-resolving models (CRM's) have been used to investigate many properties of tropical deep convection. Bryan and Fritsch (2000) used a high-resolution numerical simulation 
of a MCS to highlight how moist absolutely unstable layers affect the development of tropical convective systems. The aforementioned Mechem et al. (2002) study is another CRM investigation into tropical deep convection. Since the tropical atmosphere is usually close to the state of radiative-convective equilibrium (RCE), many studies have simulated tropical deep convection in environments of RCE (Tompkins and Craig 1998; Xu and Randall 1999; Grabowski and Moncrieff 2004; Posselt et al. 2008; Stephens et al. 2008; van den Heever et al. 2011; Posselt et al. 2012; Storer and van den Heever 2013).

Several of these studies used the Regional Atmospheric Modeling System (RAMS) developed at Colorado State University (Pielke et al. 1992; Cotton et al. 2003). Stephens et al. (2008) demonstrated the importance of cloud-radiative feedbacks due to high clouds created by convective outflow. Posselt et al. (2008) captured the tri-modal distribution of tropical convection and the three aforementioned stable layers reported by Johnson et al. (1999) and underscored the importance of large-scale subsidence in maintaining the tropical stable layer near the freezing level. van den Heever et al. (2011) and Storer and van den Heever (2013) investigated the role of aerosol particles on tropical convection, and Posselt et al. (2012) showed how changes in sea surface temperature might affect convective frequency and intensity in a warming climate. RAMS has a sophisticated bin-emulating microphysical scheme, which facilitates a high level of accuracy in analyzing the specific microphysical processes that contribute to latent heating in deep convection.

The CRM simulations in these aforementioned studies had long, channel-like configurations in which moist and dry bands of deep convection and corresponding subsidence organized under RCE. A Hovmöller of meridionally averaged precipitable water in an RCE simulation performed by van den Heever et al. (2011) is shown in Figure 1.11; the reader should 
note the long length and time scales on the abscissa and ordinate, respectively. This modeling framework has several advantages. The domain is large enough and long enough to resolve a statistically significant population of deep convective cores and capture the large-scale interactions between moist and dry regions. These large-scale circulations are somewhat analogous to the Walker circulation and therefore may be a good way of simulating convection within the equatorial trough zone.

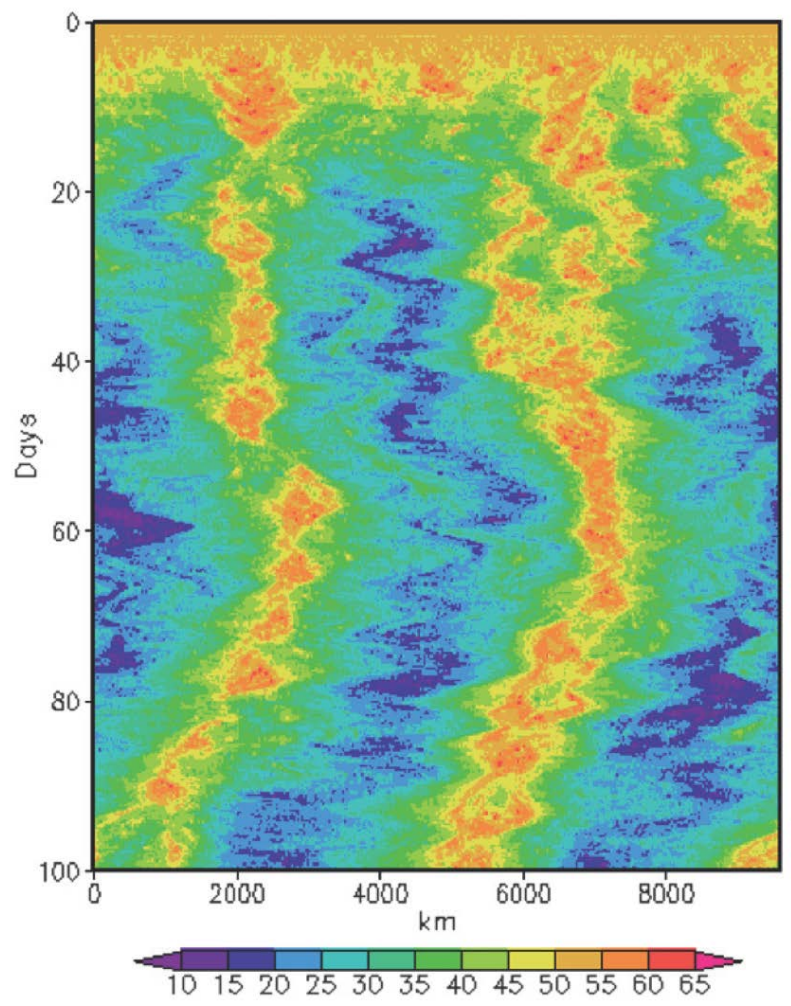

Figure 1.11: Hovmöller of meridionally averaged precipitable water in an RCE simulation (after van den Heever et al. 2011).

Recent investigations have tested the HTH by examining how entrainment and latent heating impact the vertical development of tropical deep convection. Romps and Kuang (2010) showed that the latent heat of fusion allows parcels that are diluted to reach the tropopause. Parcels that were allowed to experience the latent heat of fusion were significantly more buoyant than those that were not (Figure 1.12). Fierro et al. (2009) and Fierro et al. (2012) demonstrated 
that ascending parcels in deep convection experience a decrease in $\theta_{\mathrm{e}}$ in the lowest few

kilometers, but see $\theta_{\mathrm{e}}$ values increase above the freezing level due to latent heating from ice processes. Romps (2011) quantified a transilient matrix for an idealized simulation of deep moist convection in order to investigate the source regions of deep convective air parcels. He demonstrated that two-thirds of sub-cloud air parcels that ascend into the deep convective system come from within 100 meters of the surface.

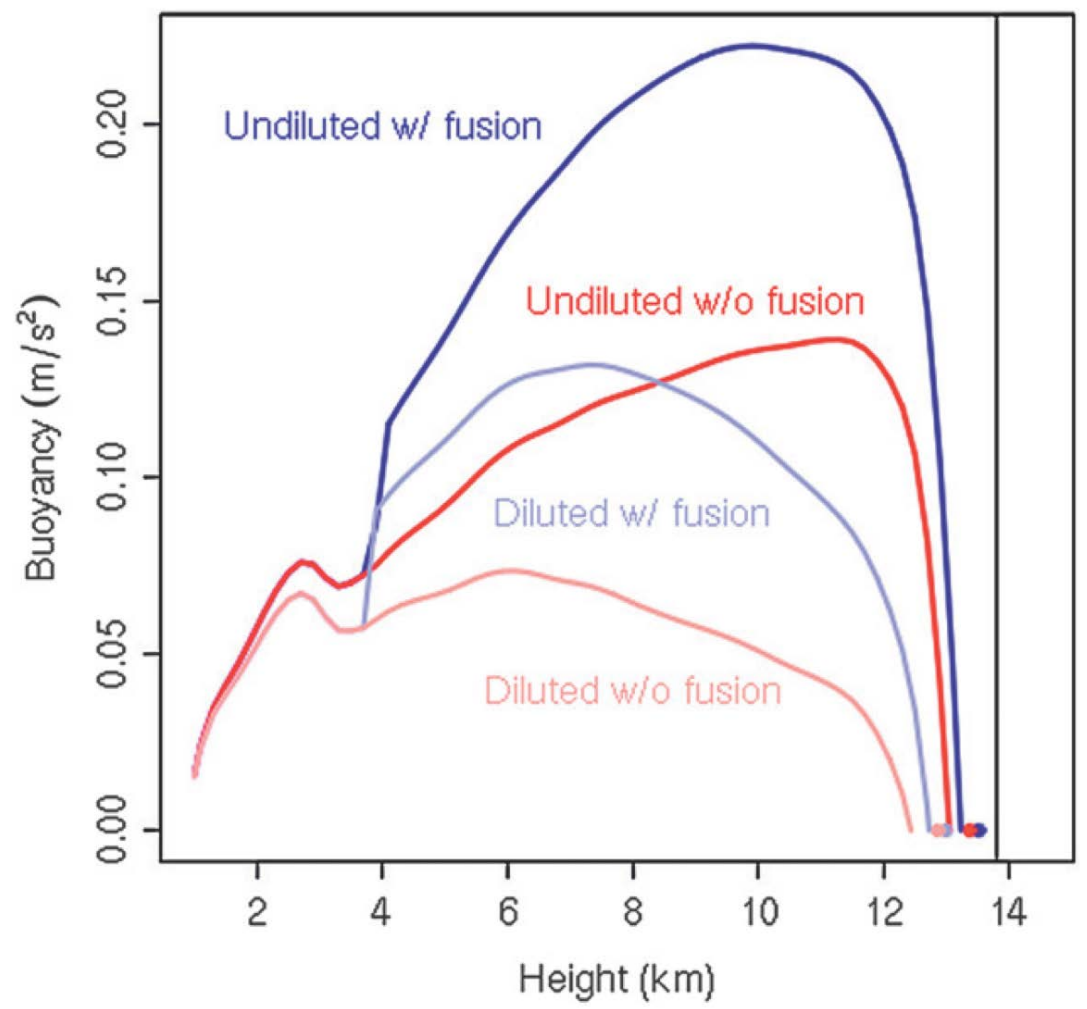

Fig. 1.12: Buoyancy of a parcel with $\theta_{\mathrm{e}}$ equal to the average $\theta_{\mathrm{e}}{ }^{*}$ at the cloud base rising either undiluted (primary colors) or diluted with $\varepsilon=5.33 \times 10^{-5} \mathrm{~m}^{-1}$ (pastel colors) and either with fusion (bluish) or without (reddish). The colored circles indicate the locations of the respective LNB $_{\max }$ (from Romps and Kuang 2010).

\subsubsection{The Role of Microphysical Schemes}

Microphysical schemes differ in their ability to capture a realistic evolution of the hydrometeor size distributions within convection. Since changing the hydrometeor size 
distribution can significantly influence latent heating processes, the choice of the microphysical scheme may have a large effect on the latent heating simulated within tropical deep convection. One notable way to separate microphysical scheme characteristics is based on the schemes' ability to prognose two moments of the size distribution (two-moment schemes, hereafter $2 \mathrm{M}$ ) as opposed to only one moment of the size distribution (one-moment schemes, hereafter 1M). 2M schemes usually prognose hydrometeor mixing ratio and number concentration, while $1 \mathrm{M}$ schemes typically prognose only the hydrometeor mixing ratio. In a $1 \mathrm{M}$ scheme, hydrometeor number concentrations are diagnosed based on the predicted mixing ratio and a shape parameter within an equation describing the size distribution. $2 \mathrm{M}$ schemes prognose number concentration independent of mixing ratio and hence allow for a more realistic evolution of a hydrometeor's size distribution. The size distribution is important in terms of implications for latent heating processes. For example, van den Heever and Cotton (2004) showed that variations in hail size have large implications for supercell cold pool strengths and overall storm evolution. Gilmore et al. (2004) demonstrated significant sensitivities in the amount of deep convective precipitation depending on the shape and intercept parameters used for hail/graupel when using a $1 \mathrm{M}$ scheme. Adams-Selin et al. (2013) showed that the parameterization of graupel impacts the characteristics of bow echoes. Morrison et al. (2009) noted that within a mid-latitude squall line, the amount of evaporation (and hence precipitation) in the stratiform region was significantly influenced by changes in the drop size distribution when using different microphysical schemes. The simulation in Morrison et al. (2009) that used a 1M scheme produced much smaller raindrops in the stratiform region, which were more readily able to evaporate due to the raindrops' relatively large ratio of surface area to volume and low fall speeds. A different simulation in the same study, which had a $2 \mathrm{M}$ scheme, led to larger raindrops with a lower surface area to volume ratio, 
and hence a lower evaporation rate. In idealized supercell simulations, Dawson et al. (2010) noted that $2 \mathrm{M}$ schemes produced cold pool strengths more in line with observations than $1 \mathrm{M}$ schemes. In summary, these studies noted that $2 \mathrm{M}$ schemes generally better represent the size distribution of hydrometeors. The size distributions of hydrometeors have important implications for the magnitudes of the microphysical latent heating processes in this study. Therefore, a $2 \mathrm{M}$ scheme is desirable for this study.

In a modeling study of tropical deep convection, Johnson et al. (2002) used the 1M scheme described in Tao et al. (1993). The Johnson et al. (2002) results showed that condensation/evaporation and vapor deposition/sublimation were the primary contributors to latent heating below and above the freezing level, respectively (Figure 1.13). In another study using a 1M scheme, Fierro et al. (2012) quantified the microphysical processes responsible for latent heating along the trajectories analyzed in Fierro et al. (2009). Latent heating along a representative trajectory above the freezing level (Figure 1.14) showed significant amounts of

(a)

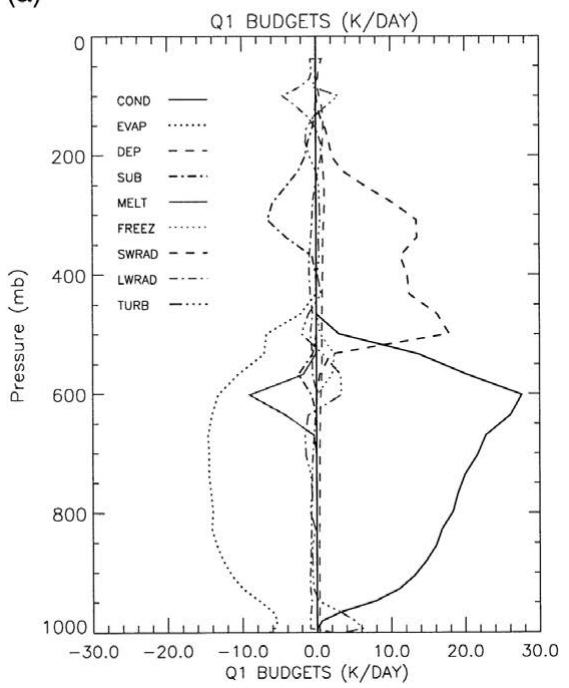

(b)

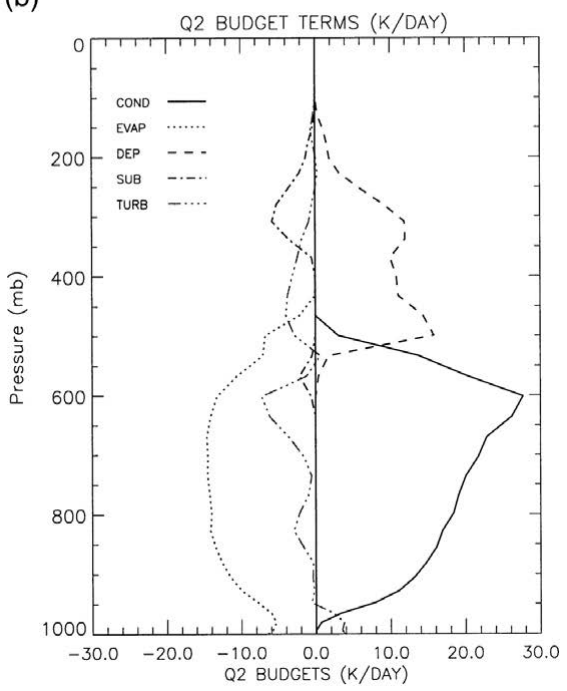

Fig. 1.13: Mean (a) Q1 and (b) Q2 budgets for the simulation with $512 \mathrm{~km}$ horizontal domain. $\mathrm{COND/EVAP}$ is the condensation/evaporation of vapor/liquid water, DEP/SUB is the deposition/sublimation of vapor/ice, MELT/FREEZ is the melting/freezing of ice/liquid water, SWRAD/LWRAD is the contribution from shortwave/longwave radiation, and TURB is the turbulent transfer processes. Units are $\mathrm{K} \mathrm{day}^{-1}$ (after Johnson et al. 2002). 
freezing and a non-negligible but considerably lower heating rate from vapor deposition. This stands in contrast to the results of Johnson et al. (2002). Fierro et al. (2009) acknowledged certain deficiencies with the $1 \mathrm{M}$ scheme employed in their own study. For example, raindrops are frozen completely and instantaneously when they enter air temperatures below $0^{\circ} \mathrm{C}$. This

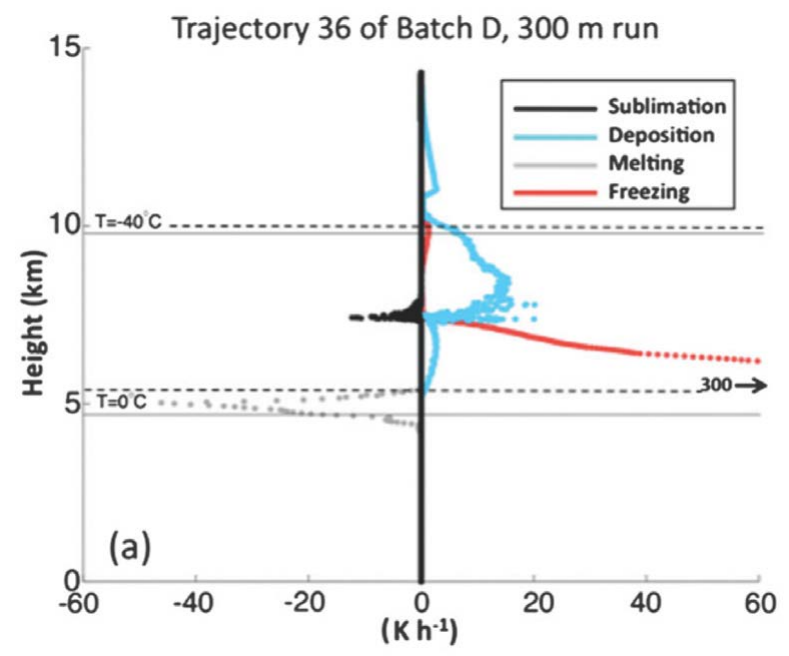

Fig. 1.14: Vertical profiles of the rates at which $\theta_{\mathrm{e}}$ changes due to various microphysical processes along a representative trajectory (adapted from Fierro et al. 2012).

formulation presumably leads to a localized maximum in latent heating immediately above the freezing level rather than a more continuous vertical distribution of heating that might be expected if freezing at temperatures below $0^{\circ} \mathrm{C}$ were not forced to be instantaneous. The authors also noted that their simulation was overpredicting graupel mixing ratios just above the freezing level compared with microphysical observations made of tropical convection by Petersen et al. (2009). The two aforementioned facts may partially explain why Fierro et al. (2012) observed latent heating rates associated with the freezing of condensate of nearly $300 \mathrm{~K} \mathrm{hr}^{-1}$ along a representative trajectory near the freezing level (Figure 1.14). It is difficult to assess precise causes for the differences in the results of Johnson et al. (2002) and Fierro et al. (2012); rather, 
this difference and the opportunity to use a $2 \mathrm{M}$ scheme warrants an additional investigation into the microphysical processes driving tropical deep convection.

For the reasons explained above, the $2 \mathrm{M}$ bin-emulating microphysical scheme used in this modeling study represents a new opportunity to evaluate many microphysical processes within tropical deep convection, including the relative magnitudes of the freezing of condensate and vapor deposition. RAMS has the capability to track latent heating/cooling rates along parcel trajectories (Saleeby and van den Heever 2013). These quantities allow along-trajectory $\theta_{\mathrm{e}}$ changes to be quantitatively partitioned into contributions from latent heating due to ice processes and a single residual term, which includes radiation and mixing (as discussed in greater detail in section 2.4.2). In summary, CRM investigations have been used to effectively simulate tropical deep convection and identify the microphysical processes that processes that contribute to latent heating. This study builds on the findings of previous studies by using a sophisticated two-moment microphysical scheme and allows convection to develop relatively naturally in a high-resolution environment that approaches radiative-convective equilibrium.

\subsubsection{Resolution Impacts}

This section examines the sensitivity of CRM simulation results to grid resolution. This information provides guidance in choosing the resolution in this study's simulation by identifying the grid spacings that adequately represent convection, turbulence, and entrainment. Numerical models have the ability to resolve features across a spectrum of scales and have been valuable tools in investigating the atmosphere from a process basis often elusive to observations. However, such models must not only represent the correct physics relatively accurately for these various scales, but must also resolve or parameterize features of interest with great fidelity. Finite 
computational resources often constrain grid size, which frequently prevents important features with small spatial scales from being resolved. These small scales must therefore be parameterized, which has many drawbacks compared to explicitly resolving such scales.

Bryan et al. (2003) investigated how grid resolution affects the results produced by a mesoscale model simulating deep moist convection. Sensitivity to grid spacing was performed in a series of squall line simulations; horizontal grid spacings of $1 \mathrm{~km}, 500 \mathrm{~m}, 250 \mathrm{~m}$, and $125 \mathrm{~m}$ were used. There were systematic differences in squall line structure and intensity as a function of grid spacing; the differences were attributed to the higher resolution simulations' ability to more adequately resolve turbulence. A particularly dramatic difference can be seen in Figure 1.15, which illustrates the $1 \mathrm{~km}$ and $125 \mathrm{~m}$ representations of the front-to-rear flow structure within the squall line. Bryan and Morrison (2012) showed in case study simulations from the Second Verification of the Origins of Rotation in Tornadoes Experiment (VORTEX2) that finer grid spacing caused storms to initiate more quickly, produce less precipitation, and have lower cloud tops. The higher resolution simulations also more adequately represented turbulence, and hence the convective storms exhibited more entrainment compared to lower resolution simulations.

The ability to at least partially represent macroscale turbulent eddies associated with entrainment by convective storms is important for modeling studies investigating the HTH, since in its original form the HTH relied on undiluted convective cores to accomplish energy transport in the equatorial trough zone. Simulations that are unable to adequately represent turbulence will likely underestimate entrainment and dilution of convective cores. Large eddy simulations, which are performed at grid spacings small enough to resolve the inertial subrange (and hence resolve turbulence more accurately) are highly computationally expensive and have been 
traditionally used in boundary layer studies, such as the intercomparison study of shallow cumulus convection performed by Siebesma et al. (2003). However, advancements in computing power have allowed for LES simulations of deep convection as well. Khairoutdinov et al. (2009) simulated maritime deep tropical convection in an LES study at 100 meter grid spacing with a domain approximately the size of GCM grid box. Convective statistics compiled from this
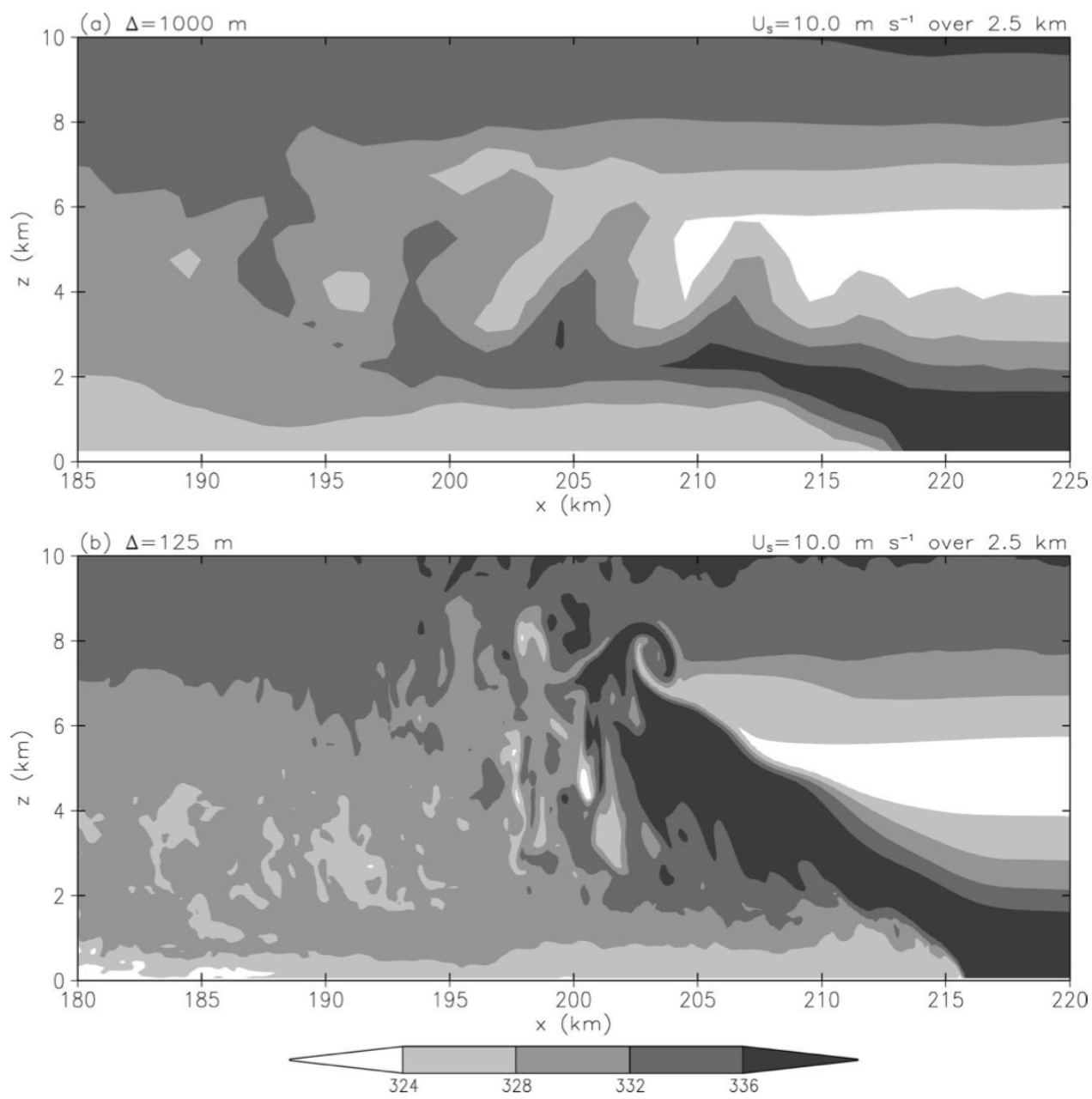

Fig. 1.15: Across-line cross sections of equivalent potential temperature $\left(\theta_{\mathrm{e}}\right.$, in $\left.\mathrm{K}\right)$ from weak shear simulations at 180 min using (a) 1000-m grid spacing (at $\mathrm{y}=45$ ) and (b) 125-m grid spacing (at $\mathrm{y}=49 \mathrm{~km}$ ) (from Bryan et al. 2003).

simulation showed a realistic representation of the tri-modal distribution of tropical convection highlighted by Johnson et al. (1999), and the simulation produced similar updraft intensities near and below the freezing level to what was observed during GATE. The aforementioned study by 
Romps and Kuang (2010) varied horizontal grid spacing from $3.2 \mathrm{~km}$ to $100 \mathrm{~m}$, but all simulations demonstrated that convective cores were highly diluted. This shows that convection is diluted by entrainment even at resolutions much coarser than what is required to accurately resolve turbulent motions. The simulation in this thesis likely partially resolves macroscale eddies contributing to entrainment, but computational constraints prevent turbulence from being resolved.

\subsubsection{Thermodynamic Variables}

Thermodynamic variables that are conserved under specific sets of atmospheric conditions provide physical insights into the systems in which they are diagnosed. Potential temperature $(\theta)$ is conserved only during dry adiabatic motion. Equivalent potential temperature $\left(\theta_{\mathrm{e}}\right)$ is an extension of $\theta$ but is also conserved during latent heating due to cloud nucleation, condensation, and evaporation. However, entrainment, ice processes, and radiative heating will cause $\theta_{\mathrm{e}}$ to change. As introduced by Tripoli and Cotton (1981), ice-liquid water potential temperature $\left(\theta_{\mathrm{il}}\right)$ can be used as a prognostic variable in numerical models and is conserved under dry motion and when total condensate of the parcel (including liquid water and ice) does not change.

The HTH was originally developed in the context of MSE profiles. MSE equals the summation of sensible heat $c_{p} T$ (where $c_{p}$ is the specific heat at constant pressure in $\mathrm{J} \mathrm{kg}^{-1} \mathrm{~K}^{-1}$ and $\mathrm{T}$ is temperature in $\mathrm{K}$ ), potential energy $\mathrm{gz}$ (where $\mathrm{g}$ is gravity in $\mathrm{m} \mathrm{s}^{-2}$ and $\mathrm{z}$ is the height above ground level in meters), and latent energy $L_{v} q$ (where $L_{v}$ is the latent heat of vaporization in $\mathrm{J} \mathrm{kg}^{-1}$ and $\mathrm{q}$ is the water vapor mixing ratio in $\mathrm{kg} \mathrm{kg}^{-1}$ ), as shown in Equation 1.1:

$$
\mathrm{MSE}=\mathrm{c}_{\mathrm{p}} \mathrm{T}+\mathrm{gz}+\mathrm{L}_{\mathrm{v}} \mathrm{q}
$$


MSE's closest thermodynamic analog is $\theta_{\mathrm{e}}$. The difference between MSE and $\theta_{\mathrm{e}}$ is that moist static energy assumes a hydrostatic atmosphere, while $\theta_{\mathrm{e}}$ allows for non-hydrostatic impacts.

Recent modeling investigations into the HTH have used $\theta_{\mathrm{e}}$ as opposed to MSE because of the non-hydrostatic nature of convective updrafts (Fierro et al. 2009; Romps and Kuang 2010; Fierro et al. 2012).

The equivalent potential temperature $\left(\theta_{\mathrm{e}}\right)$ of a parcel is its potential temperature after all water vapor is condensed through lifting to the top of the atmosphere. There are many different formulations of $\theta_{\mathrm{e}}$ in the literature, including the pseudoadiabatic form derived by Emanuel (1994), and a reversible form conserved for ice processes derived by Romps and Kuang (2010). The two primary classes are distinguished on the treatment of condensate within a parcel. "Reversible" forms carry all condensate as it is lifted moist adiabatically (i.e. all condensate that forms is lofted with the parcel), while the "pseudoadiabatic" forms carry none of the condensate (i.e. all condensate that forms precipitates out instantaneously). The exact analytical form of the reversible $\theta_{\mathrm{e}}$ (shown as $\theta_{\mathrm{e}}^{\mathrm{r}}$ ) has been derived by Iribarne and Godson (1981) and also shown by Emanuel (1994) in Equation 1.2:

$$
\theta_{\mathrm{e}}^{\mathrm{r}}=\mathrm{T}\left(\frac{\mathrm{p}_{00}}{\mathrm{p}_{\mathrm{a}}}\right)^{\mathrm{R}_{\mathrm{a}} /\left(\mathrm{c}_{\mathrm{pa}}+\mathrm{c}_{\mathrm{l}} \mathrm{r}_{\mathrm{t}}\right)}\left(\mathrm{H}_{\mathrm{l}}\right)^{-\mathrm{R}_{\mathrm{v}} \mathrm{r}_{\mathrm{v}} /\left(\mathrm{c}_{\mathrm{pa}}+\mathrm{c}_{\mathrm{l}} \mathrm{r}_{\mathrm{t}}\right)} \exp \left[\frac{\mathrm{L}_{\mathrm{lv}} \mathrm{r}_{\mathrm{v}}}{\left(\mathrm{c}_{\mathrm{pa}}+\mathrm{c}_{\mathrm{l}} \mathrm{r}_{\mathrm{t}}\right) \mathrm{T}}\right]
$$

where $\mathrm{T}$ is temperature $(\mathrm{K}), \mathrm{p}_{00}$ is the reference pressure (typically $1000 \mathrm{hPa}$ ), $\mathrm{p}_{\mathrm{a}}$ is the pressure of dry air $(\mathrm{hPa}), \mathrm{R}_{\mathrm{a}}$ is the dry air gas constant $\left(287.04 \mathrm{~J} \mathrm{~kg}^{-1} \mathrm{~K}^{-1}\right), \mathrm{c}_{\mathrm{pa}}$ is the specific heat of air at constant pressure $\left(1005.7 \mathrm{~J} \mathrm{~kg}^{-1} \mathrm{~K}^{-1}\right), \mathrm{R}_{\mathrm{v}}$ is gas constant of moist air $\left(461.5 \mathrm{~J} \mathrm{~kg}^{-1} \mathrm{~K}^{-1}\right), \mathrm{r}_{\mathrm{v}}$ is the mixing ratio of water vapor $\left(\mathrm{kg} \mathrm{kg}^{-1}\right), \mathrm{c}_{1}$ is the specific heat of liquid water $\left(4218 \mathrm{~J} \mathrm{~kg}^{-1} \mathrm{~K}^{-1}\right), \mathrm{r}_{\mathrm{t}}$ is the total water mixing ratio $\left(\mathrm{kg} \mathrm{kg}^{-1}\right)$, and $\mathrm{L}_{\mathrm{lv}}$ is the latent heat of vaporization $\left(\mathrm{J} \mathrm{kg}^{-1} \mathrm{~K}^{-1}\right)$. The 
inclusion of the condensate term $\left(c_{1} r_{t}\right)$ is what makes this form reversible. Bryan (2008) derived a pseudoadiabatic form of $\theta_{\mathrm{e}}$ (shown as $\theta_{\mathrm{e}}^{\mathrm{p}}$ ) that excludes the condensate term $\mathrm{c}_{1} \mathrm{r}_{\mathrm{t}}$, as shown in Equation 1.3:

$$
\theta_{\mathrm{e}}^{\mathrm{p}}=\mathrm{T}\left(\frac{\mathrm{p}_{00}}{\mathrm{p}_{\mathrm{a}}}\right)^{\mathrm{R}_{\mathrm{a}} / \mathrm{c}_{\mathrm{pa}}}\left(\mathrm{H}_{\mathrm{l}}\right)^{-\mathrm{R}_{\mathrm{v}} \mathrm{r}_{\mathrm{v}} / \mathrm{c}_{\mathrm{pa}}} \exp \left[\frac{\mathrm{L}_{0} \mathrm{r}_{\mathrm{v}}}{\mathrm{c}_{\mathrm{pa}} \mathrm{T}}\right]
$$

Aside from setting $\mathrm{L}_{\mathrm{lv}}$ to a constant $\mathrm{L}_{0}$ as a way to compensate for the error incurred when the entropy of water vapor is neglected, the only difference between the reversible and pseudoadiabatic forms is the treatment of $r_{t}$, where $r_{t}$ is the sum of the vapor and liquid condensate mixing ratios. By removing condensate from the parcel and neglecting the entropy of water vapor, $r_{t}$ is set to zero in the equation for $\theta_{\mathrm{e}}$. When $r_{t}$ is omitted, the denominator in each of the exponential terms causes $\theta_{\mathrm{e}}^{\mathrm{p}}$ to be greater than $\theta_{\mathrm{e}}^{\mathrm{r}}$.

For modeling studies of the tropical atmosphere investigating $\theta_{\mathrm{e}}$ along trajectories, Fierro et al. (2009) and Fierro et al. (2012) used the pseudoadiabatic form (Emanuel 1994). Assuming instantaneous condensate fallout is a good assumption in the tropical atmosphere because the warm rain process is very efficient in this region. However, even in the tropics, where condensate production is efficient within clouds, some liquid water is lofted with ascending parcels. Therefore, any pseudoadiabatic form will likely overestimate $\theta_{\mathrm{e}}$ to some degree. The pseudoadiabatic assumption is used in this study and is examined in more detail in chapter IV.

\subsubsection{Goals}

In order to understand what allows tropical deep convection to reach the upper troposphere, previous studies have been focused on identifying the relative contributions of processes that enhance and reduce convective buoyancy. Johnson et al. (2002) and Fierro et al. 
(2012) have documented the magnitudes of the microphysical processes contributing to latent heating in tropical deep convection, while Zipser (2003), Fierro et al. (2009), and Romps and Kuang (2010) payed particular attention to the role of dry air entrainment in deep convective development. The original Hot Tower Hypothesis of Riehl and Malkus (1958) was modified by these findings to reflect the conceptual model illustrated in Figure 1.4, in which latent heating above the freezing level is necessary to overcome dry air entrainment primarily in the lower levels that would otherwise inhibit tropical convection from having sufficient buoyancy to reach the upper troposphere. This study is unique from the investigations listed above in three key respects: 1) it extends the results of Fierro et al. (2012) by using a more sophisticated microphysical scheme, 2) it analyzes the relative impacts of convective inflow coming from both near the surface and in the middle troposphere, and 3) quantifies the relative changes to $\theta_{\mathrm{e}}$ from latent heating, mixing due to entrainment, and radiation. More specifically, the goals of this study are:

1) To quantify the relative contributions to latent heating from all microphysical processes in simulated tropical deep convection; this is necessary in order to understand which microphysical processes are most important.

2) To quantify the relative importance of latent heating above the freezing level compared to all other processes (radiation and mixing) that cause $\theta_{\mathrm{e}}$ to change along trajectories above the freezing level.

3) To determine the relative roles of near-surface and elevated inflow in the latent heating within the deep convection.

Chapter II describes the model setup, environmental conditions, initialization of the forward and backward trajectories, and the thermodynamic variables used in the analysis. In 
chapter III, results for the maximum heights achieved by forward trajectories originating from different levels ahead of the convective cells are given, along with detailed budgets of the microphysical processes contributing to latent heating and along-trajectory $\theta_{\mathrm{e}}$ change. Chapter III also includes a comparison between the forward and backward trajectories. Conclusions in chapter IV address the goals of the study. This study is soon to be submitted for publication to the Journal of Atmospheric Science. 


\section{Methodology and Analysis Framework}

\subsection{Model Setup}

This study uses the Regional Atmospheric Modeling System (RAMS) (Cotton et al. 2003; Saleeby and van den Heever 2013) to simulate oceanic tropical deep convection within an idealized, large-domain, high-resolution framework that approaches RCE. The model domain initially consists of a single coarse grid, but the convection analyzed in this study exists within a finer nested grid that is added later to the simulation. The dimensions of the outer coarse grid in which the convection of interest develops are described in Table 2.1. It should be noted that 300 $\mathrm{K}$ is within the range of observations of TOGA COARE sea surface temperatures (SST's) and those commonly found in the western Pacific warm pool, and that $100 \mathrm{~cm}^{-3}$ is a typical background aerosol value for relatively pristine environments over the tropical oceans. Table 2.1. Characteristics of the RCE simulation

\begin{tabular}{|c|c|}
\hline Characteristic & Description \\
\hline Initial sounding & $\begin{array}{c}\text { December 5, } 199200 \text { GMT TOGA COARE, horizontally } \\
\text { homogeneous }\end{array}$ \\
\hline Initiation mechanism & Randomized $0.1 \mathrm{~K}$ temperature perturbations near surface \\
\hline Domain size & $3000 \mathrm{~km}$ x $200 \mathrm{~km}$ x $24.8 \mathrm{~km}$ \\
\hline Domain resolution & $1 \mathrm{~km}$ horizontal grid spacing, stretched grid with 65 levels \\
\hline Location and time & $10^{\circ} \mathrm{N}$ and $40^{\circ} \mathrm{E}$ (160 minutes ahead of UTC) \\
\hline Boundary conditions & Doubly periodic \\
\hline Time step & 5 seconds \\
\hline Surface type & Fixed SST of $300 \mathrm{~K}$ \\
\hline Coriolis force & Off \\
\hline Radiation & Two-stream radiation scheme (Harrington et al. 1999) \\
\hline Turbulence & Smagorinsky (1963) deformation $K$ closure \\
\hline Microphysics & Two-moment bin-emulating scheme (Saleeby and Cotton 2004) \\
\hline Aerosols & Uniformly set to $100 \mathrm{~cm}^{-3}$ \\
\hline
\end{tabular}


At $1 \mathrm{~km}$ grid spacing, the outer grid is of marginally cloud-resolving resolution but is much too coarse to adequately represent turbulent mixing (Bryan et al. 2003). The large domain size of $3000 \mathrm{~km}$ by $200 \mathrm{~km}$ is required to facilitate realistic convective organization and largescale subsidence in the tropics, but computational constraints prevent a finer resolution from being employed over the whole domain. Therefore, as the simulation approaches radiativeconvective equilibrium, an inner nested grid is placed in the eastern third of the domain where a line of convective cells develops. Figure 2.1 shows a plan view of near-surface temperature for the two grids. The inner grid is added overnight on simulation day 16 via a history restart of the

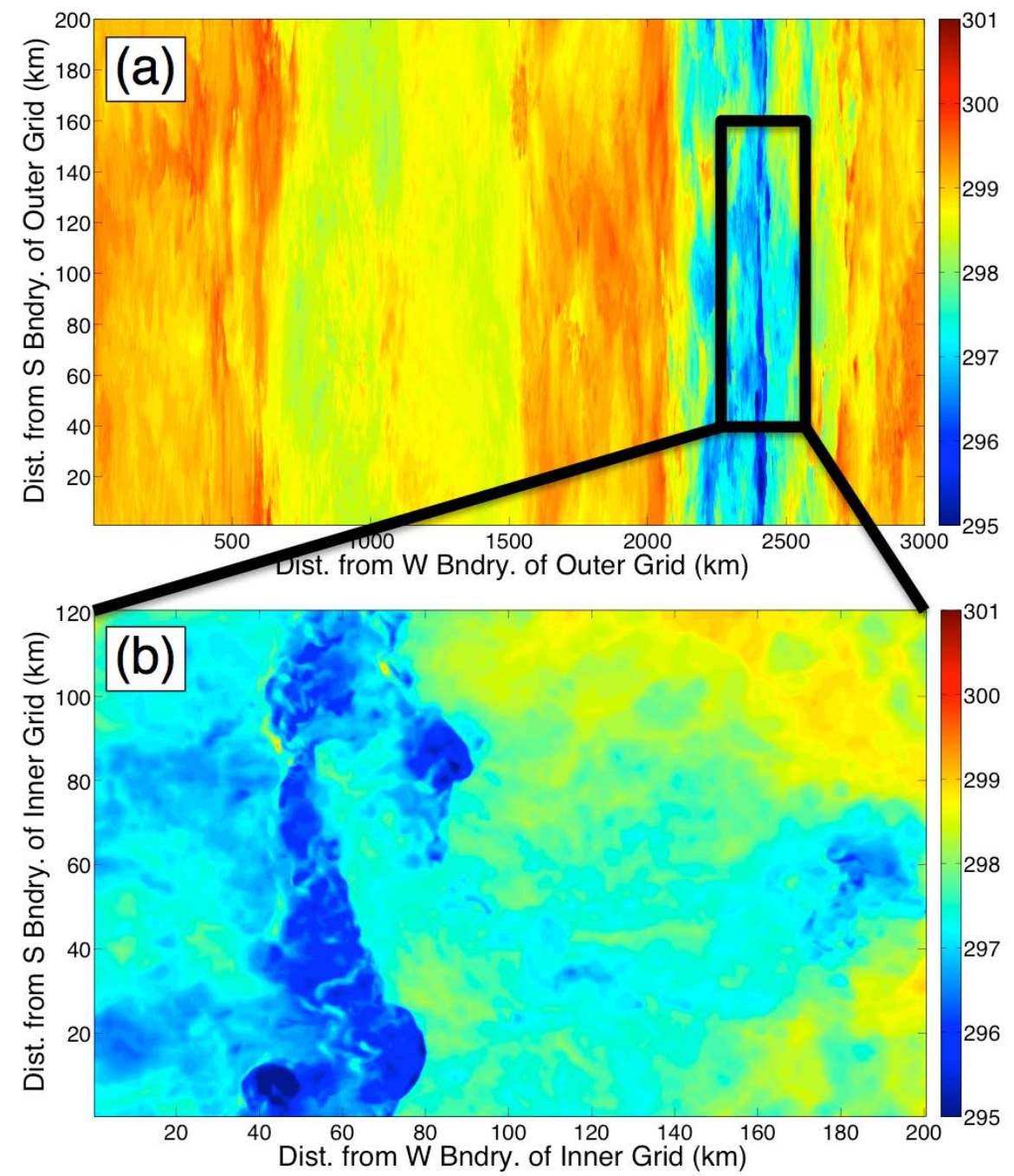

Fig. 2.1: Plan view of near-surface temperature for the (a) outer grid and (b) inner grid at 2310 UTC. The location of the nested grid in the larger domain is shown by the black outline. 
model. The resolution of the inner grid is significantly higher compared to the parent grid, with a horizontal grid spacing of 250 meters and vertical grid spacing that is finer by a factor of two in each column relative to the outer grid. Although fully resolving turbulent flows requires a grid spacing of $0.1 \mathrm{~mm}$ (Bryan et al. 2003), which is clearly not feasible computationally, Bryan et al. (2003) also showed that a horizontal grid spacing on the order of 100 meters does allows turbulent flow and partially resolves entrainment within clouds, especially compared with the much more laminar flow structures they observed when grid spacing was $1 \mathrm{~km}$. Thus, it is expected that the finer grid at 250 meter grid spacing should reasonably resolve entrainment, especially compared to the outer coarse grid at $1 \mathrm{~km}$ grid spacing. In total, there are 802 by 482 grid points in the horizontal and 128 vertical levels on the finer inner grid. At the history restart, the time step is reduced to 3 seconds for both grids. The simulation is run for an additional 100 minutes, during which two-way communication occurs between the grids. The first 10 minutes after the restart are used to allow the inner domain to adjust to its finer resolution, and the following 90 minutes (extending from 2310 UTC on day 15 to 0040 UTC on day 16) constitutes the time during which intensive analysis is performed. The general environmental characteristics of the simulation are summarized in the following section.

\subsection{Environmental Conditions}

The convection that develops by the end of day 15 is oriented north-to-south and traveling to the east at about $5 \mathrm{~m} \mathrm{~s}^{-1}$ along a large-scale line of convergence. Convective activity during the analysis period reaches a maximum early on day 16. A cross-section of meridionallyaveraged zonal wind and total condensate is shown in Figure 2.2 at 2310 UTC, which is the start of the analysis period. The cross-section is averaged along the meridional direction, and shows 
easterly winds associated with the front-to-rear inflow into the convection. Also shown are areas of westerly lower-level cold-pool driven outflow and upper-level divergent outflow. The inflow region of the storm is quite deep, extending to about $8 \mathrm{~km}$ AGL. Convective cells develop in association with the large-scale area of convergence and localized regions of gust front outflow. These cells are generally characterized by vertical velocities up to $15 \mathrm{~m} \mathrm{~s}^{-1}$ (although a few cells' vertical velocities reach near $25 \mathrm{~m} \mathrm{~s}^{-1}$ ), cloud mixing ratios of nearly $2.6 \mathrm{~g} \mathrm{~kg}^{-1}$, rain mixing

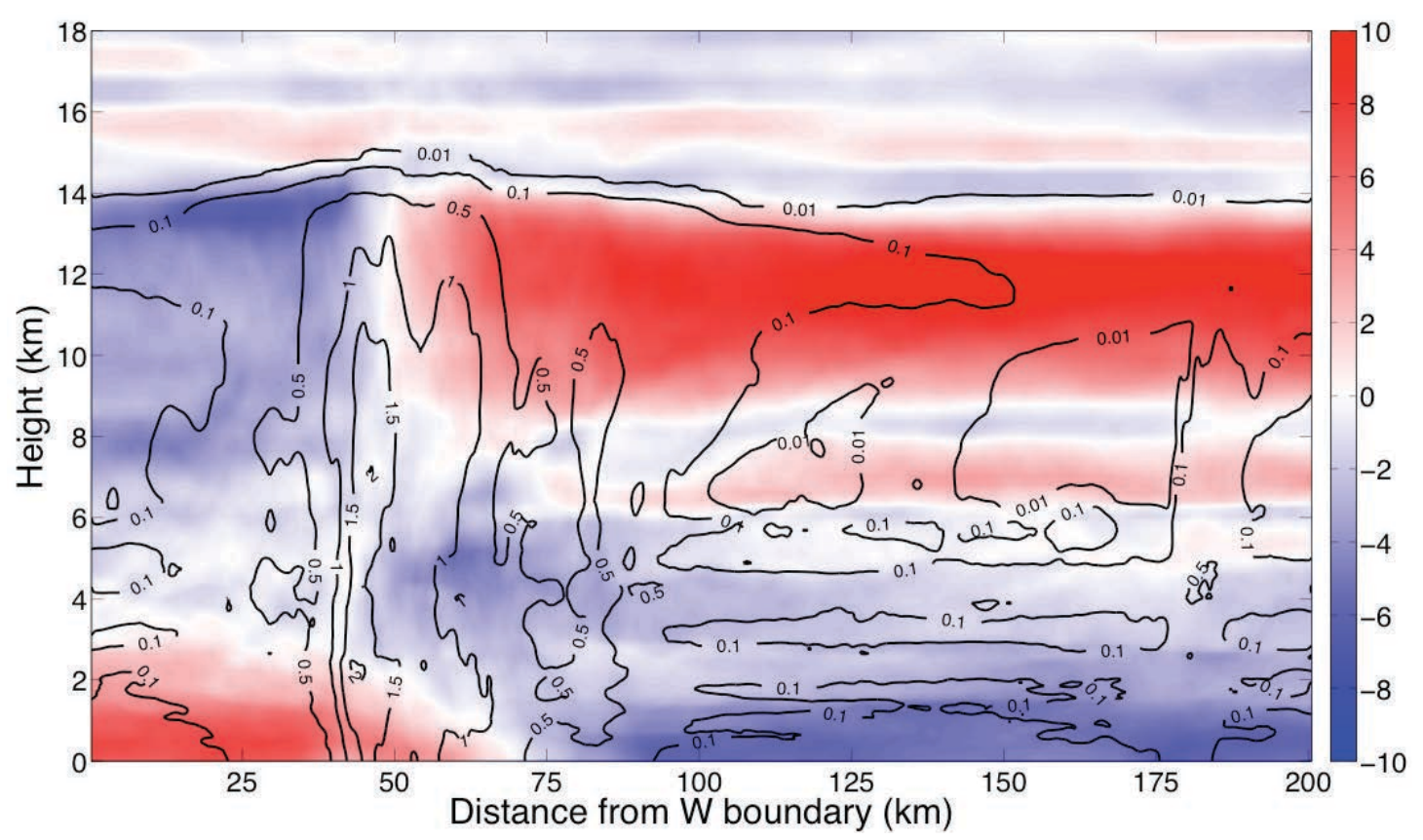

Fig. 2.2: Inner grid at 2310 UTC: Vertical profile of meridionally averaged zonal wind in $\mathrm{m} \mathrm{s}^{-1}$ (shaded) and meridionally averaged total condensate in $\mathrm{g} \mathrm{kg}^{-1}$ (black contours).

ratios that maximize around $9 \mathrm{~g} \mathrm{~kg}^{-1}$ at $3 \mathrm{~km} \mathrm{AGL}$, and ice mixing ratios as high as $8 \mathrm{~g} \mathrm{~kg}^{-1}$ in the elevated convective cores. The freezing level in the domain is approximately $4.6 \mathrm{~km}$. There is a broad area of upper level divergent outflow, which covers much of the inner grid domain, and pristine ice mixing ratios reach $0.7 \mathrm{~g} \mathrm{~kg}^{-1}$ within the anvil. A cross-section through a sample convective cell is shown in Figure 2.3. 


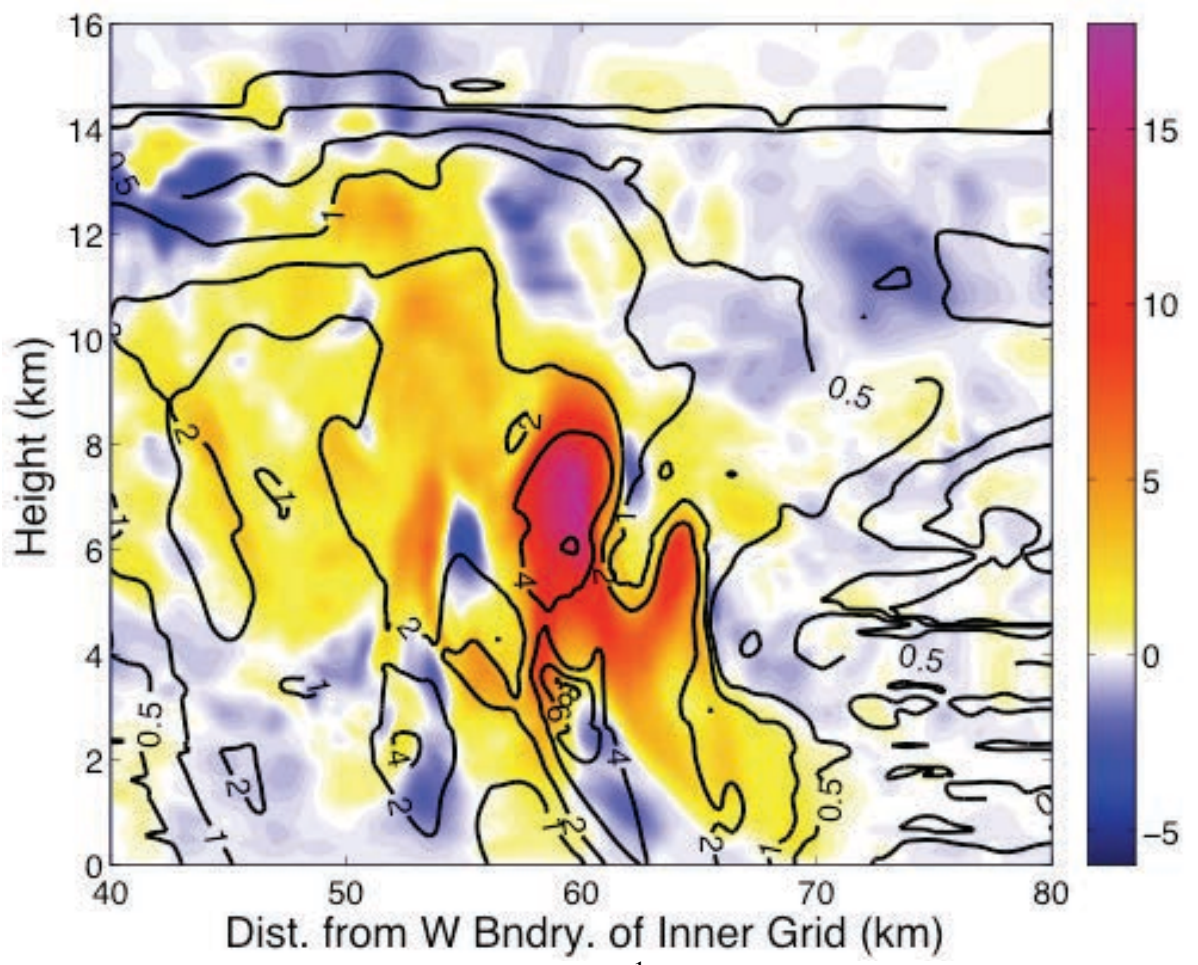

Fig. 2.3: Vertical profile of vertical velocity in $\mathrm{m} \mathrm{s}^{-1}$ (shaded) and total condensate in $\mathrm{g} \mathrm{kg}^{-1}$ (black contours) through a sample convective cell at 2310 UTC.

\subsection{Trajectory Setup}

\subsubsection{General Approach}

Forward trajectories differ from backward trajectories most obviously in terms of the time and locations at which they are initialized. Since a major goal of this study is to assess latent heating and associated changes to $\theta_{\mathrm{e}}$ in a Lagrangian framework within ascending deep convective cells, forward trajectories are initialized in convective inflow regions and backward trajectories are initialized in upper tropospheric anvil regions of processed convective air. Both groupings require careful placement, since no trajectory is guaranteed to pass through all regions of the convection or its inflow. We therefore elected to use both forward and backward trajectories and report on the most useful findings from each, as described in the outline in section 1.3.5 and presented in detail in chapter III. 
Dahl et al. (2012) noted while using trajectories in supercell simulations that forward trajectories run online within the model may have significantly different flow patterns compared to post-processed backward trajectories initialized at the ending positions of the forward trajectories. The difference in positions between forward and backward trajectories was related to the fact that the post-processed wind field was not outputted every model time step, and hence did not resolve the wind field temporally as well as the online calculations. Forward and backward trajectories in this study do not have this inconsistency because both groups are advected/convected offline using model output of the 4-D wind field. Although even the online trajectories are subject to interpolation errors in position (Dahl et al. 2012), position errors are likely to be small within the context of this study for several reasons. First, the wind field is output for trajectory calculations on the model time step of 3 seconds, making the trajectories relatively well resolved temporally. Second, a linear spatial interpolation (described in section 2.3.4) is performed between the grid cells nearest each trajectory. This interpolation scheme was used successfully by Seigel and van den Heever (2012) in their investigation into dust lofting within supercells. Finally, in assessing the sensitivity of various thermodynamic parameters to trajectory inflow height, this study is primarily concerned with the first-order difference between boundary layer and mid-tropospheric inflow. It is assumed that position errors are too small to cause a fundamental shift in the distribution of trajectory heights between the boundary layer and the middle troposphere, since this would require errors of several kilometers in the vertical for many trajectories. Therefore, interpolation errors should not affect the conclusions of this study in this regard. 


\subsubsection{Forward Trajectories}

The forward trajectories are initiated in a "curtain" between 10 and $50 \mathrm{~km}$ from the southern boundary and $5 \mathrm{~km}$ ahead of the location of the surface cold pool at 2310 UTC (Figure 2.4), which is also the start of the analysis period. The surface cold pool gust front is calculated as the location where wind direction at the first model level above the surface switches from westerly to easterly. Trajectories are placed $1 \mathrm{~km}$ apart in the meridional direction and at heights of $50 \mathrm{~m}, 250 \mathrm{~m}, 500 \mathrm{~m}$, and every 500 meters thereafter up to $10 \mathrm{~km}$ AGL. In total, there are 902 separate forward trajectories. Figure 2.4 shows a plan view of surface temperature between 50 and $100 \mathrm{~km}$ from the western boundary of the fine grid and in the southern portion of the domain shown in Figure 2.1b. The cold pools analyzed in the southern portion of the domain in Figure $2.1 \mathrm{~b}$ are more linearly oriented than the disorganized cold pools farther to the north. This makes the region shown in Figure 2.4 the most logical region in the inner grid in which to initiate the curtain of trajectories. The black dots in Figure 2.4 are the initial trajectory locations for each level. The average sounding through the trajectory curtain is shown in Figure 2.5. The environment is nearly saturated below $600 \mathrm{hPa}$ and the temperature profile is closely constrained to the moist adiabatic lapse rate.

\subsubsection{Backward Trajectories}

Backward trajectories are initialized at 0040 UTC, the end of the analysis period, within regions of deep convection above $10 \mathrm{~km}$ AGL that have total condensate mixing ratios greater than $0.01 \mathrm{~g} \mathrm{~kg}^{-1}$. Trajectories in what is referred to as Group A meet the following conditions: 1) they have vertical velocities either greater than $1 \mathrm{~m} \mathrm{~s}^{-1}$ or less than $-1 \mathrm{~m} \mathrm{~s}^{-1}$, and 2) they are above but spatially connected to the $10 \mathrm{~km}$ level via a continuous field of vertical velocities that 


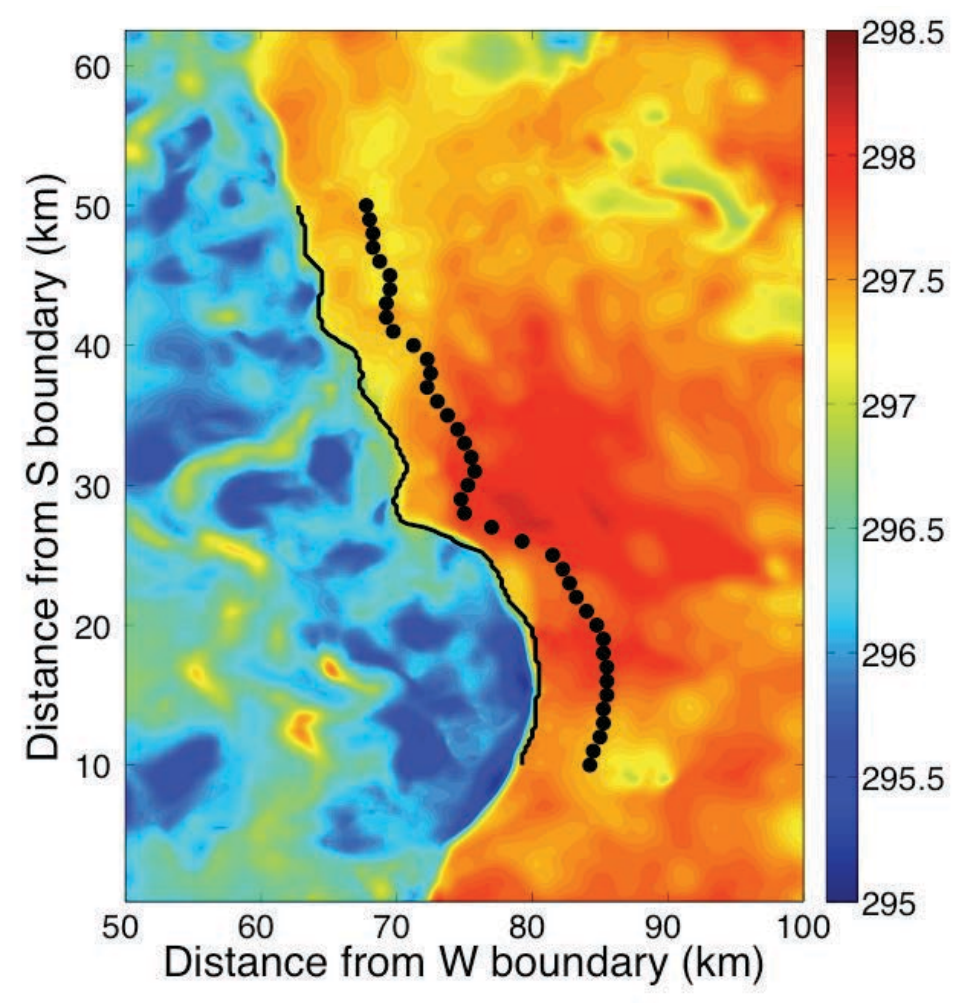

Fig. 2.4: Surface temperature (K) (shaded), locations of forward trajectory origins (black dots), and the gust front defined to be where zonal wind at the surface switches from westerly to easterly (solid black line).

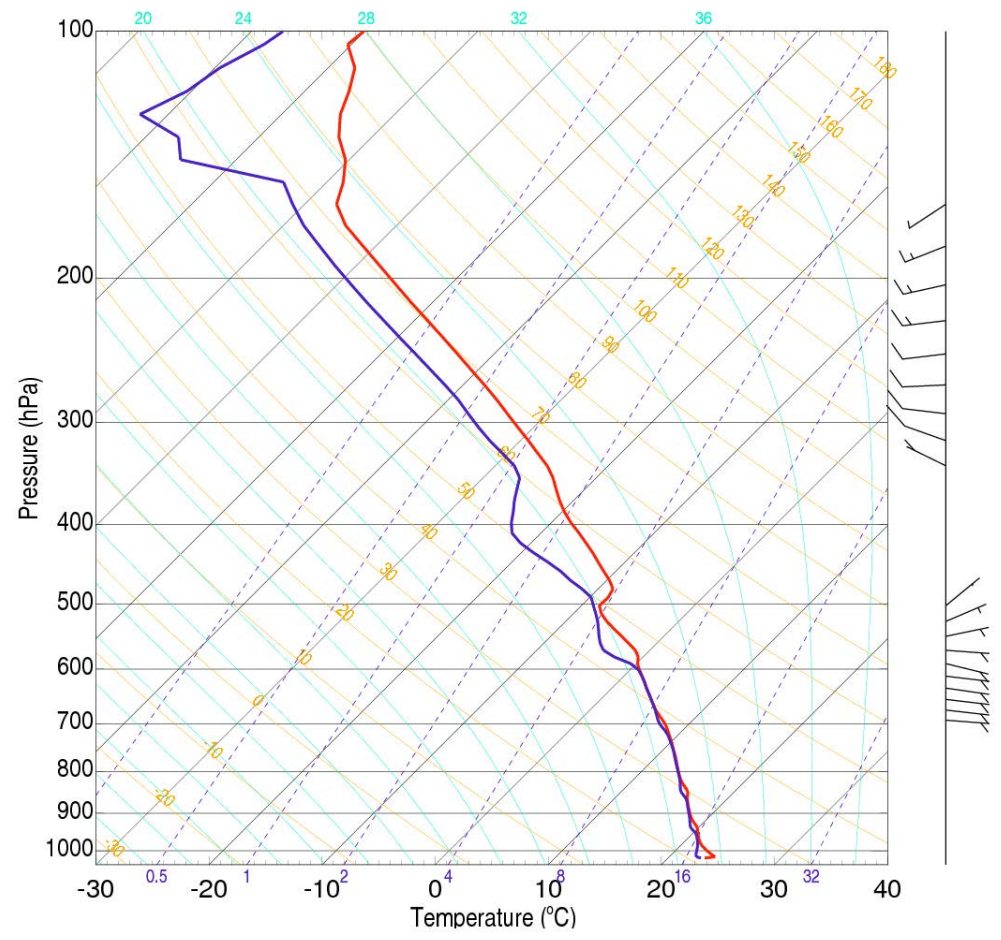

Fig. 2.5: Average sounding of the profiles from which forward trajectories originate. 
meet the first criterion. Trajectories that are in regions above $10 \mathrm{~km}$ AGL where the total condensate mixing ratio is greater than $0.01 \mathrm{~g} \mathrm{~kg}^{-1}$ but do not meet the aforementioned vertical velocity criteria are placed into what is called Group B. This partitioning is designed to differentiate to first order between backward trajectories that end in convective cores (where there are strong updrafts and downdrafts) and those that end in the anvil region (where vertical motions are comparatively weaker). Trajectories within regions contiguous with a vertical velocity maximum greater than $1 \mathrm{~m} \mathrm{~s}^{-1}$ or less than $-1 \mathrm{~m} \mathrm{~s}^{-1}$ that is above but spatially discontinuous with the $10 \mathrm{~km}$ level are placed into Group B. This allows Group A to be composed solely of vertical velocity maxima that are sufficiently spatially continuous with lower altitudes to be justified as true convective cores. Group A (Group B) trajectories are spaced 2.5 $\mathrm{km}(10 \mathrm{~km})$ apart horizontally, and both groups' trajectories are spaced $500 \mathrm{~m}$ apart vertically from $10 \mathrm{~km}$ upwards. There are 1363 trajectories in Group A, and 1822 trajectories in Group B. Figure 2.6 illustrates the initial spatial distribution of the backward trajectories.

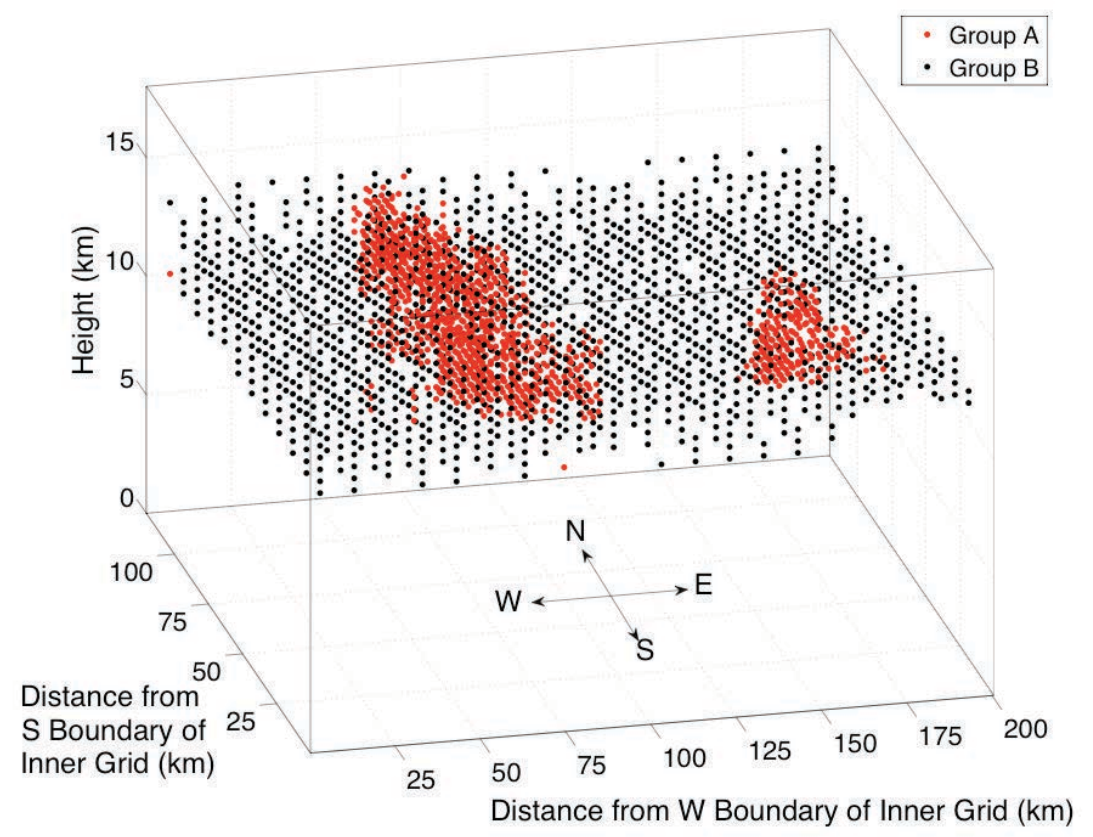

Fig. 2.6: Three-dimensional view of the inner grid, showing the initiation locations for back trajectories in Group A (red) and Group B (black). 


\subsubsection{Interpolation and Ignored Trajectories}

For both the forward and backward trajectories, offline spatial interpolation is applied to facilitate the smoothest possible transitions of all variables as the trajectories are advected to different grid cells. Three-dimensional linear interpolation of all fields is performed at a factor of 20 between the eight grid cells nearest the trajectory's position. In this interpolation scheme, these eight grid cells form the eight edges of a cube through which values are interpolated linearly in three dimensions. Since the linear factor is 20 , each variable has $20^{3}=8000$ values in each cube. All trajectories are advected within this fine resolution cube at every time step; if a trajectory leaves a cube, interpolation continues in the neighboring cube, whose edges are the values of the eight new grid cells surrounding the trajectory. The main purpose of this interpolation scheme is to lessen the magnitude of abrupt jumps in scalar variables as trajectories travel between grid cells.

There are several conditions under which trajectories are ignored. Trajectories that at any time are within $5 \mathrm{~km}$ of the finer grid boundary, are advected out the top of the domain, or are advected below model level 2 are ignored for all analyses described in subsequent sections. As a result, $3.2 \%$ of the forward trajectories, 5.4\% of the Group A backward trajectories, and $12.8 \%$ of the Group B backward trajectories are excluded from all analyses. The following variables are tracked along each trajectory: position, three-dimensional velocity $\left(\mathrm{m} \mathrm{s}^{-1}\right)$, pressure $(\mathrm{hPa}), \theta(\mathrm{K})$, $\theta_{\mathrm{e}}(\mathrm{K})$, total condensate $\left(\mathrm{g} \mathrm{kg}^{-1}\right)$, vapor mixing ratio $\left(\mathrm{g} \mathrm{kg}^{-1}\right)$, and mixing ratios in $\mathrm{g} \mathrm{kg}^{-1}$ of the mass converted during phase transitions for seven latent heating processes, as described in the following section. 


\subsection{Thermodynamic Variables}

\subsubsection{Latent Heating in RAMS}

In order to diagnose the latent heating budgets along trajectories in a manner similar to Fierro et al. (2012), microphysical tracking variables within RAMS are utilized at every time step: these are the mass mixing ratios involved with phase transitions for specific microphysical

processes. The following variables (shown in Table 2.2, each with units $\mathrm{kg} \mathrm{kg}^{-1}$ dry air per model time step "tstep") encompass all processes responsible for latent heating/cooling in the model and are output along trajectories every time step.

Table 2.2. Microphysical Variables in RAMS

\begin{tabular}{|l|l|}
\hline Variable Name & \multicolumn{1}{|c|}{ Description } \\
\hline NucCld & Amount of water vapor condensed onto an aerosol to form a cloud droplet \\
\hline NucIce & Amount of water vapor deposited onto an aerosol to form an ice nucleus \\
\hline VapLiq & $\begin{array}{l}\text { Amount of water vapor condensed (evaporated) onto (from) existing cloud, } \\
\text { drizzle, and rain }\end{array}$ \\
\hline VapIce & $\begin{array}{l}\text { Amount of water vapor deposited (sublimated) onto (from) any ice species, } \\
\text { including pristine ice, aggregates, graupel, snow, and hail }\end{array}$ \\
\hline RimeCld & Amount of cloud water rimed \\
\hline Rain2Ice & Amount of rain water frozen \\
\hline Ice2Rain & Amount of ice melted when rain collects ice \\
\hline MeltIce & Amount of all other ice melted \\
\hline
\end{tabular}

Accordingly, the total latent heating rate $(\mathrm{LH})$ in $\mathrm{K} \mathrm{hr}^{-1}$ is computed using Equation 2.1:

$$
\mathrm{LH}=\frac{3600}{\text { tstep }}(\mathrm{VAP}+\mathrm{FUS})
$$

where VAP and FUS are the heating rates per time step due to processes involving the latent heat of vaporization and fusion in Equations 2.2 and 2.3, respectively:

$$
\mathrm{VAP}=\frac{\mathrm{L}_{\mathrm{v}}}{\mathrm{c}_{\mathrm{p}}}[\mathrm{NucCld}+\text { VapLiq }+ \text { VapIce }]
$$




$$
\mathrm{FUS}=\frac{\mathrm{L}_{\mathrm{f}}}{\mathrm{c}_{\mathrm{p}}}[\text { NucIce }+ \text { VapIce }+ \text { Rain2Ice }+ \text { RimeCld }- \text { Ice2Rain }- \text { MeltIce }]
$$

The specific heat at constant pressure $\left(c_{\mathrm{p}}\right)$ is $1004 \mathrm{~J} \mathrm{~kg}^{-1} \mathrm{~K}^{-1}$, the latent heat of vaporization $\left(\mathrm{L}_{\mathrm{v}}\right)$ is $2.5 \times 10^{6} \mathrm{~J} \mathrm{~kg}^{-1}$, the latent heat of fusion $\left(\mathrm{L}_{\mathrm{f}}\right)$ is $3.34 \times 10^{5} \mathrm{~J} \mathrm{~kg}^{-1}$, and the time step (tstep) is 3 seconds. The term "VapIce" is included in both VAP and FUS to reflect the fact that the latent heat of sublimation, which applies to "VapIce", is the sum of the latent heat of vaporization and the latent heat of fusion. Although the latent heat of vaporization and latent heat of fusion vary with temperature, constants are used for these two quantities since RAMS uses constants for these variables online as the simulation evolves.

\subsubsection{Equivalent Potential Temperature}

As described in chapter I, there are several different formulations for equivalent potential temperature. This study uses the pseudoadiabatic formulation not conserved for ice processes put forward by Bolton (1980), which is appropriate for the tropical atmosphere in which the warm rain process is very efficient and condensate is often rapidly rained out of convective storms. Bolton's empirically derived pseudoadiabatic $\theta_{\mathrm{e}}$ is given in Equations 2.4 and 2.5:

$$
\begin{gathered}
\theta_{\mathrm{e}}=\mathrm{T}\left(\frac{1000}{\mathrm{p}}\right)^{0.2854(1-0.28 \mathrm{r})} \times \exp \left[\mathrm{r}(1-0.81 \mathrm{r})\left(\frac{3376}{\mathrm{~T}^{*}}-2.54\right)\right] \\
\mathrm{T}^{*}=\frac{2840}{3.5 \ln \mathrm{T}-\ln \mathrm{e}-4.805}+55
\end{gathered}
$$

where $\mathrm{T}$ is temperature $(\mathrm{K}), \mathrm{r}$ is water vapor mixing ratio, $\mathrm{T}^{*}$ is the saturation temperature, and $\mathrm{e}$ is the vapor pressure. Following a trajectory, $\theta_{\mathrm{e}}$ is conserved during dry motion, condensation, and evaporation, but changes due to mixing, radiative effects, and latent heating/cooling due to 
ice processes. The change in $\theta_{\mathrm{e}}$ along a trajectory between two temporally adjacent time steps " $\mathrm{t}$ " and " $t+1$ " can therefore be approximated using Equation 2.6:

$$
\Delta \theta_{\mathrm{e}} \approx \frac{\mathrm{L}_{\mathrm{v}}}{\mathrm{c}_{\mathrm{p}}} \frac{\theta_{\mathrm{e}}^{\mathrm{t}}}{\mathrm{T}^{\mathrm{t}}}\left[\mathrm{ICE}^{\mathrm{t}}\right]+\text { mixing }^{\mathrm{t}}+\text { radiation }^{\mathrm{t}}
$$

where $\Delta \theta_{\mathrm{e}}=\theta_{\mathrm{e}}^{\mathrm{t}+1}-\theta_{\mathrm{e}}^{\mathrm{t}}$, the first term on the RHS is the change in $\theta_{\mathrm{e}}$ due to latent heating/cooling from ice processes, and the second and third terms are changes in $\theta_{\mathrm{e}}$ due to mixing and radiative processes, respectively. The scale factor of $\theta_{\mathrm{e}} / \mathrm{T}$ is an approximation that assumes the ratio of $\theta_{\mathrm{e}}$ to T remains constant in one time step. Since $\Delta \theta_{\mathrm{e}}$ is evaluated very frequently (on the model time step of 3 seconds), this approximation appears to be reasonable. After calculating $\theta_{\mathrm{e}}$ at every time step along each trajectory using equation $2.4, \Delta \theta_{\mathrm{e}}$ is calculated as shown above. Subtracting the latent heating due to ice processes from $\Delta \theta_{\mathrm{e}}$ leaves mixing and radiation as a combined residual term.

For the sake of model runtime efficiency, radiative tendencies are only updated every 20 minutes; this time scale is too infrequent to allow an accurate diagnosis of radiative heating rates along trajectories ascending rapidly through an updraft. However, latent heating dominates radiative heating by several orders of magnitude throughout most of the finer grid. Figure $2.7 \mathrm{a}$ shows the ratio of the absolute value of total latent heating to the absolute value of total radiative heating rate for the outer grid, with the finer nested grid highlighted in the translucent white box. In most of the outer grid, which is characterized by clear air, radiative heating dominates latent heating. But inside the fine grid, where there is more active convection, latent heating greatly exceeds radiative heating. Even at cloud top on the fine grid, where radiative heating becomes more important, the total radiative heating rates do not exceed $2 \mathrm{~K} \mathrm{hr}^{-1}$ (Figure 2.7b). Therefore, 
the effects of radiation on $\theta_{\mathrm{e}}$ are treated as negligible, and the along-trajectory change in $\theta_{\mathrm{e}}$ not explained by latent heating/cooling due to ice processes is understood to be an approximate representation of mixing. The equation for $\Delta \theta_{\mathrm{e}}$ is therefore modified to the following form in Equation 2.7, where the negligible radiative contributions are implicitly included within the mixing term:

$$
\Delta \theta_{\mathrm{e}} \approx \frac{\mathrm{L}_{\mathrm{v}}}{\mathrm{c}_{\mathrm{p}}} \frac{\theta_{\mathrm{e}}^{\mathrm{t}}}{\mathrm{T}^{\mathrm{t}}}\left[\mathrm{ICE}^{\mathrm{t}}\right]+\text { mixing }^{\mathrm{t}}
$$
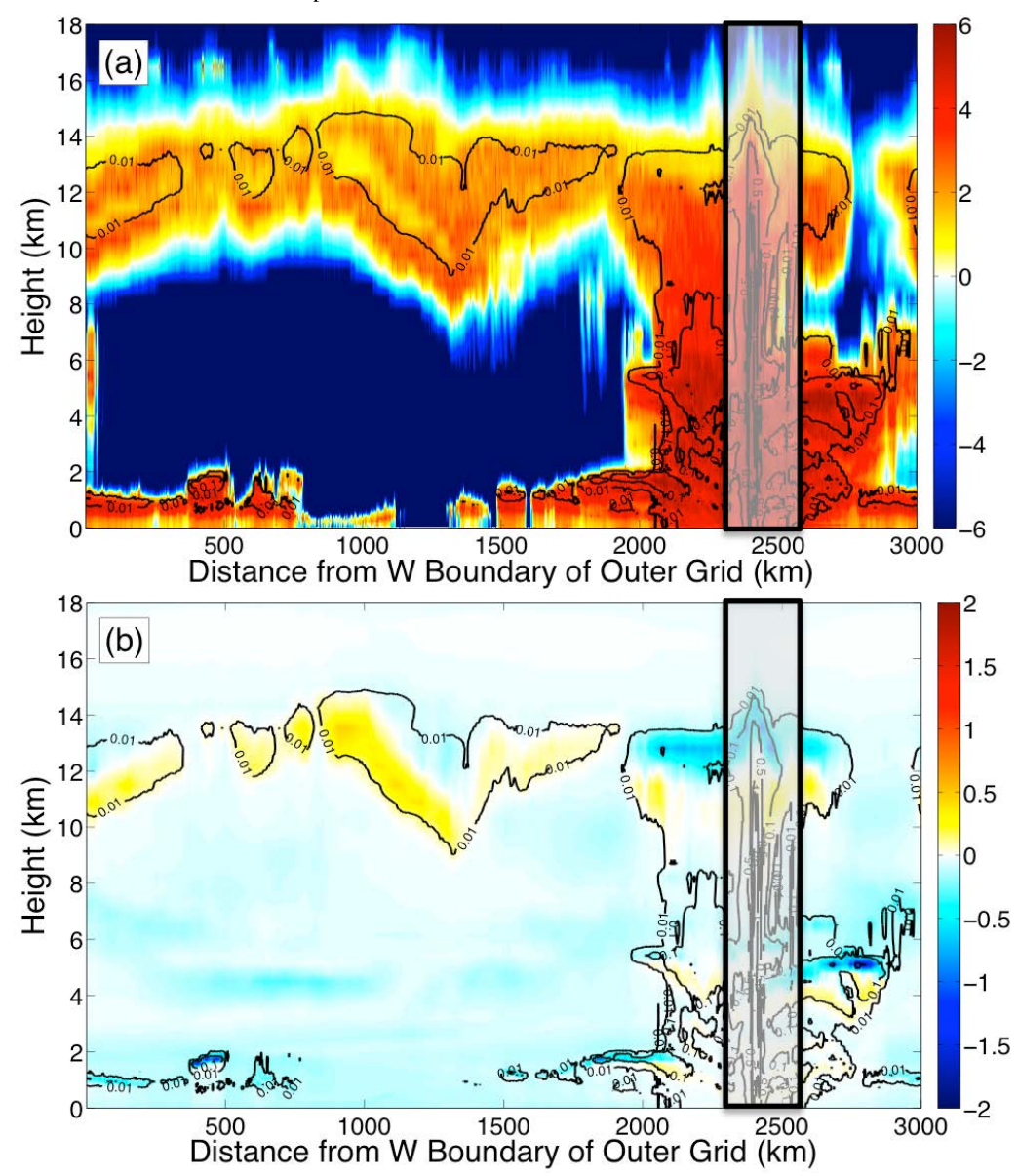

Fig. 2.7: (a) Meridionally averaged cross-section at 2310 UTC; shaded contours are the unitless ratio between the absolute value of total latent heating rate in $\mathrm{K} \mathrm{hr}^{-1}$ and the absolute value of the heating rate in $\mathrm{K} \mathrm{hr}^{-1}$ for all radiative processes, shown on a log scale (for example, values of +2 (-2) indicate latent heating being two orders of magnitude larger (smaller) than radiative heating). Translucent boxes indicate the location of the finer grid. Warm (cool) colors indicate where latent heating is larger (smaller) than radiation. Contours indicate meridionally averaged total condensate in $\mathrm{g} \mathrm{kg}^{-1}$. (b) Same as (a), but shaded contours are meridionally averaged radiative heating rate in $\mathrm{K} \mathrm{hr}^{-1}$. 


\section{Results}

\subsection{Forward Trajectories}

The forward trajectories ascend to various heights during the simulation. Figure 3.1

shows the maximum heights achieved by trajectories as a function of their starting altitudes, and Figure 3.2 shows the pathways of the forward trajectories and their corresponding $\theta_{\mathrm{e}}$ values.

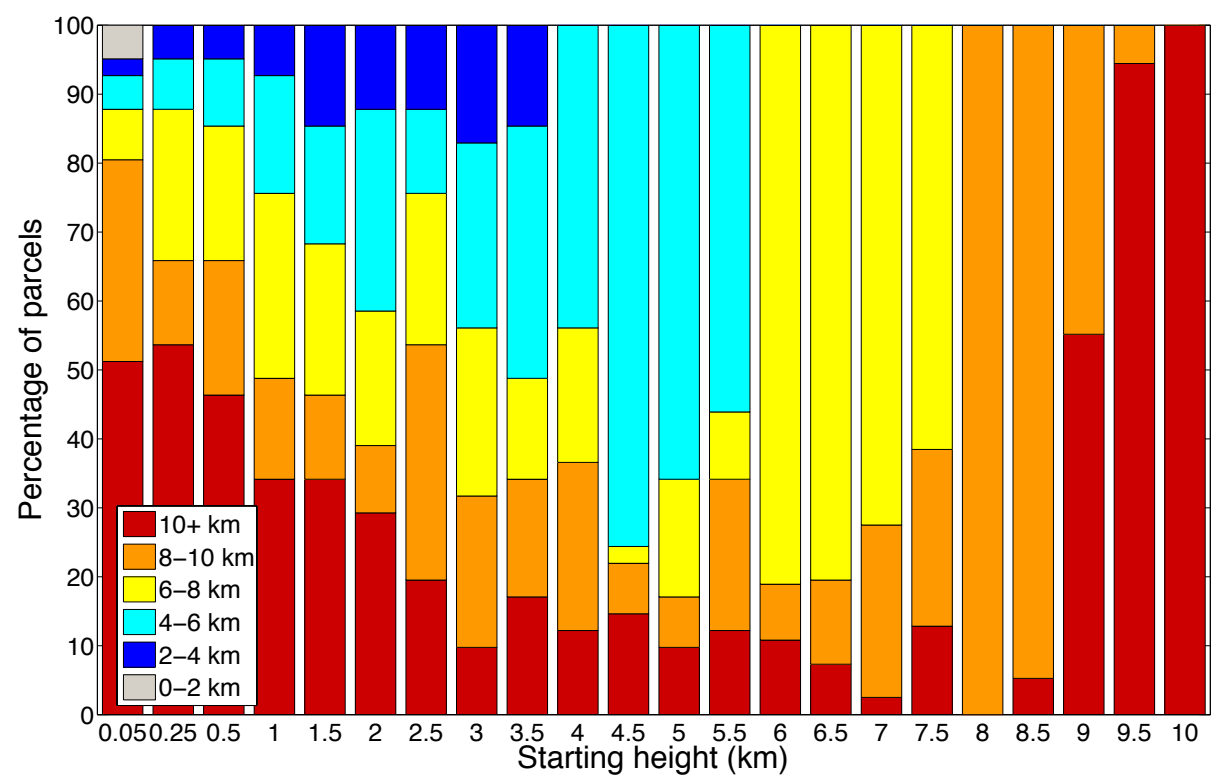

Fig. 3.1: Distribution of maximum trajectory heights by starting altitude for forward trajectories.

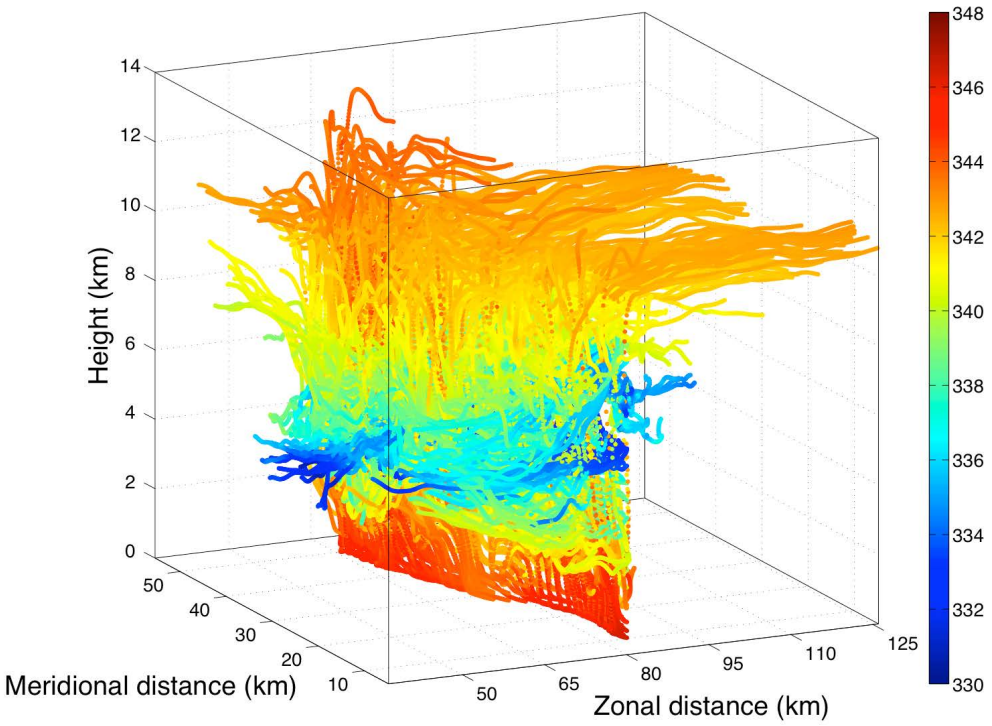

Fig. 3.2: Forward trajectory positions throughout the 90 minute simulation, color-coded by $\theta_{\mathrm{e}}$. 
Trajectories that begin close to the surface are more likely to reach the upper troposphere than trajectories that begin in the middle troposphere. For example, $51.2 \%(80.5 \%)$ of trajectories that begin 50 meters AGL ascend higher than 10 (8) km AGL, while 9.8\% (17.1\%) of trajectories that begin $5 \mathrm{~km}$ AGL ascend higher than 10 (8) km AGL. Fierro et al. (2009) showed a similar percentage of near-surface trajectories reaching above $10 \mathrm{~km}$ AGL. Mechem et al. (2002) showed a qualitative agreement with the maximum height distribution in Figure 3.1; fewer trajectories originating from around the mid-tropospheric $\theta_{\mathrm{e}}$ minimum reached the upper troposphere than those starting from near the surface in higher $\theta_{\mathrm{e}}$ air. Trajectories that begin above $8 \mathrm{~km}$ are very likely to reach above $10 \mathrm{~km}$ AGL simply by virtue of having a limited vertical distance to travel.

The fact that as many as $\sim 10 \%$ of mid-level trajectories ascend to the upper troposphere within the convection may be due to the highly moist middle troposphere, as shown in the sounding in Figure 2.5. The moist environment in this study is similar to the environment in Mechem et al. (2002) with higher mid-level relative humidity, and is also similar to their simulations with moister middle levels in terms of the difference in the $\theta_{\mathrm{e}}$ values between the surface and the middle troposphere. Both moist simulations in Mechem et al. (2002) showed a higher percentage of mid-level parcels ascending to the upper troposphere within the convective updrafts than their drier simulation. This was attributed to the mid-level inflow in the moister simulations saturating more quickly than the mid-level inflow in the drier simulation upon interacting with the convection.

The mid-level forward trajectories are initially farther from the convection than the boundary layer trajectories since the convective updrafts slope rearward over their associated cold pools. This front-to-rear structure is evident in Figure 2.2. Since the zonal winds at lower 
and middle levels are of comparable magnitude, it takes the mid-level trajectories longer to interact with the convection. By the time they to do interact, the cells' updrafts have weakened. This is evident in Figure 3.3a, which shows the time-varying average upward convective mass flux as a function of height averaged over the region between 25 and $125 \mathrm{~km}$ from the western boundary of the finer grid and between 10 and $50 \mathrm{~km}$ from the southern boundary of the finer grid. This region is large enough to capture all the updrafts that interact with the forward trajectories at all times of the simulation. The decreasing mass flux with time at all heights illustrates the temporal loss of convective intensity in the convective cells near the forward trajectories. Therefore, the number of mid-level trajectories that ascend to the upper troposphere may be an underestimate compared to what would be expected if forward trajectories had been initiated elsewhere in the inner grid where the convective intensity remains more nearly constant with time (Figure 3.3b). Figure 3.4 shows the average amount of time it takes for trajectories that ascend to above $10 \mathrm{~km}$ AGL to ascend $1 \mathrm{~km}$ above their initial height. The increasing amount of time as a function of initial height shows that it takes trajectories beginning at mid-levels longer to reach the line of convective cells than trajectories that begin closer to the surface.

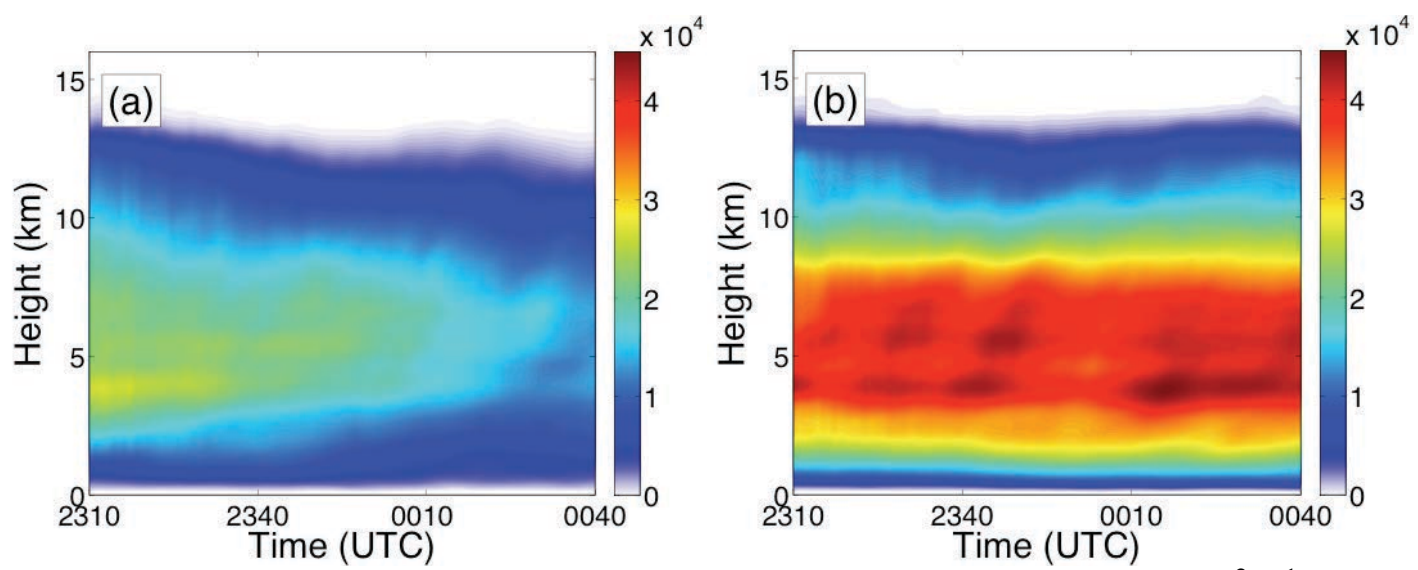

Fig. 3.3: Hovmoller diagrams of the vertical profiles of upward mass flux $\left(\mathrm{kg} \mathrm{m}^{-2} \mathrm{~s}^{-1}\right)$ integrated within cloudy regions (total cond. $>0.01 \mathrm{~g} \mathrm{~kg}^{-1}$ ) and strong updrafts (vertical velocity $>1 \mathrm{~m} \mathrm{~s}^{-1}$ ) for the regions: (a) between 25 and $125 \mathrm{~km}$ from the western boundary of the finer grid and 10 and $50 \mathrm{~km}$ from the southern boundary of the finer grid (near forward trajectories), and (b) throughout the remainder of the domain. 


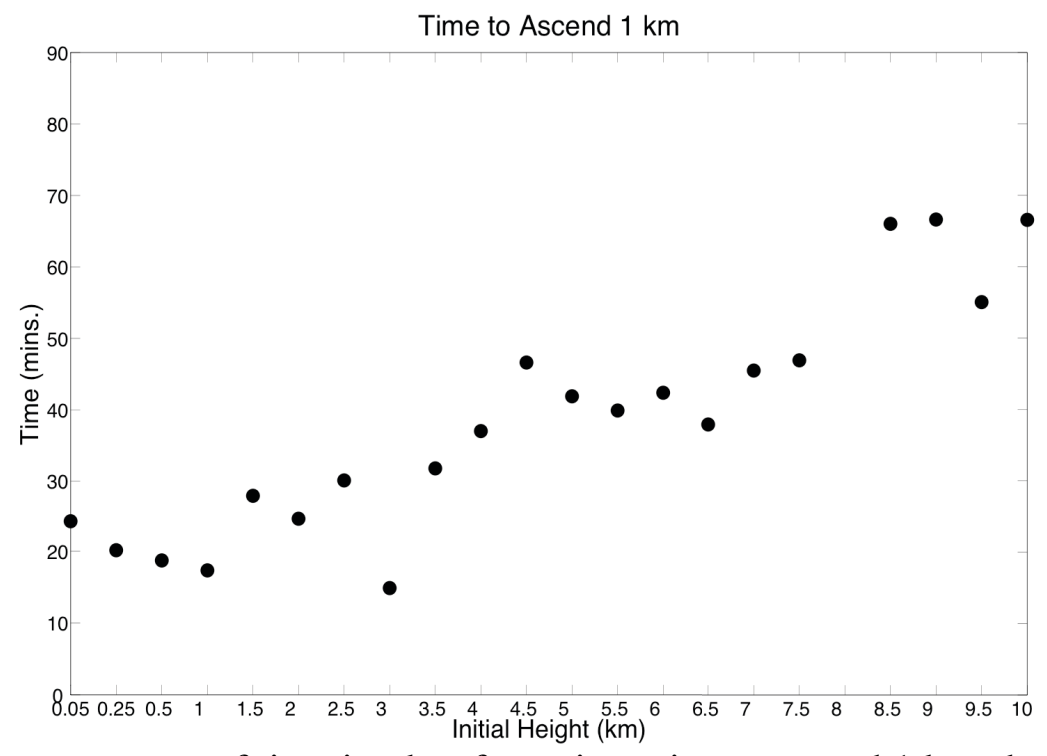

Fig. 3.4: The average amount of time it takes for trajectories to ascend $1 \mathrm{~km}$ above their initial height (among trajectories that ascend to at least $10 \mathrm{~km} \mathrm{AGL).}$

\subsection{Backward Trajectories}

\subsubsection{Heights}

Figure 3.5 illustrates the height distribution of the backward trajectories. At the end of the simulation, when the backward trajectories are initialized (0040 UTC; Figure 3.5a), Group A and Group B trajectories are both above $10 \mathrm{~km}$ AGL, as described in chapter II. Ten minutes prior to the end of the simulation (0030 UTC; Figure 3.5b), nearly half of the Group A trajectories are below $10 \mathrm{~km}$, with a small number below $5 \mathrm{~km}$. Most Group B trajectories remain above $10 \mathrm{~km}$. Fifty minutes before the end of the simulation (2350 UTC; Figure 3.5c), Group A trajectories are relatively evenly distributed throughout the troposphere, while Group B trajectories are still predominantly confined to above $10 \mathrm{~km}$. At the start of the simulation (2310 UTC; Figure $3.5 \mathrm{~d})$, some of the Group B trajectories are spread through the lower and middle troposphere, but most still remain above $10 \mathrm{~km}$. There is very little change in the height distributions of both trajectory groups in the first hour of the simulation; most of the vertical motion within convective updrafts 
for both groups occurs in the last half hour. Only $23.1 \%$ (30.6\%) of the Group A (Group B) backward trajectories that are not ignored based on the criteria outlined in section 2.3.4 are initialized within the forward trajectory region, which is characterized by upward convective mass flux that decreases substantially by the last half hour of the simulation (Figure 3.3a). If a larger fraction of the backward trajectories had been initialized within this forward region, it might have prevented the majority of the vertical motion within convective updrafts from occurring toward the end of the simulation. Instead, partially due to the fact that a majority of backward trajectories are initialized outside the forward region and instead within regions where upward mass flux remains nearly constant in time throughout the simulation (Figure 3.3b), much of the backward trajectories' upward motion does occur in the last half hour.

Since Group A trajectories were defined as those within stronger updrafts and downdrafts contiguous with the $10 \mathrm{~km}$ level, it is not surprising that many more Group A than Group B trajectories have their origin in the lower and middle troposphere. It is noteworthy that $66 \%$ of the Group A trajectories that are analyzed have their origin above $2 \mathrm{~km}$ AGL. For Group B trajectories that are analyzed, 94\% have their origin above $2 \mathrm{~km}$ AGL. It is thus apparent that air originating in the middle troposphere contributes significantly to the development of the deep convection in the simulation. The forward trajectories seem to suggest a lesser importance of mid-level inflow compared what is seen in the Group A backward trajectories; this supposed contradiction can be interpreted as an artifact of the vertical motion threshold of $1 \mathrm{~m} \mathrm{~s}^{-1}$ placed on Group A backward trajectories. The trajectories with the highest vertical velocities in Group A tend to originate closer to the surface (not shown).

As evidenced by the fact that $24.8 \%(73.5 \%)$ of trajectories that are analyzed within Group A (Group B) remain above the $10 \mathrm{~km}$ level during the entire simulation, Group A has 
more trajectories that represent lower and middle tropospheric convective inflow than Group B. Therefore, analyses of latent heating and mixing in the remainder of this study will primarily be focused on Group A. The microphysical processes contributing to latent heating along the Group
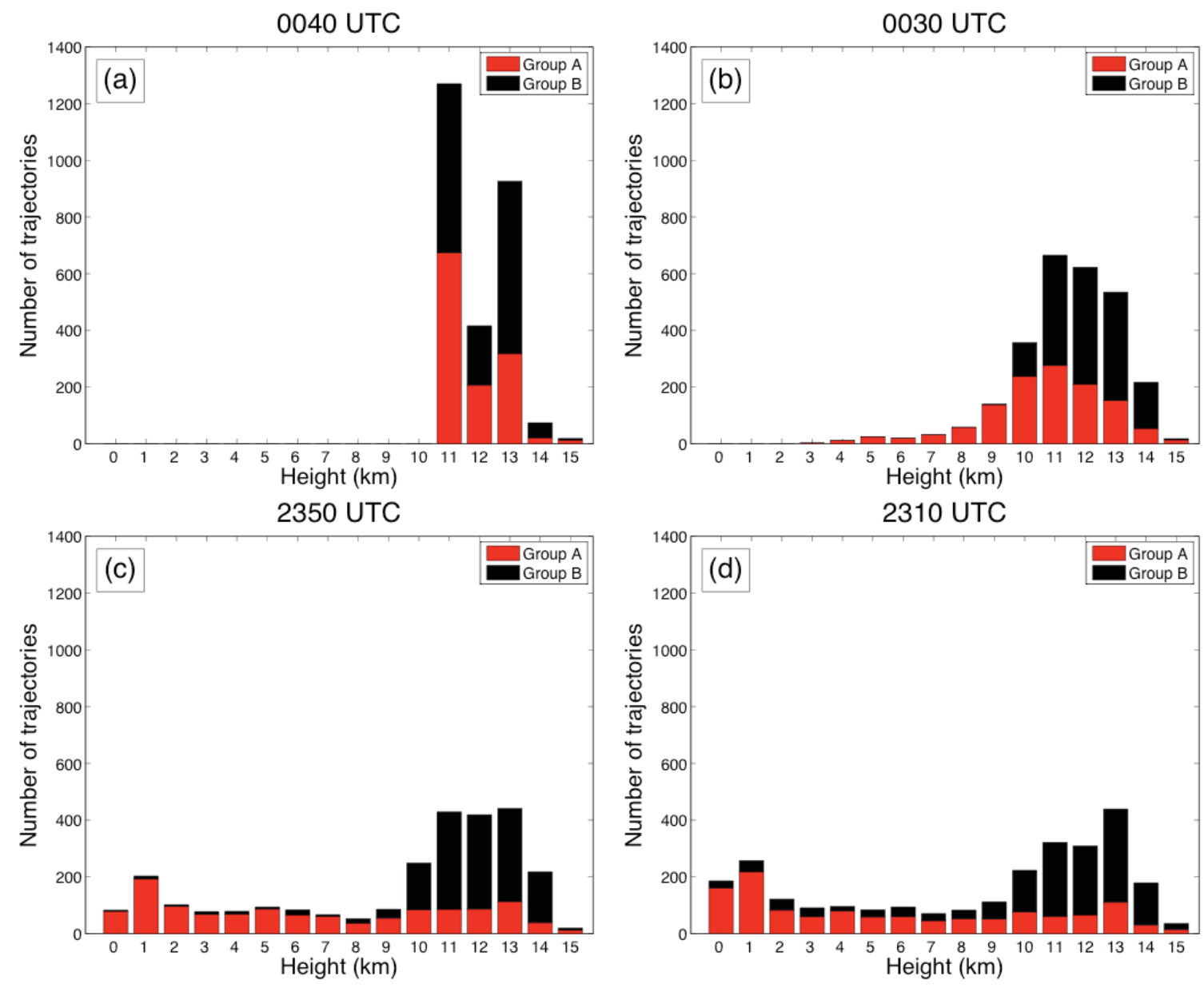

Fig. 3.5: Histograms of backward trajectory heights (Group A in red, Group B in black) at (a) 0040 UTC when backward trajectories are initialized, all above $10 \mathrm{~km}$ AGL, (b) 0030 UTC, (c) 2350 UTC, and (d) 2310 UTC, which is the initial time of the simulation.

A trajectories throughout the simulation are shown in Figure 3.6, binned as a function of the trajectories' height at 2310 UTC (the beginning of the analysis period, as discussed in chapter II, section 1) and height at any later time. 


\subsubsection{Latent Heating Changes}

Figures for cloud nucleation (NucCld), condensation and evaporation (VapLiq), deposition and sublimation (VapIce), freezing (RimeCld+Rain2Ice), and melting (Ice2Rain+MeltIce) are shown in Figure 3.6 (the definitions for these microphysical variables are given in Table 2.2). Group A trajectories have ice nucleation rates greater than $1 \mathrm{~K} \mathrm{hr}^{-1}$ only $0.04 \%$ of the time and are therefore not shown. The solid black line on the plots indicates where the initial height equals the height at any later time. In general, trajectories that start at lower initial heights have higher latent heating rates for all processes, although this is particularly true for cloud nucleation and condensation.

Cloud nucleation and condensation both contribute to latent heating significantly up to approximately $6 \mathrm{~km}$ AGL, with average heating rates peaking at about $5 \mathrm{~km}$. Cloud nucleation rates exceed $80 \mathrm{~K} \mathrm{hr}^{-1}$ and condensation rates reach $40 \mathrm{~K} \mathrm{hr}^{-1}$. Evaporation along trajectories is localized in the 1-2 model levels above the top edge of where condensation occurs within updrafts, resulting in an evaporation rate that averages $10 \mathrm{~K} \mathrm{hr}^{-1}$ around $7 \mathrm{~km}$ AGL. These 1-2 model levels are also where vapor deposition onto ice first becomes strongly positive in the vertical and where the vapor pressure is greater than (less than) the saturated vapor pressure with respect to ice (water) (not shown). The evaporation of liquid water around $7 \mathrm{~km}$ AGL is thus evidence of the Wegener-Bergeron-Findeisen process. Melting rates are generally between 5 to $10 \mathrm{~K} \mathrm{hr}^{-1}$ in the $2 \mathrm{~km}$ below the freezing level and are highest for trajectories that begin in the lowest $2 \mathrm{~km}$ AGL. Above the freezing level, both the freezing of condensate and vapor deposition onto ice contribute to latent heating. Condensate freezing predominantly occurs just above the freezing level; at $2310 \mathrm{UTC}, 33.9 \%$ of freezing occurs at temperatures below $-5^{\circ} \mathrm{C}$, $6.2 \%$ occurs below $-10^{\circ} \mathrm{C}$, and just $1.0 \%$ occurs below $-15^{\circ} \mathrm{C}$. It is encouraging from the 

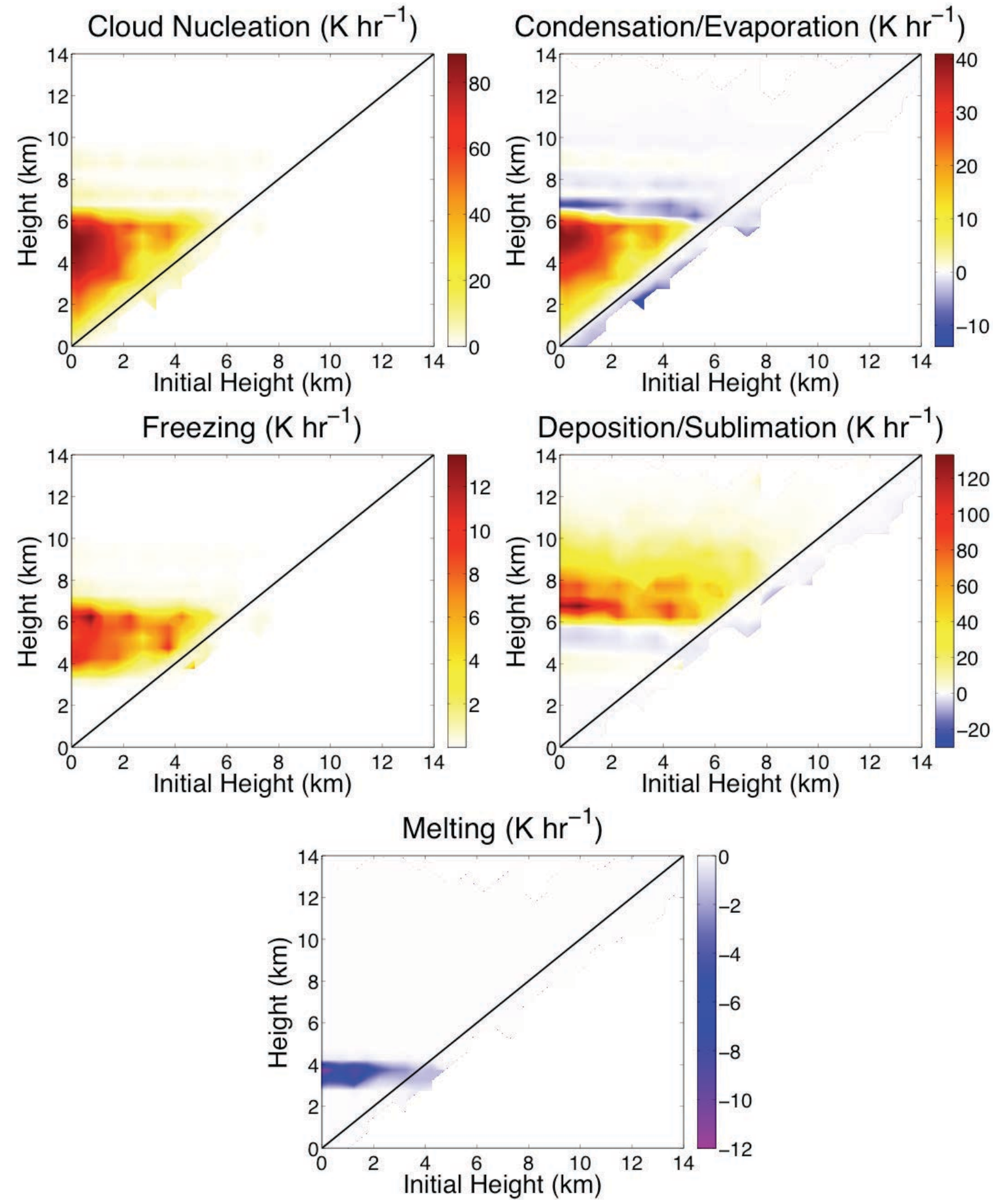

Fig. 3.6: Mean heating/cooling rates in association with cloud nucleation, condensation/evaporation, deposition/sublimation, freezing, and melting within RAMS, where colors are the mean heating/cooling rates for these processes. Heating/cooling rates are binned as a function of initial height and current height. Heating rates are positive and cooling rates are negative. Solid line is where initial height equals current height. 
standpoint of model performance to note that the amounts of supercooled water as a function of temperature for observations in Stith et al. (2002) agree well with the freezing percentages as a function of temperature observed in this study. Condensate freezing has heating rates just over $10 \mathrm{~K} \mathrm{hr}^{-1}$ between 4 and $7 \mathrm{~km}$ AGL for trajectories of near-surface origin; these heating rates are nearly an order of magnitude smaller than the heating rates due vapor deposition, which sometimes exceeds $100 \mathrm{~K} \mathrm{hr}^{-1}$ and occur between $6.5 \mathrm{~km}$ and $12 \mathrm{~km}$ AGL.

All of the microphysical processes that contribute to latent heating vary in magnitude as a function of vertical velocity. Figure 3.7 illustrates the latent heating of cloud nucleation, condensation, evaporation, freezing, deposition, sublimation, and melting as a function of vertical velocity. Specifically, Figure 3.7a and 3.7c show the mean latent heating rates as a function of vertical velocity for Group A backward trajectories that at 2310 UTC are in the lowest $2 \mathrm{~km}$ AGL and between 4 and $6 \mathrm{~km}$ AGL, respectively; Figure 3.7b and Figure 3.7d show the total integrated latent heating over the 90 minute analysis period as a function of vertical velocity along Group A backward trajectories that at 2310 UTC are in the lowest $2 \mathrm{~km}$ AGL and between 4 and $6 \mathrm{~km}$ AGL, respectively. For trajectories starting in the lowest $2 \mathrm{~km}$ AGL, cloud nucleation (vapor deposition onto ice) contributes the most latent heating for regions where the vertical velocity is less (greater) than $10 \mathrm{~m} \mathrm{~s}^{-1}$. This is indicative of the fact that ascending trajectories accelerate as they transition from heights where cloud nucleation is the dominant microphysical process to heights where vapor deposition is the dominant microphysical process. This same trend is seen for trajectories that start between 4 and $6 \mathrm{~km}$ AGL. The total integrated heating along trajectories beginning below $2 \mathrm{~km}$ AGL shows that cloud nucleation contributes the most latent heating of any process, followed by nearly equal magnitudes of condensation and vapor deposition. Trajectories spend less time in stronger upward velocities than weaker upward 
velocities; hence, most of the integrated heating happens at velocities weaker than $10 \mathrm{~m} \mathrm{~s}^{-1}$. The same is true for trajectories starting between 4 and $6 \mathrm{~km}$ AGL. However, these trajectories have much smaller integrated heating values for all microphysical processes, and have particularly
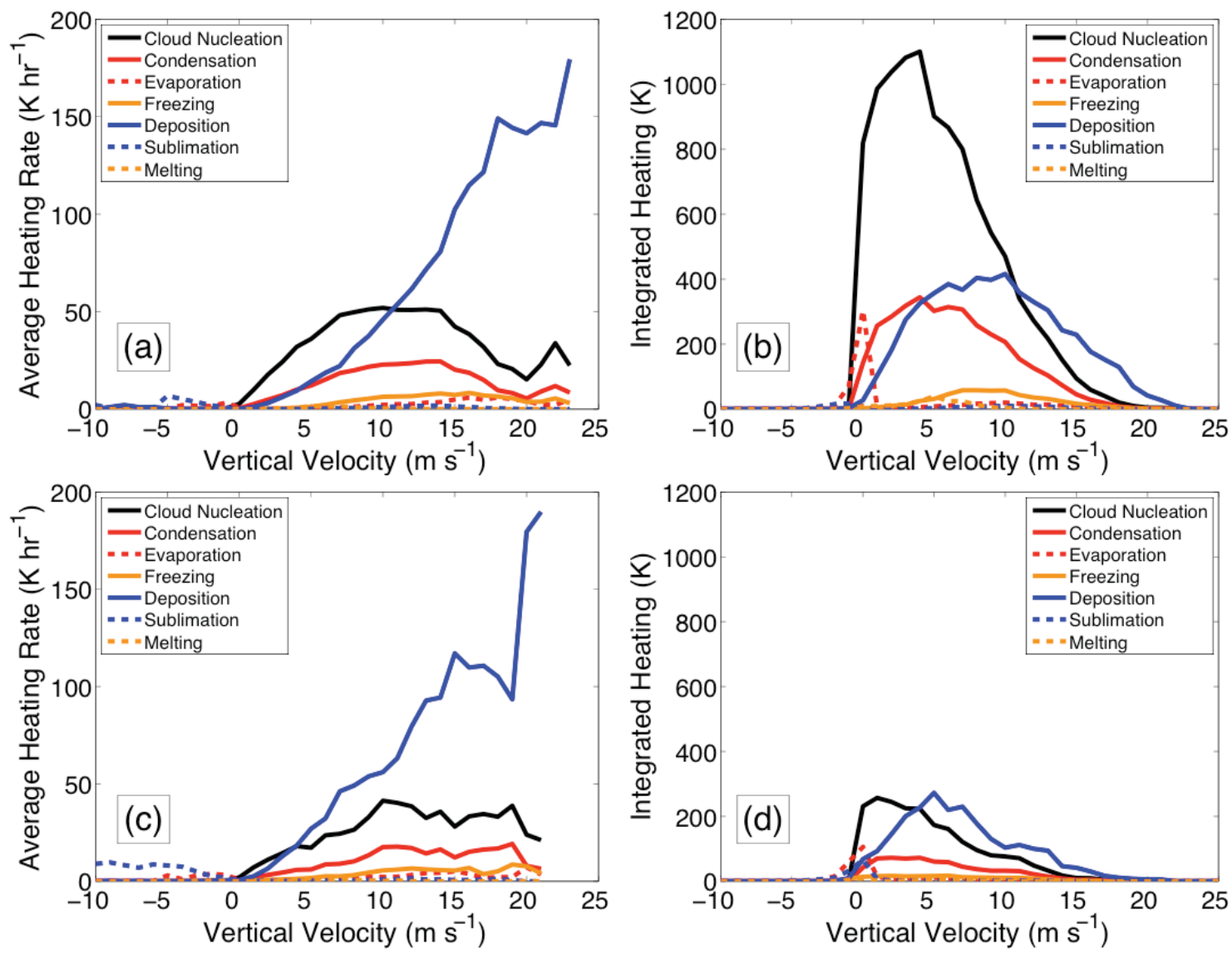

Fig. 3.7: (a) Average latent heating rate as a function of vertical velocity along Group A backward trajectories in the lowest $2 \mathrm{~km}$ AGL at 2310 UTC for the microphysical processes listed in the legend. (b) Integrated heating over the 90 minute analysis period amount along all Group A backward trajectories in the lowest $2 \mathrm{~km}$ AGL at 2310 UTC for the microphysical processes listed in the table. (c) Same as (a), but for Group A backward trajectories between 4 and $6 \mathrm{~km}$ AGL at 2310 UTC. (d) Same as (b), but for Group A backward trajectories between 4 and $6 \mathrm{~km}$ AGL at $2310 \mathrm{UTC}$.

small heating values for cloud nucleation since mid-level trajectories begin above the level of maximum cloud nucleation.

One of the more notable findings from this section is that the net effect of vapor being deposited onto all ice species may be more important than the freezing of rain water in providing 
latent heating in tropical deep convection. The dominant role of vapor deposition compared to freezing is supported by the modeling study Johnson et al. (2002) and stands in contrast to the results offered by Fierro et al. (2012), who showed condensate freezing heating rates of $300 \mathrm{~K} \mathrm{hr}^{-1}$ and vapor deposition heating rates of $20 \mathrm{~K} \mathrm{hr}^{-1}$. The Fierro et al. (2012) study made an assumption that all rain water freezes instantaneously when being lofted above the freezing level, which is an oversimplification of the real atmosphere, even though most supercooled water lofted within convective updrafts does tend to exist relatively close to the freezing level (Stith et al. 2002). The study herein was performed with a 2M microphysical scheme, and the comparable results in the Johnson et al. (2002) study were produced using a 1M scheme, so speculating on the reasons for the agreement between this study and the Johnson et al. (2002) study is difficult. It can be said, however, that the results in this study and the Johnson et al. (2002) are both physically plausible, since the latent heat of sublimation is nearly an order of magnitude greater than the latent heat of fusion. The order of magnitude separating these two heating rates may be influencing the result that vapor deposition heating rates are larger than freezing heating rates. The fact that this study used a $2 \mathrm{M}$ versus a $1 \mathrm{M}$ microphysical scheme provides a measure of confidence to the results presented herein.

It should be noted that $\theta_{\mathrm{e}}$ changes due to the latent heat of fusion but not due to the latent heat of vaporization. Vapor deposition releases the latent heat of fusion, but it also releases the latent heat of vaporization. Therefore, the portion of vapor depositional latent heating due to the latent heat of vaporization cannot change $\theta_{\mathrm{e}}$. Since the latent heat of fusion $\mathrm{L}_{\mathrm{f}}$ is nearly an order of magnitude smaller than the latent heat of vaporization $\mathrm{L}_{\mathrm{v}}$ (as noted by the definitions of $\mathrm{L}_{\mathrm{f}}$ and $\mathrm{L}_{\mathrm{v}}$ in section 2.4.1), the changes to $\theta_{\mathrm{e}}$ due to vapor deposition are likewise nearly an order of magnitude smaller than the total amount of latent heat released during vapor deposition. As a 
result, despite the fact that the magnitude of the latent heat released by vapor deposition is roughly an order of magnitude greater than the latent heat released by freezing of condensate, the freezing of condensate changes $\theta_{\mathrm{e}}$ by roughly the same order of magnitude as vapor deposition for trajectories starting in the lowest $2 \mathrm{~km}$ (Figure 3.8a).

For Group A backward trajectories starting between 4 and 6 km AGL (Figure 3.8b), vapor deposition onto ice changes $\theta_{\mathrm{e}}$ more than freezing of condensate due to many trajectories starting above the level of the maximum freezing of condensate. Also, trajectories that start in the lowest $2 \mathrm{~km}$ AGL see $\theta_{\mathrm{e}}$ increase more due to ice processes than those starting between 4 and $6 \mathrm{~km}$ AGL. This may be due to the fact that trajectories of near-surface origin have relatively high initial $\theta_{\mathrm{e}}$ values, and hence are relatively more buoyant than mid-level trajectories and correspondingly more likely to ascend within the middle of convective updrafts where latent heating is maximized. The next section examines the relative impacts of latent heating and dry air entrainment on along-trajectory $\theta_{\mathrm{e}}$ change in the simulation.
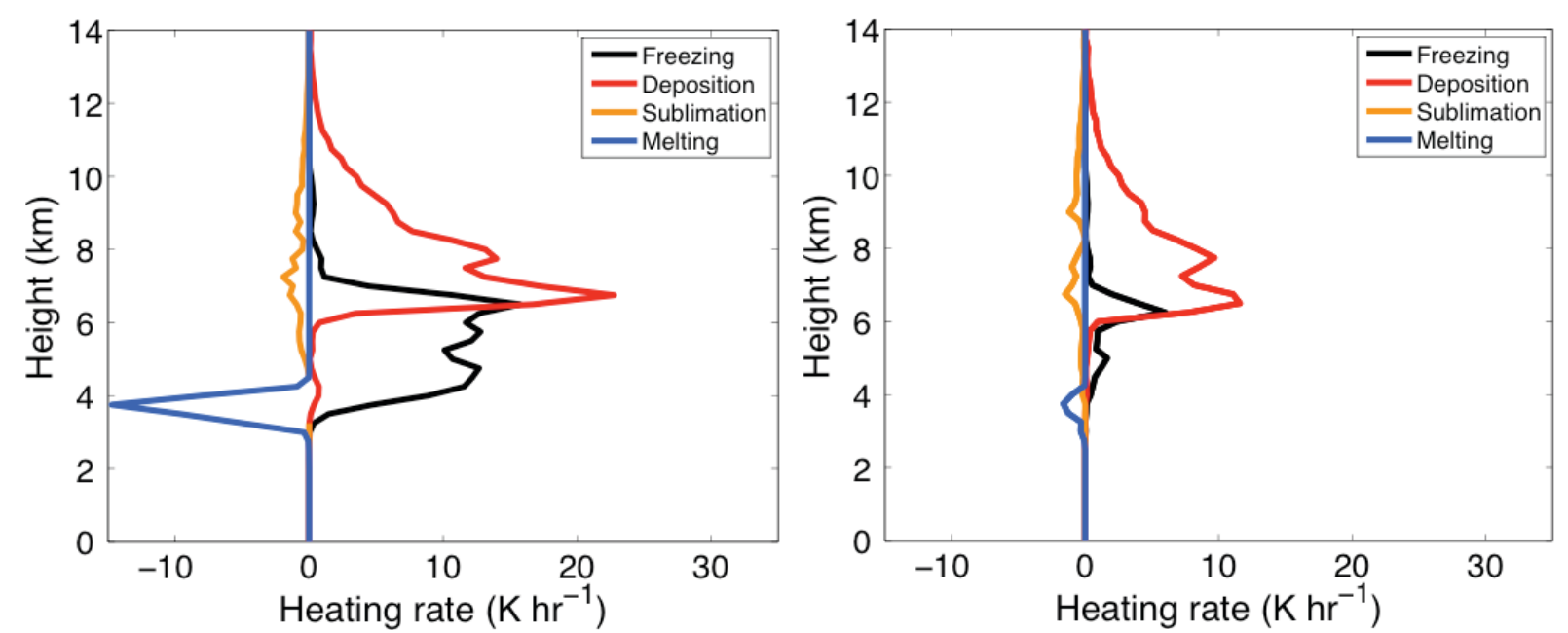

Fig. 3.8: The rate at which $\theta_{\mathrm{e}}$ changes expressed in $\mathrm{K} \mathrm{hr}^{-1}$ along Group A backward trajectories that at 2310 UTC are (a) below $2 \mathrm{~km}$ AGL and (b) between 4 and $6 \mathrm{~km}$ AGL, each partitioned by freezing, deposition, sublimation, and melting. 


\subsubsection{Equivalent Potential Temperature Changes}

Due to the limited magnitudes of the radiative heating rates in deep convection, changes to $\theta_{\mathrm{e}}$ along the Group A backward trajectories can be partitioned into contributions from latent heating due to ice processes and mixing, as described in chapter II. For the remainder of the thesis, the ice latent heating term is referred to as LAT and the residual term as RES. A positive (negative) value of RES along a trajectory means that the trajectory is mixing with higher (lower) $\theta_{\mathrm{e}}$ air. Figure 3.9 illustrates the average magnitudes of LAT as a function of height and $\theta_{\mathrm{e}}$; Figure 3.10 shows the average magnitudes of RES in the same manner. The black curve represents the average $\theta_{\mathrm{e}}$ within columns occupied by Group A trajectories at 2310 UTC. From Figure 3.9 through Figure 3.13, the (a) subplot shows the results of trajectories that begin less than $2 \mathrm{~km}$ above the surface, while the (b) subplot shows the results of trajectories that begin between 4 and $6 \mathrm{~km}$ AGL. The choice of these two layers facilitates a comparison of latent heating and mixing between near-surface inflow and mid-level inflow. In summary, Figures 3.9 through 3.13 show the following: average latent heating rate due to ice processes (Figure 3.9), average residual heating rate (3.10), average latent heating rate due to ice processes plus the average residual heating rate (3.11), a contour frequency by altitude (CFAD) plot (the number of observations, converted to $\log _{10}$ of the number of minutes) (Figure 3.12), and average vertical velocity (Figure 3.13).

Latent heating due to ice processes and mixing are first examined for trajectories that begin in the lowest $2 \mathrm{~km}$ AGL. RES is slightly negative (up to $-5 \mathrm{~K} \mathrm{hr}^{-1}$ ) from the surface to 4 $\mathrm{km}$ (Figure 3.10a) and LAT is also negative, with rates of about $-10 \mathrm{~K} \mathrm{hr}^{-1}$ around $1 \mathrm{~km}$ below the freezing level (Figure 3.9a). RES is negative whenever a parcel trajectory mixes with drier and/or cooler environmental air (where the term "environmental" is taken to mean "outside the 

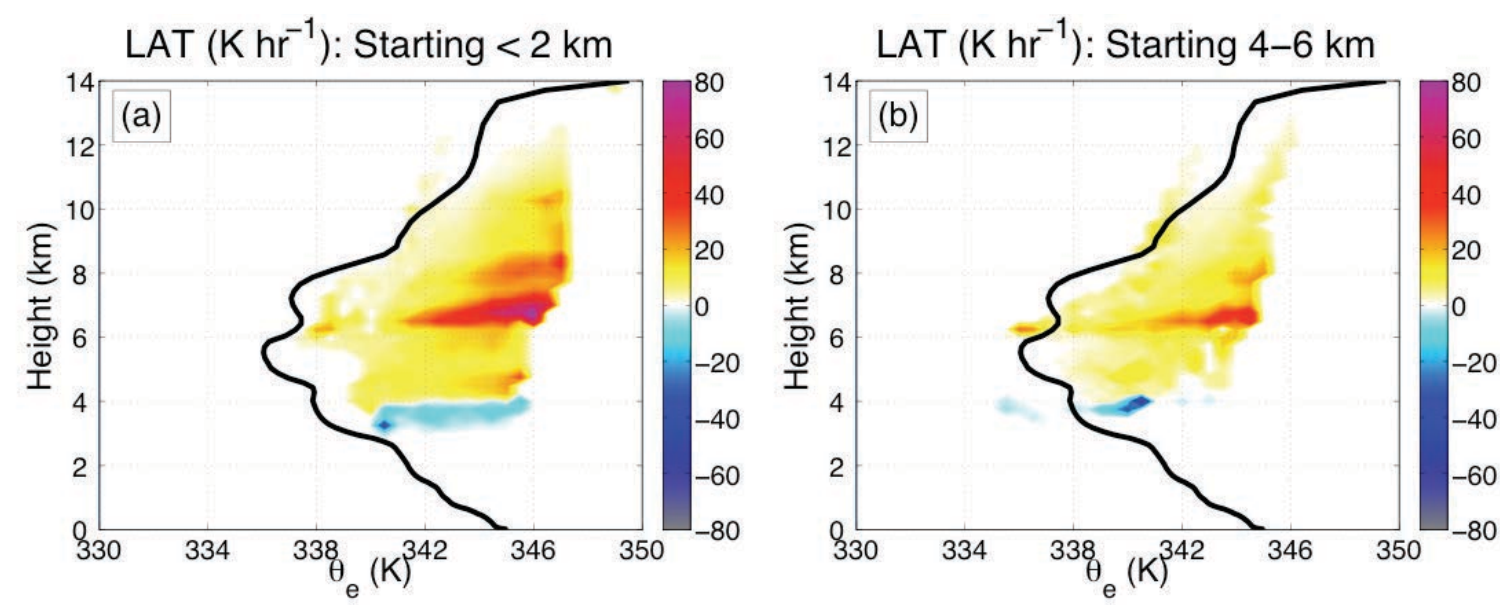

Fig. 3.9: Average latent heating due to ice processes along Group A trajectories that at 2310 are (a) below $2 \mathrm{~km}$ AGL, and (b) between 4-6 km AGL. Black curve represents average $\theta_{\mathrm{e}}$ of all Group A trajectories at that level at 2310 UTC.
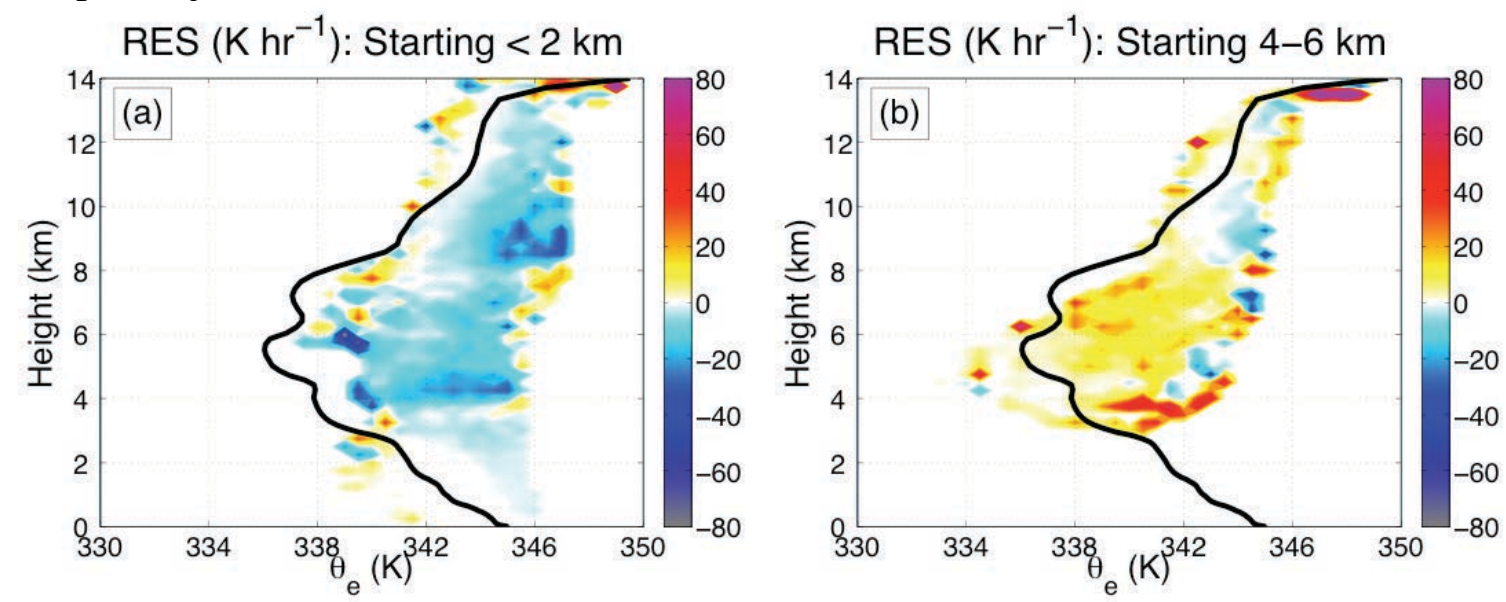

Fig. 3.10: Average residual heating rate along Group A trajectories that at 2310 are (a) below 2 km AGL, and (b) between 4-6 km AGL. Black curve represents average $\theta_{\mathrm{e}}$ of all Group A trajectories at that level at $2310 \mathrm{UTC}$.
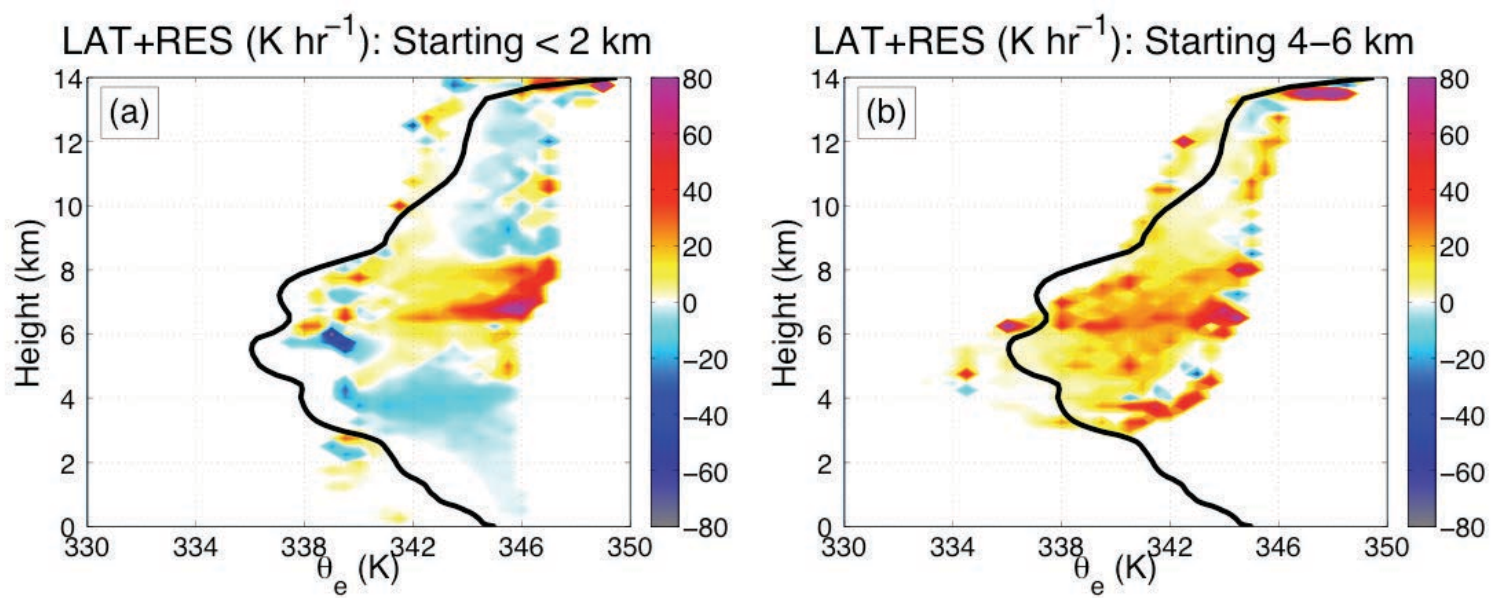

Fig. 3.11: Average latent heating due to ice processes plus the residual heating rate along Group A trajectories that at 2310 are (a) below $2 \mathrm{~km}$ AGL, and (b) between 4-6 km AGL. Black curve represents average $\theta_{\mathrm{e}}$ of all Group A trajectories at that level at 2310 UTC. 

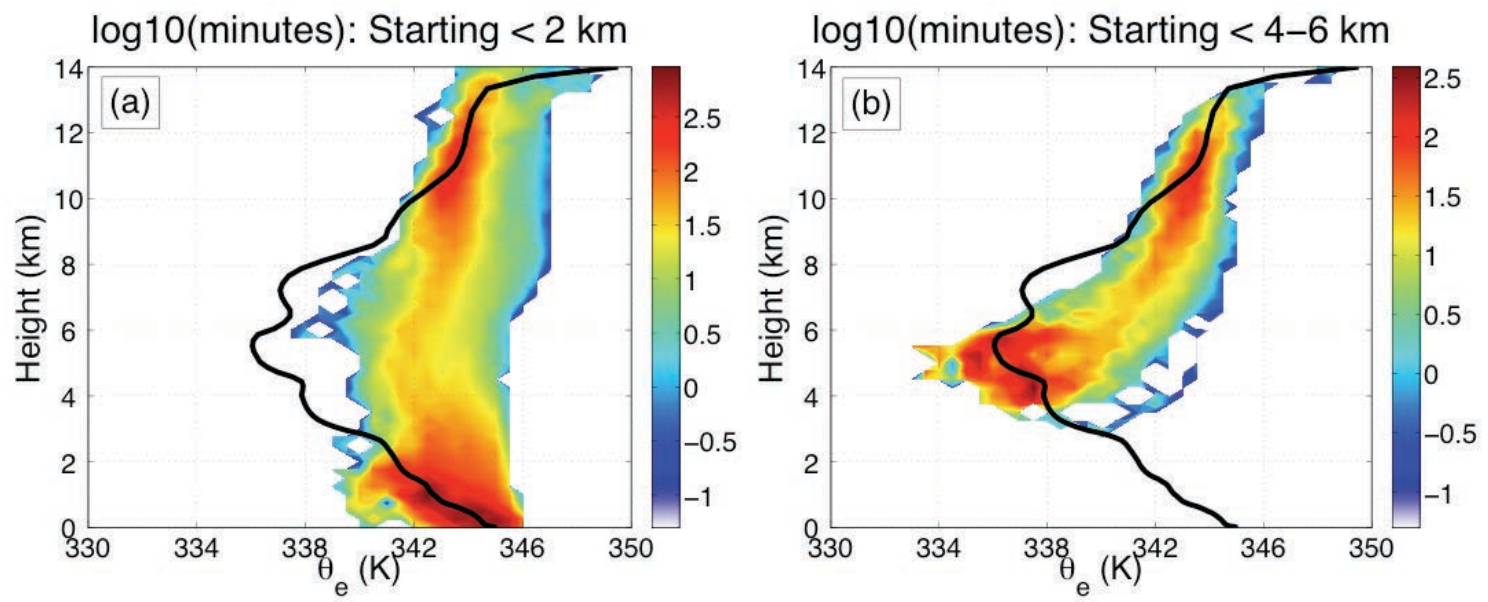

Fig. 3.12: CFAD of number of Group A trajectories (expressed as $\log _{10}$ of the number of observations, converted to minutes) that at 2310 are (a) below $2 \mathrm{~km}$ AGL, and (b) between 4-6 $\mathrm{km}$ AGL. Black curve shows average $\theta_{\mathrm{e}}$ of all Group A trajectories at that level at 2310 UTC.
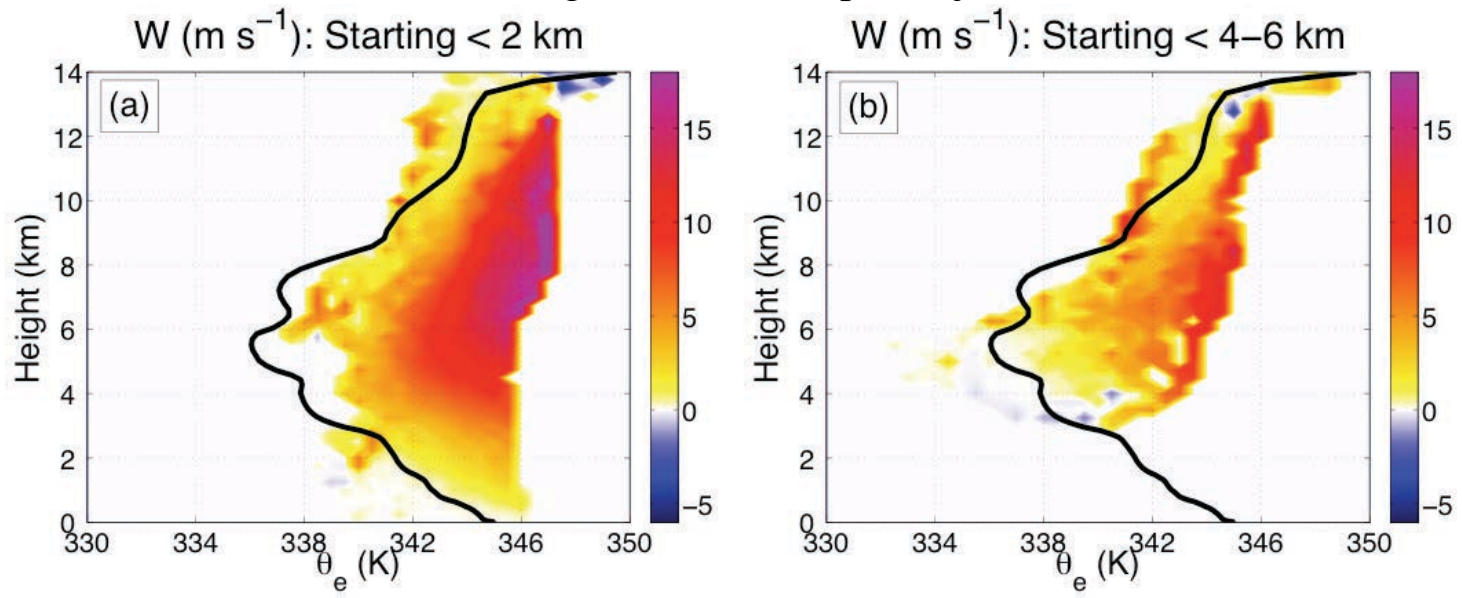

Fig. 3.13: Average vertical velocity in $\mathrm{m} \mathrm{s}^{-1}$ of Group A trajectories that at 2310 are (a) below 2 km AGL, and (b) between 4-6 km AGL. Black curve represents average $\theta_{\mathrm{e}}$ of all Group A trajectories at that level at 2310 UTC.

cloudy updraft") or when a parcel trajectory mixes with air in the cloudy updraft that is drier and/or cooler. Mixing with environmental air is likely associated with entrainment of cooler and/or drier air, while a reduction in $\theta_{\mathrm{e}}$ due to mixing within the updraft is likely due to the parcel entering a region where the amount of latent heating due to ice processes (LAT) is positive but decreasing along the trajectory.

Therefore, since the environmental profile of $\theta_{\mathrm{e}}$ decreases strongly with height in the lower troposphere and LAT is zero in the lower troposphere, the negative RES values at these 
heights indicate reductions in $\theta_{\mathrm{e}}$ due to entrainment of drier and/or cooler air. Above the melting level $(\sim 4.6 \mathrm{~km})$ it is likely that entrainment of drier and/or cooler air is still present, since environmental $\theta_{\mathrm{e}}$ values are significantly lower than parcel $\theta_{\mathrm{e}}$ values in the middle and upper troposphere. However, in regions above the melting level where LAT is both positive and decreasing in magnitude with height along ascending trajectories, negative RES values may also indicate mixing with cooler (and possibly drier) air within the updraft. Regardless of whether RES is negative due to the trajectories' mixing with drier and/or cooler environmental air or lower $\theta_{\mathrm{e}}$ air in the cloudy updraft, it is clear that from 6 to $9 \mathrm{~km} \mathrm{LAT} \mathrm{becomes} \mathrm{strongly} \mathrm{positive}$ such that it more than cancels the negative RES at these levels (Figure 3.11a). Thus, the general narrative of what changes $\theta_{\mathrm{e}}$ along parcels ascending from near the surface is similar to what has been concluded previously in other studies (Fierro et al. 2009; Fierro et al. 2012; Romps and Kuang 2010; Zipser 2003). For these trajectories of near-surface origin, $\theta_{\mathrm{e}}$ decreases in the lower troposphere due to entrainment-induced cooling and increases in the middle and upper troposphere due to ice processes.

Between 4 and 6 km AGL is where Fierro et al. (2012) found significant amounts latent heating due to the freezing of rain water, but as mentioned earlier, these amounts may have been artificially high due to their microphysics scheme, which allowed for the immediate freezing of any rain water that encounters below-freezing air temperatures. The magnitudes of the latent heating due to condensate freezing are smaller in the study within this thesis, which uses a more sophisticated 2M microphysical scheme, than in Fierro et al. (2012). The major consequence of this difference is that $\theta_{\mathrm{e}}$ along trajectories does not increase significantly until ascending above about $6 \mathrm{~km}$ AGL, which is where both freezing of condensate and vapor deposition are both contributing to latent heating; between 4 and $6 \mathrm{~km}$, cooling and drying likely due to entrainment 
are large enough to balance the latent heating from the freezing of condensate (Figure 3.11a), resulting in little $\theta_{\mathrm{e}}$ change at these levels. This result, which applies to trajectories of nearsurface origin, illustrates that latent heating must be larger than the cooling due to entrainment in order for $\theta_{\mathrm{e}}$ to increase along trajectories.

The RES cooling rates for trajectories of near-surface origin are smaller between the surface and $6 \mathrm{~km}$ where the environmental profile of $\theta_{\mathrm{e}}$ is decreasing with height than above 6 $\mathrm{km}$ where the environmental profile of $\theta_{\mathrm{e}}$ is increasing with height (Figure 3.10a). In the lower troposphere, even with low RES cooling rates, the trajectories of near-surface origin have long residence times (Figure 3.12a) and low vertical velocities (Figure 3.13a) and hence experience a large $\theta_{\mathrm{e}}$ decrease of between $2-4 \mathrm{~K}$. In the middle troposphere, the increased vertical velocities and the difference between these trajectories' $\theta_{\mathrm{e}}$ and environmental $\theta_{\mathrm{e}}$ is at a maximum; this may explain why the RES cooling rates are higher in the middle troposphere than the lower troposphere. In the upper troposphere, RES cooling rates are also generally strong, and are strongest for trajectories with higher $\theta_{\mathrm{e}}$ and vertical velocities (Figures 3.10a and 3.13a). The trajectories with the highest $\theta_{\mathrm{e}}$ values are the ones farthest from the environmental profile, and therefore not surprisingly have the largest RES cooling rates. Thus, the RES cooling rate is more a function of vertical velocity and the difference between the parcel and environmental $\theta_{\mathrm{e}}$ value than the vertical rate of change of the environmental $\theta_{\mathrm{e}}$ profile.

Trajectories that begin between 4 and $6 \mathrm{~km}$ AGL are now discussed. LAT is maximized at the same heights as trajectories that ascend from the lowest $2 \mathrm{~km}$ AGL, but the magnitudes are smaller (Figure 3.9b). Negative LAT values in the melting layer are also less pronounced since most of the trajectories begin above that level. RES is positive throughout most of the 
troposphere, particularly between 3 and $8 \mathrm{~km}$ AGL (Figure 3.10b). As these trajectories are entrained into the convection from the drier mid-level environment, they mix with higher $\theta_{\mathrm{e}}$ air of the convective cores, causing the positive RES response. Thus, the combined effect of LAT+RES is strongly positive, even at levels vertically well away from the latent heating maximum (Figure 3.11b). As these mid-level trajectories acquire the properties of the updrafts that entrain them, the updraft itself must become diluted. This is reflected in the negative midlevel RES values for trajectories ascending from the lowest $2 \mathrm{~km}$ (Figure 3.11a). The vertical velocities of the trajectories of mid-level origin are not as strong as those that ascend from near the surface (Figure 3.13). This suggests that entrained mid-level trajectories may not be buoyant enough to support the strongest updrafts.

\subsection{Forward/Backward Trajectory Comparison}

Figure 3.14 shows $\theta_{\mathrm{e}}$ profiles averaged over different subsets of the domain at 2310 UTC.

The forward profile is the average $\theta_{\mathrm{e}}$ in the curtain from which the forward trajectories are initialized. The backward profile is the average $\theta_{\mathrm{e}}$ in all the columns occupied by Group A backward trajectories. These two average profiles are very similar, showing that the forward and backward trajectories come from fundamentally similar environments. The ambient profile is taken farther away from the convection in a square domain, which extends between 10 and 30 $\mathrm{km}$ from the southeastern boundary of the inner grid. Despite being farther away from the convection, the ambient $\theta_{\mathrm{e}}$ profile is qualitatively similar to the other two; $\theta_{\mathrm{e}}$ decreases in the lower and middle troposphere to a minimum around $6 \mathrm{~km}$ AGL, and increases back to the surface value around $12 \mathrm{~km}$ AGL. If trajectories would have been initialized from the ambient 


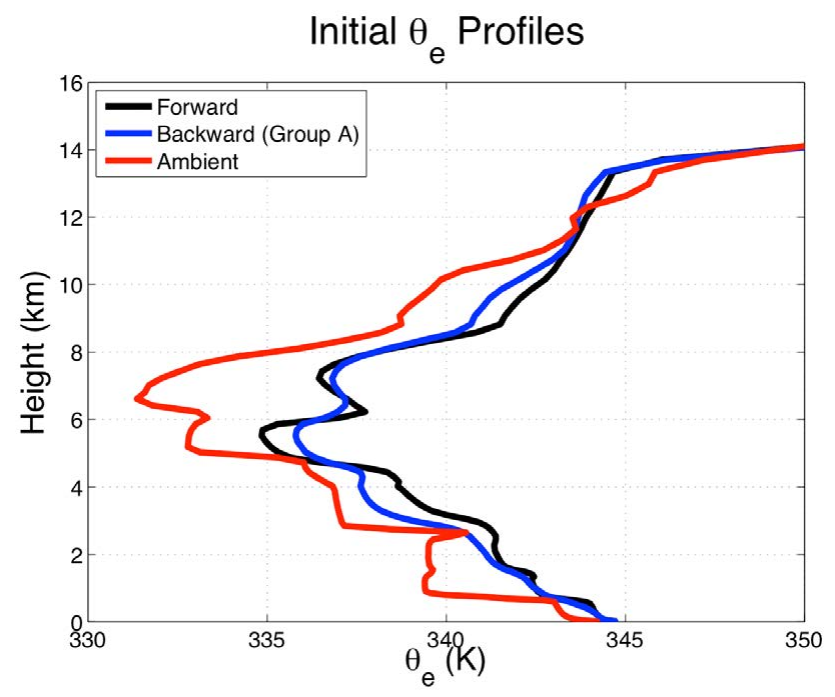

Fig. 3.14: $\theta_{\text {e }}$ profiles averaged over different regions of the domain at 2310 UTC; black curve is averaged over the forward trajectory curtain, blue curve is averaged over initial Group A backward trajectory profiles, and ambient is within the square domain between 10 and $30 \mathrm{~km}$ from the southeastern boundary of the inner grid.

region, the results of this study in terms of latent heating processes and mechanisms by which $\theta_{\mathrm{e}}$ changes would not likely have been qualitatively different.

Figure 3.15 compares LAT, RES, and vertical velocity among the three trajectory groups (forward, backward Group A, and backward Group B). The average $\theta_{\mathrm{e}}$ profile for each group at 2310 UTC is also shown. Group A and Group B are the most similar, suggesting that the backward trajectories from Group B that do have their origins in the lower and middle troposphere are fundamentally similar to trajectories starting at similar heights within Group A. Although there are quantitative differences between the forward and backward trajectories, they are very similar qualitatively despite differences in where they are initialized. The results of this study thus appear to be qualitatively insensitive to the location of trajectory initialization.

The results in this study underscore the importance of deep layer inflow in tropical deep convection within moist environments. Also, the roles of both vapor deposition and freezing of condensate in changing $\theta_{\mathrm{e}}$ above the freezing level are quantified. This study also quantifies the 
residual term of $\theta_{\mathrm{e}}$ change as mixing due to entrainment, since radiative heating rates are small compared to latent heating rates within cloudy regions and in the convective inflow. A more thorough summary of the conclusions of this study is presented in chapter V. 

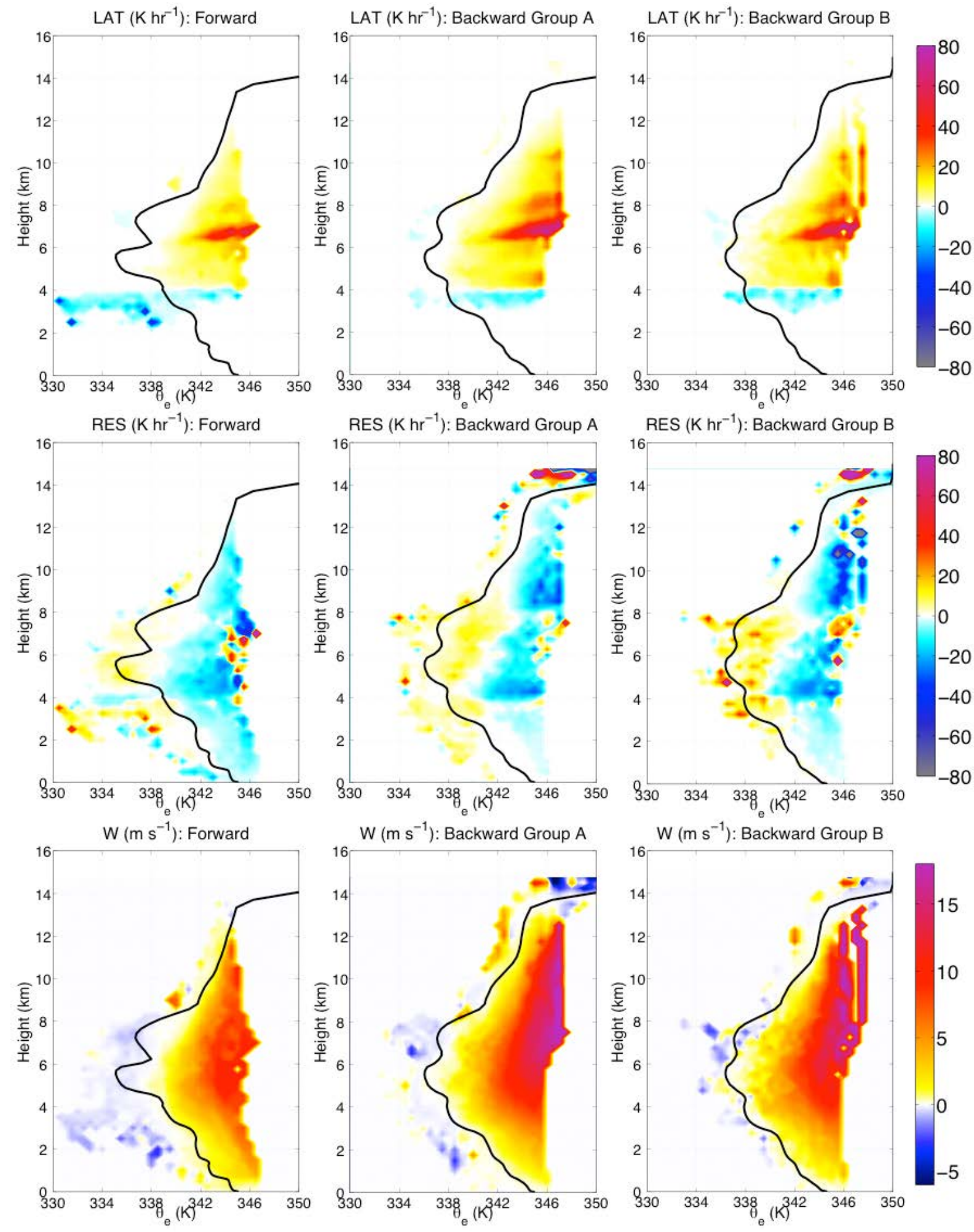

Fig. 3.15: Top panel (from left to right): Latent heating rate due to ice processes for forward, backward Group A, and backward Group B, respectively. Middle panel (from left to right): Same as top panel, but for residual heating rate. Bottom panel (from left to right): Same as top panel, but for vertical velocity. Black curve represents the average $\theta_{\mathrm{e}}$ profile of all trajectories of the group shown at 2310 UTC. 


\section{Discussion}

\subsection{Broader Implications}

The large magnitudes of the negative mixing rates above the freezing level suggest that entrainment may be important at all levels of the convection, not just below the freezing level where $\theta_{\mathrm{e}}$ change is unambiguously due to the entrainment of drier and/or cooler air. The presence of entrainment above the freezing level is implicitly noted by Romps and Kuang (2010); their results indicate a "constant probability per vertical distance of mixing with environmental air", and that "this probability per distance is sufficiently large that undiluted updrafts are negligible above a height of $4-5 \mathrm{~km}$ and virtually absent above $10 \mathrm{~km}$ ". Entrainment above the freezing level was also inferred by Fierro et al. (2009) from the fact that trajectories ascending within strong convective updrafts had $\theta_{\mathrm{e}}$ values smaller than the $\theta_{\mathrm{e}}$ values that would be expected in undiluted updrafts. The large negative RES cooling rate in the middle and upper troposphere in this simulation underscores the presence of entrainment above the freezing level, even where latent heating due to ice processes is occurring. Parameterized convection in global climate models should ideally reflect the reality of latent heating above the freezing level being greater in magnitude than what would be necessary to produce the net $\theta_{\mathrm{e}}$ change of ascending parcels.

Some convective parameterization schemes rely only on the characteristics of nearsurface air for convective inflow. This study and the Mechem et al. (2002) study have both shown that tropical deep convection in its mature stage can draw on inflow from all levels. Therefore, having some representation of deep-layer inflow in all GCM cumulus parameterizations would seem to be a positive step. 
However, in the GCM's that assume near-surface convective inflow, there may be other assumptions that would be more pressing concerns to address in the short term. Many GCM's do not represent an ice phase, which can be a serious limitation. The consistent claim of all recent hot tower literature is that latent heating due to ice processes is important in allowing diluted convection to reach the upper troposphere. One can easily imagine that the residual term in this analysis would change dramatically if latent heating due to ice processes were neglected in this study. Another limitation in GCM's is the coarse vertical resolution, which may prevent a realistic representation of deep layer inflow from being included in the first place. In short, the importance of deep layer inflow needs to be recognized in parameterizations, but amidst other shortcomings it is unclear whether the inclusion of deep layer inflow at the present time would substantially strengthen overall parameterization quality. The greatest utility of this study therefore lies in the inherent benefits of a greater process understanding of tropical convection. In the long run, process studies such as this one will accumulate and interlock to provide fundamental improvements in our ability to simulate the climate system.

\subsection{Consequences of the Pseudoadiabatic Assumption}

The Bolton (1980) formulation used in this study includes the pseudoadiabatic assumption, which is appropriate for the tropical atmosphere, causes some overestimation in $\theta_{\mathrm{e}}$ that is reflected in the mixing term. The last section of chapter III claims that all results are qualitatively similar among the different regions in the finer grid from which trajectories were initialized. However, this will not necessarily hold true if the pseudoadiabatic assumption causes $\theta_{\mathrm{e}}$ to change by a much greater magnitude in one region than another. Therefore, in the brief following analysis, profiles of $\theta_{\mathrm{e}}$ within several different regions in the finer grid (as defined 
below) are calculated using the Bolton and the exact reversible form. These forms are compared within one another at 2310 UTC. Profiles within five different regions are identified: forward trajectories, Group A backward trajectories, ambient region described in chapter III, profiles containing updrafts greater than $5 \mathrm{~m} \mathrm{~s}^{-1}$, and the entire inner grid. These regions are referred to as forward, backward, ambient, strong, and all, respectively. Figure 4.1 shows the average $\theta_{\mathrm{e}}^{\mathrm{r}}$ subtracted from the average $\theta_{\mathrm{e}}^{\mathrm{p}}$ within each region as a function of height. In all regions, the difference in $\theta_{\mathrm{e}}$ is maximized at the surface and decreases nearly linearly with height up to about $8 \mathrm{~km}$. The differences in $\theta_{\mathrm{e}}$ are remarkably similar between regions. This result adds credence to the fact that the qualitative results of this study hold in all regions of the domain.

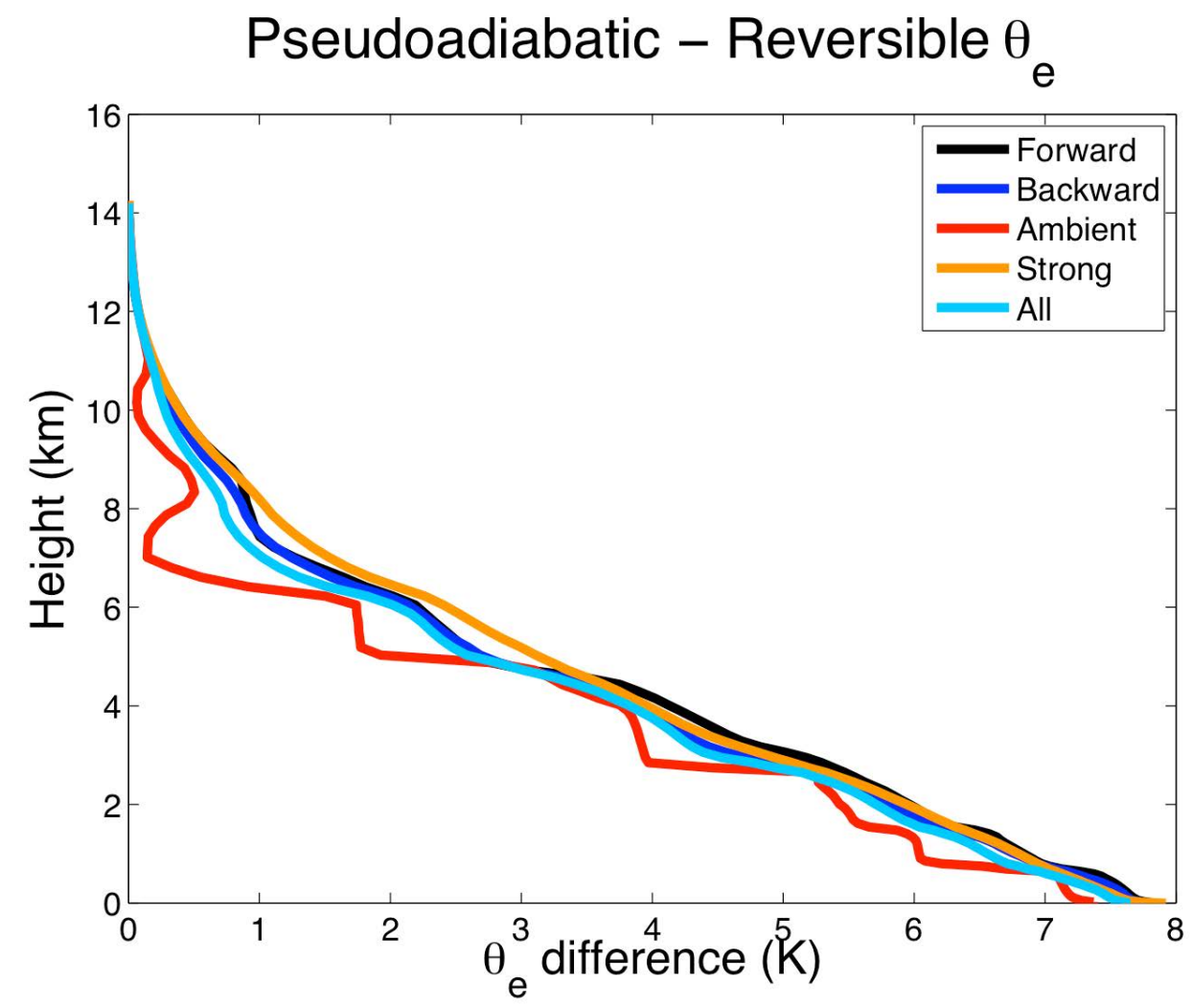

Fig. 4.1: Pseudoadiabatic $\theta_{\mathrm{e}}$ minus reversible $\theta_{\mathrm{e}}$ for different regions of the domain. 
Since the greatest differences in pseudoadiabatic and reversible $\theta_{\mathrm{e}}$ values are in the lower troposphere, it may be that some of the largest errors in the mixing rates due to the pseudoadiabatic assumption are in the lower tropospheric entrainment of drier and/or cooler air. Since $\theta_{\mathrm{e}}^{\mathrm{p}}>\theta_{\mathrm{e}}^{\mathrm{r}}$ and both $\theta_{\mathrm{e}}^{\mathrm{p}}$ and $\theta_{\mathrm{e}}^{\mathrm{r}}$ decrease with height up to $\sim 5.5 \mathrm{~km}$ (Figure 4.2), it can be concluded that entrainment of drier and/or cooler air is at least somewhat overestimated in the lower troposphere by the pseudoadiabatic form. The exact error cannot be known and depends on the amount of precipitation fallout along ascending trajectories. Performing this study with the reversible form would provide an upper bound on the amount of error potentially incurred in the lower tropospheric mixing rate by the pseudoadiabatic assumption.

\section{$\theta_{e}$ : whole domain}

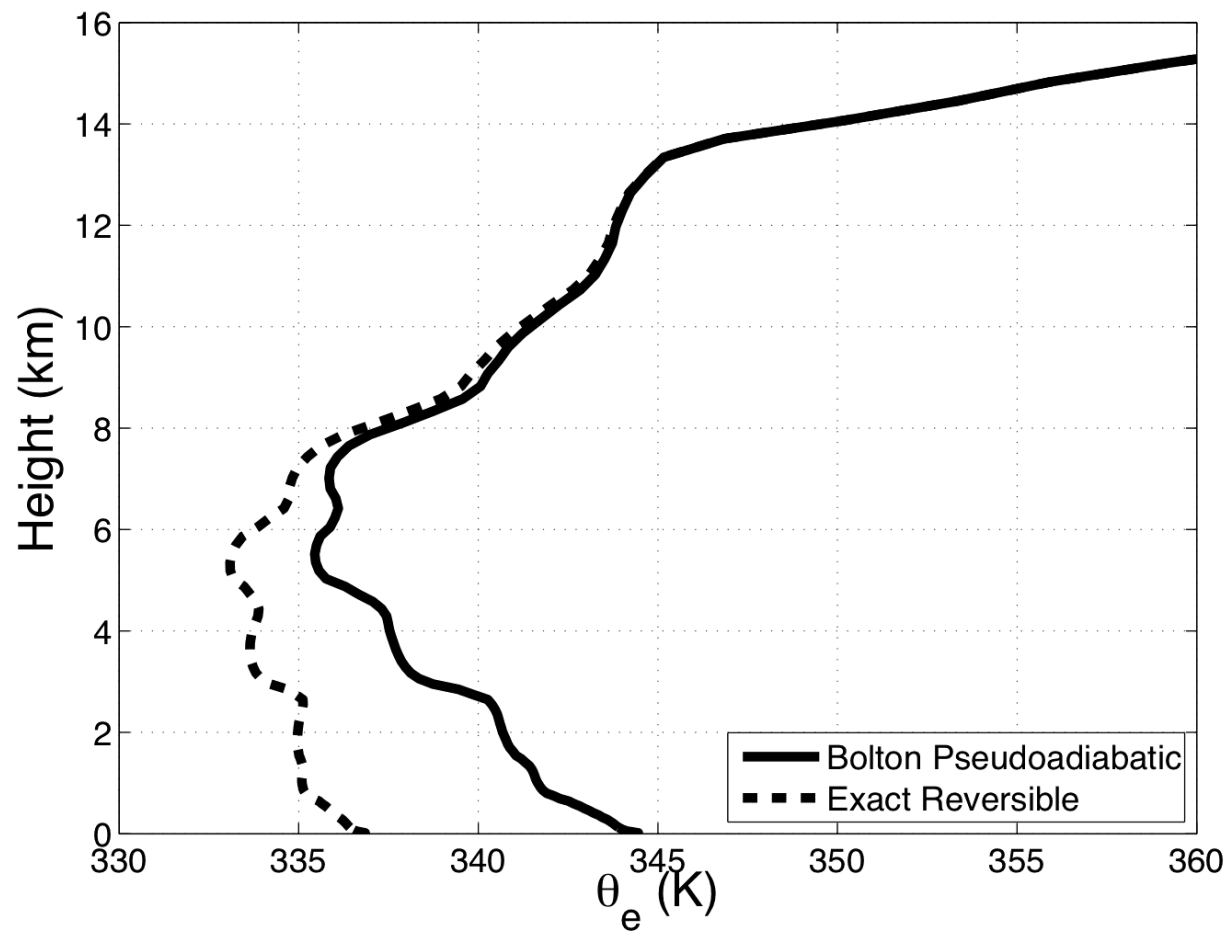

Fig. 4.2: Bolton pseudoadiabatic $\theta_{\mathrm{e}}$ using equation 2.2 and exact reversible $\theta_{\mathrm{e}}$ using equation 4.1 


\subsection{Continued Need for CRM's}

Due to computational limitations of performing climate simulations on a global scale with explicitly resolved convection, cumulus parameterizations in global climate models (GCM's) will continue to remain extremely important for a number of years to come. These parameterizations often fail to capture the full range of temporal and spatial scales of convective features (Donner et al. 2001), owing to the oversimplified representations of mass flux within such parameterization schemes. Measurements of vertical velocity within deep convection would therefore go a long way in constraining convective parameterizations. Satellites such as TRMM and CloudSat have made detailed measurements of clouds on a global scale, but these platforms are not equipped with Doppler radar capabilities to directly measure vertical motion. The Earth Clouds, Aerosols, and Radiation Explorer (EarthCARE) (Harris and Battrick 2001) satellite is scheduled for launch in 2015 as a joint collaboration among the European Space Agency (ESA), Japan Aerospace Exploration Agency (JAXA), and others. It will be a significant advancement in atmospheric remote sensing since it will allow for Doppler radar measurements in space for the first time. However, the finite radar resolution means that the accuracy of EarthCARE vertical velocity retrievals will be maximized for broad and more homogeneous vertical motions. Anderson et al. (2005) noted that field experiments have documented convective cores as being generally rather narrow (around $1 \mathrm{~km}$ width), making clouds containing convective-scale updrafts highly inhomogeneous. As noted by Schutgens (2008), large uncertainty in EarthCAREretrieved velocities will exist for such deep convective cloud systems.

Table 4.1 summarizes the best-case scenarios of what can be obtained from several platforms commonly used to analyze convective systems. Sun-synchronous platforms make high-resolution measurements of clouds and their vertical profiles, but lack any temporal 
resolution of individual cloud elements. They view clouds globally from a statistical perspective over several years of observations. Geostationary satellites have high horizontal and temporal resolution and observed large portions of hemispheric regions but cannot observe the vertical profiles of clouds and hence are quite limited from the framework of understanding process physics. Radars, aircraft, and other similar sensors used in field campaigns may have extremely high resolution depending on the nature of the instruments and the experiment but naturally lack global coverage needed to constrain global budgets.

Both temporally and spatially, CRM's offer extremely high resolution and nearly continuous data output. Notable caveats with CRM's include the need to parameterize turbulent scales of motion and the uncertainties in how to represent ice microphysics. However, for the foreseeable future, cloud-resolving modeling will remain a viable to way to analyze the atmosphere on both high temporal and spatial resolution. As resolution capabilities and microphysical schemes within CRM's continue to improve, studies like the one performed here should be repeated and the sensitivities of the conclusions presented here due to model improvements should be examined.

Table 4.1. Summary of best-case scenario dataset quality

\begin{tabular}{|l|c|c|c|c|}
\hline Approach & $\begin{array}{c}\text { High Horizontal } \\
\text { Resolution? }\end{array}$ & $\begin{array}{c}\text { High Vertical } \\
\text { Resolution? }\end{array}$ & $\begin{array}{c}\text { High Temporal } \\
\text { Resolution? }\end{array}$ & $\begin{array}{c}\text { Global } \\
\text { Dataset? }\end{array}$ \\
\hline $\begin{array}{l}\text { Sun-synchronous } \\
\text { satellites (e.g. CloudSat) }\end{array}$ & $\checkmark$ & $\checkmark$ & $\checkmark *$ & $\checkmark$ \\
\hline $\begin{array}{l}\text { Geostationary satellites } \\
\text { (e.g. GOES) }\end{array}$ & $\checkmark$ & & $\checkmark$ & $\checkmark$ \\
\hline $\begin{array}{l}\text { Radars and aircraft, etc. } \\
\text { (e.g WSR-88D radars) }\end{array}$ & $\checkmark$ & $\checkmark$ & $\checkmark$ & \\
\hline CRM's (e.g. RAMS) & $\checkmark$ & $\checkmark$ & $\checkmark$ & $\sqrt{*}$ \\
\hline
\end{tabular}

*captures data continuously, but moves too quickly for high temporal resolution of individual cloud systems

**true for global CRM's such as NICAM and OLAM 


\section{Conclusions}

\subsection{Goals Addressed}

Studies in recent years have modified the Hot Tower Hypothesis (HTH) first proposed by Riehl and Malkus (1958) toward an understanding that latent heating due to ice processes is sufficient to drive convective towers to the upper troposphere despite environmental dilution (Zipser 2003; Fierro et al. 2009; Fierro et al. 2012). Through Lagrangian trajectory analysis in an idealized, high-resolution CRM simulation of tropical deep convection with two-moment microphysics that is approaching radiative-convective equilibrium, this study tests the claims of the modified HTH. New details about the inflow characteristics and the microphysical processes contributing to the thermodynamics within the convection are also provided, which are described in more detail in the following paragraphs. The goals of this study were introduced at the end of chapter I, and the results that relate to these goals are presented below.

The first goal of this study was to analyze the microphysical processes that contribute to latent heating in deep convection. This was performed along backward trajectories in a line of convective cells that develops in the simulation. These simulations demonstrate that latent heating comes from cloud nucleation and condensation between the surface and $6 \mathrm{~km}$. Within the lower troposphere and middle troposphere, cloud nucleational heating rates peak at about $80 \mathrm{~K}$ $\mathrm{hr}^{-1}$ and condensational heating rates maximize at about $40 \mathrm{~K} \mathrm{hr}^{-1}$. Above the freezing level, which is at approximately $4.6 \mathrm{~km}$, riming of cloud water and freezing of rain water contribute to latent heating up to $7 \mathrm{~km}$ and contribute a combined $8-12 \mathrm{~K} \mathrm{hr}^{-1}$ for most trajectories ascending from the lowest $2 \mathrm{~km}$. Between 6 and $12 \mathrm{~km}$, vapor deposition onto ice dominates the latent heating rate, which frequently exceeds $40 \mathrm{~K} \mathrm{hr}^{-1}$ and sometimes reaches over $100 \mathrm{~K} \mathrm{hr}^{-1}$ between 6 and $8 \mathrm{~km}$. Melting rates near the freezing level are generally low, averaging around 5 to $10 \mathrm{~K}$ 
$\mathrm{hr}^{-1}$ for trajectories originating near the surface. For all microphysical processes, the magnitude of the latent heating/cooling decreases as the initial height of the trajectory increases. This is particularly true for cloud nucleation and condensation. Also, regardless of trajectory starting altitude, most of the integrated heating along trajectories occurs at upward vertical velocities weaker than $10 \mathrm{~m} \mathrm{~s}^{-1}$. This is true because the integrated amount of time that trajectories spend traveling upward at greater than $10 \mathrm{~m} \mathrm{~s}^{-1}$ is much less than the integrated amount of time traveled with weaker upward motions.

The second goal was to assess causes of $\theta_{\mathrm{e}}$ change along trajectories. Along trajectories, radiative heating rates are shown to be much smaller than latent heating rates, which means that $\theta_{\mathrm{e}}$ changes primarily due to latent heating from ice processes and mixing with either higher $\theta_{\mathrm{e}}$ or lower $\theta_{\mathrm{e}}$ parcels. The following two paragraphs describe the how $\theta_{\mathrm{e}}$ changes along the Group $\mathrm{A}$ backward trajectories.

For trajectories starting in the lowest $2 \mathrm{~km}$, the entrainment of drier and/or cooler air causes $\theta_{\mathrm{e}}$ to decrease below the freezing level, which is at approximately $4.6 \mathrm{~km}$. Above the freezing level, cooling rates due to mixing are larger than below the freezing level. Between 4 and $6 \mathrm{~km}$ AGL, latent heating due to freezing processes (hereafter representing the combined effect of the riming of cloud water and the freezing of rain water) are exceeded by the cooling due to mixing. Above $6 \mathrm{~km}$, cooling and/or drying due to mixing remains substantial, but the latent heating due to vapor deposition becomes enough to offset the cooling/drying and cause $\theta_{\mathrm{e}}$ to increase. Above the freezing level, the relative contribution of freezing processes to latent heating is approximately an order of magnitude less than vapor deposition onto ice; this is related to the fact that the latent heat of sublimation is an order of magnitude greater than the latent heat of fusion. However, since the latent heat of fusion is the only contributor to $\theta_{\mathrm{e}}$ change, it turns 
out that freezing processes have approximately the same combined effect on $\theta_{\mathrm{e}}$ as vapor deposition onto ice. This result stands in contrast to the relative importance of vapor deposition and on changing $\theta_{\mathrm{e}}$ as identified in Fierro et al. (2012); they showed that freezing processes caused $\theta_{\mathrm{e}}$ to increase by nearly an order of magnitude greater than vapor deposition onto ice. The fact that this study used a $2 \mathrm{M}$ versus a $1 \mathrm{M}$ scheme means that the hydrometeor size distribution was likely more realistically represented in this study than in Fierro et al. (2012), which assumed instantaneous freezing of rain water above the freezing level; this lends confidence to the results regarding the quantitative partitioning of latent heating between vapor deposition and freezing of condensate presented herein. The results of this study uphold the general narrative supported by Zipser (2003), Fierro et al. (2009), Romps and Kuang (2010), and Fierro et al. (2012), namely that $\theta_{\mathrm{e}}$ decreases in the lower troposphere due to entrainment cooling and increases in the middle and upper troposphere due to ice processes. In addition, this study explicitly quantifies the residual cooling due to mixing (which may be largely due to entrainment of cooler and/or drier air) above the freezing level. This represents an advancement compared with Fierro et al. (2009) and Fierro et al. (2012), which mention entrainment above the freezing level in a more qualitative fashion. The results of this study underscore the importance of latent heating even more compared to previous studies, since latent heating must compensate for quite substantial rates of RES cooling due to mixing above the freezing level.

Trajectories starting between 4 and $6 \mathrm{~km}$ AGL have latent heating profiles qualitatively similar to those starting in the lowest $2 \mathrm{~km}$ AGL, with the main exception being lower magnitudes of latent heating due to microphysical processes that occur below the trajectory starting level (especially true for cloud nucleation and freezing of condensate). Residual rates that change $\theta_{\mathrm{e}}$ are positive since these trajectories are being entrained into the higher $\theta_{\mathrm{e}}$ cloudy 
region or updraft. Well above the freezing level, mean vertical velocities are somewhat diminished compared to trajectories starting in the lowest $2 \mathrm{~km}$; this could indicate that mid-level trajectories exist on the peripheries of updrafts or that they are not buoyant enough to drive the strongest updrafts.

The final goal was to determine the relative roles of near-surface and elevated inflow in the latent heating of deep convection. Nearly two-thirds of backward trajectories in Group A beginning above $10 \mathrm{~km}$ have their origin above $2 \mathrm{~km}$ AGL, and forward trajectories starting in the lowest $2 \mathrm{~km}$ were more likely to ascend to the upper troposphere than those beginning at mid-levels by virtue of being closer to a weakening portion of the convective line than the forward trajectories of mid-level origin. Latent heating rates along trajectories originating from the middle troposphere are smaller than their near-surface counterparts but are not insubstantial. A significant percentage of mid-level inflow reached the upper troposphere; this may be due to high relative humidities at mid-levels and the relative ease with which moist inflow layers can saturate (Mechem et al. 2002). Particularly within moist environments, Lagrangian trajectory studies of deep convection should analyze inflow from both the lower and middle troposphere.

In summary, this study was focused on analyzing latent heating and mixing due to entrainment in tropical deep convection. Through the use of a high-resolution cloud-resolving model simulation that utilized a sophisticated double-moment microphysical scheme, new insights have been gained into the characteristics of tropical deep convection from a Lagrangian perspective. The role of deep layer inflow in particularly moist tropical environments was also illuminated in this study, as reflected in the updated schematic for the Hot Tower Hypothesis given below in Figure 5.1. These results have helped to increase our understanding of tropical deep convection in general, and provide possible avenues for the improvement of global climate 
models by highlighting the roles of deep-layer inflow and the simultaneous contributions of entrainment and latent heating above the freezing level. The likely presence of entrainment of cooler and drier air above the freezing level highlights even more clearly than in previous studies the critical role of latent heating in allowing convection to reach the upper troposphere. The significant role of tropical deep convection in the climate system continues to make it an area of fascinating and rewarding research.

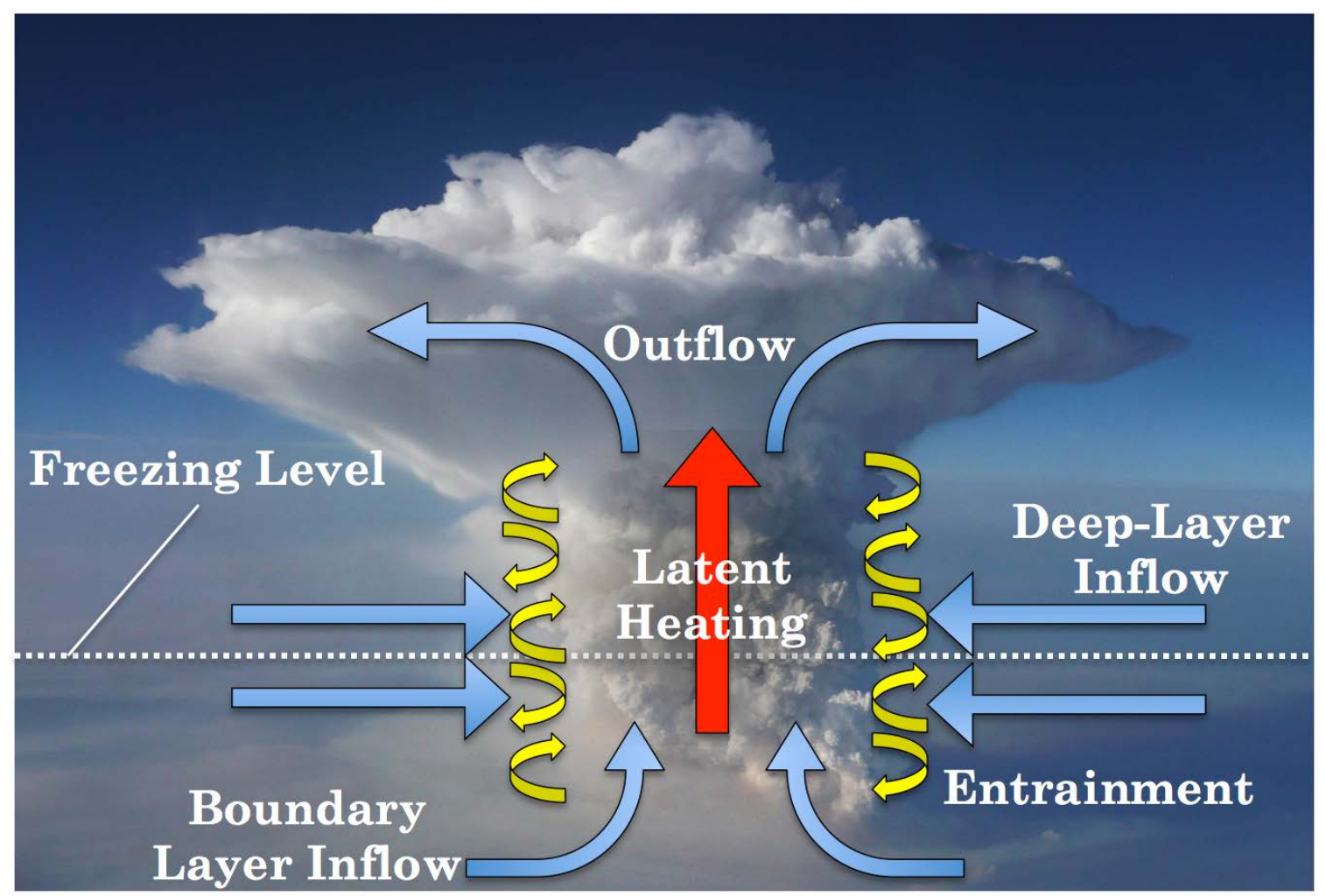

Fig. 5.1: Updated schematic of a hot tower showing the added presence of deep-layer inflow.

\subsection{Future Work}

Additional investigation is warranted into the character and evolution of tropical deep convection. One avenue for future work that would be straightforward to implement would be testing the pseudoadiabatic assumption by performing the quantitative analyses in this study with a reversible form of $\theta_{\mathrm{e}}$. Another opportunity would be to simulate convective systems that are 
both more and less organized than what was analyzed here for the purpose of understanding the distribution of responses in latent heating and mixing as a function of the spatial scale of convective systems and their corresponding elements; perhaps the role of entrainment of drier and/or cooler air plays a different role in isolated convection compared with a squall line, for example. This study could also be repeated for mid-latitude convection with stronger updrafts that are more likely to be undiluted, as noted by Zipser (2003). Accordingly, the impacts of layer inflow in mid-latitude convection could also be investigated for different environmental shear and moisture profiles; this may have important implications for the prediction of warm season precipitation in the United States, for example, where an accurate depiction of mesoscale convective systems in numerical models may depend to some degree on understanding the heights of convective inflow. Also, the simulation in this study could be repeated by using different microphysical schemes in order to investigate feedbacks of the microphysics on latent heating and entrainment. Higher resolution simulations would also illustrate the effects of better resolved turbulent eddies. Finally, further observational studies that measure both convective storm dynamics and microphysics would be helpful toward attaining a better understanding of latent heating and entrainment within tropical deep convection. 


\section{References}

Adams-Selin, R. D., S. C. van den Heever, and R. H. Johnson, 2013: Impacts of graupel parameterization schemes on idealized bow echo simulations. Mon. Wea. Rev., in press.

Anderson, N. F., C. A. Grainger, and J. L. Stith, 2005: Characteristics of strong updrafts in precipitation systems over the central tropical Pacific Ocean and in the Amazon. J. Appl. Meteor., 44, 731-738.

Balsley, B. B., W. L. Ecklund, D. A. Carter, A. C. Riddle, and K. S. Gage, 1988: Average vertical motions in the tropical atmosphere observed by a radar wind profiler on Pohnpei ( $78 \mathrm{~N}$ latitude, 1578E longitude). J. Atmos. Sci., 45, 396-405.

Betts, A. K., 1976: The Thermodynamic Transformation of the Tropical Subcloud Layer by Precipitation and Downdrafts. J. Atmos. Sci., 33, 1008-1020.

Blyth, A. M., W. A. Cooper, and J. B. Jensen, 1988: A study of the source of entrained air in Montana cumuli. J. Atmos. Sci., 45, 3944-3964.

Bolton, D., 1980: The Computation of Equivalent Potential Temperature. Mon. Wea. Rev., 108, 1046-1053.

Bryan, G. H., H. Morrison, 2012: Sensitivity of a Simulated Squall Line to Horizontal Resolution and Parameterization of Microphysics. Mon. Wea. Rev., 140, 202-225.

------, J. M. Fritsch, 2000: Moist Absolute Instability: The Sixth Static Stability State. Bull. Amer. Meteor. Soc., 81, 1207-1230.

-------, J. C. Wyngaard, J. M. Fritsch, 2003: Resolution Requirements for the Simulation of Deep Moist Convection. Mon. Wea. Rev., 131, 2394-2416.

Chilson, P. B., C. W. Ulbrich, M. F. Larsen, P. O. Perillat, and J. E. Keener, 1993: Observations of a tropical thunderstorm using a vertically pointing, dual-frequency collinear beam Doppler radar. J. Atmos. Oceanic Technol., 10, 663-673.

Cifelli, R. C., Rutledge, S. A., 1998: Vertical motion, diabatic heating, and rainfall characteristics in N. Australia convective systems, Quart. J. R. Meteor. Soc., 124, 1133-1162.

Cotton, W. R., and Coauthors, 2003: RAMS 2001: Current status and future directions. Meteor. Atmos. Phys., 82, 5-29.

Dahl, J. M. L., M. D. Parker, L.J. Wicker, 2012: Uncertainties in Trajectory Calculations within Near-Surface Mesocyclones of Simulated Supercells. Mon. Wea. Rev., 140, 2959-2966. 
Dawson, D. T., M. Xue, J. A. Milbrandt, and M. K. Yau, 2010: Comparison of evaporation and cold pool development between single-moment and multimoment bulk microphysics schemes in idealized simulations of tornadic thunderstorms. Mon. Wea. Rev., 138, 1152-1171.

Donner, L. J., C. J. Seman, R. S. Hemler, and S. Fan, 2001: A cumulus parameterization including mass fluxes, convective vertical velocities, and mesoscale effects: Thermodynamic and hydrological aspects in a general circulation model. J. Climate, 14, 3444-3463.

Emanuel, K. A., 1994: Atmospheric Convection. Oxford University Press, 580 pp.

Fierro, A. O., J. Simpson, M. A. LeMone, J. M. Straka, B. F. Smull, 2009: On How Hot Towers Fuel the Hadley Cell: An Observational and Modeling Study of Line-Organized Convection in the Equatorial Trough from TOGA COARE. J. Atmos. Sci., 66, 2730-2746.

------, E. J. Zipser, M. A. LeMone, J. M. Straka, J. (Malkus) Simpson, 2012: Tropical Oceanic Hot Towers: Need They Be Undilute to Transport Energy from the Boundary Layer to the Upper Troposphere Effectively? An Answer Based on Trajectory Analysis of a Simulation of a TOGA COARE Convective System. J. Atmos. Sci., 69, 195-213.

Gilmore, M. S., J. M. Straka, E. N. Rasmussen, 2004: Precipitation Uncertainty Due to Variations in Precipitation Particle Parameters within a Simple Microphysics Scheme. Mon. Wea. Rev., 132, 2610-2627.

Grabowski, W. W., 1995: Entrainment and mixing in buoyancy reversing convection with applications to cloud-top entrainment instability. Quart. J. Roy. Met. Soc., 121, 231-253.

Harrington, J., T. Reisin, W. Cotton, and S. Kreidenweis, 1999: Cloud resolving simulations of Arctic stratus Part II: Transition-season clouds. Atmos. Res., 51, 45-75.

Harris, R., and B. Battrick, Eds., 2001: EarthCARE—Earth Clouds, Aerosols and Radiation Explorer. ESA Rep. SP- 1257 (1), 130 pp.

Heymsfield, G. M., L. Tian, A. J. Heymsfield, L. Li, S. Guimond, 2010: Characteristics of Deep Tropical and Subtropical Convection from Nadir-Viewing High-Altitude Airborne Doppler Radar. J. Atmos. Sci., 67, 285-308.

Houze, R. A., Jr., 1982: Cloud clusters and large-scale vertical motion in the tropics. J. Meteor. Soc. Japan, 60, 396-410.

-------, Jr., 1988: Convective and stratiform precipitation in the tropics. In Tropical Rainfall Measurements (J. S. Theon and N. Fugono, Eds.), 27-35.

Igau, R. C., M. A. LeMone, and D. Wei, 1999: Updraft and downdraft cores in TOGA COARE: Why so many buoyant downdraft cores? J. Atmos. Sci., 56, 2232-2245.

Iribarne, J. V., and W. L. Godson, 1981: Atmospheric Thermodynamics. 2nd ed. D. 
Reidel, 259 pp.

Johnson, D. E., W-K. Tao, J. Simpson, C-H. Sui, 2002: A Study of the Response of Deep Tropical Clouds to Large-Scale Thermodynamic Forcings. Part I: Modeling Strategies and Simulations of TOGA COARE Convective Systems. J. Atmos. Sci., 59, 3492-3518.

Johnson, R. H., T. M. Rickenbach, S. A. Rutledge, P. E. Ciesielski, W. H. Schubert, 1999: Trimodal Characteristics of Tropical Convection. J. Climate, 12, 2397-2418.

Jorgensen, D. P., E. J. Zipser, and M. A. LeMone, 1985: Vertical motions in intense hurricanes. J. Atmos. Sci., 42, 839-856.

Khairoutdinov, M. F., S. K. Krueger, C. H. Moeng, P. Bogenschutz, and D. A. Randall, 2009: Large-eddy simulation of maritime deep tropical convection. J. Adv. Model. Earth Syst., 1 (15), doi:10.3894/JAMES.2009.1.15.

Kingsmill, D. E., and R. A. Houze Jr., 1999b: Thermodynamic characteristics of precipitating convection over the west Pacific warm pool. Quart. J. Roy. Meteor. Soc., 125, 1209-1229.

LeMone, M. A., E. J. Zipser, 1980: Cumulonimbus Vertical Velocity Events in GATE. Part I: Diameter, Intensity and Mass Flux. J. Atmos. Sci., 37, 2444-2457.

Lucas, C., E. J. Zipser, and M. A. LeMone, 1994: Vertical velocity in oceanic convection off tropical Australia. J. Atmos. Sci., 51, 3183-3193.

-------, E. J. Zipser, 2000: Environmental Variability during TOGA COARE. J. Atmos. Sci., 57, 2333-2350.

Luo, Z., G. Y. Liu, and G. L. Stephens, 2008: CloudSat adding new insight into tropical penetrating convection, Geophys. Res. Lett., 35, L19819, doi:10.1029/2008GL035330.

-------, G. Y. Liu, G. L. Stephens, and R. H. Johnson, 2009: Terminal versus transient cumulus congestus: A CloudSat perspective. Geophys. Res. Lett., 36, doi:10.1029/2008GL036927.

May, P. T., D. K. Rajopadhyaya, 1996: Wind Profiler Observations of Vertical Motion and Precipitation Microphysics of a Tropical Squall Line. Mon. Wea. Rev., 124, 621-633.

Mechem, D. B., R. A. Houze, and S. S. Chen, 2002: Layer inflow into precipitating convection over the western tropical Pacific. Quart. J. Roy. Meteor. Soc., 128, 1997-2030.

Meyers, M. P., R. L. Walko, J. Y. Harrington, and W. R. Cotton, 1997: New RAMS cloud microphysics parameterization. Part II: The two-moment scheme. Atmos. Res., 45, 3-39. 
Morrison, H., G. Thompson, and V. Tatarskii, 2009: Impact of cloud microphysics on the development of trailing stratiform precipitation in a simulated squall line: Comparison of oneand two-moment schemes. Mon. Wea. Rev., 137, 991-1007.

Paluch, I. R., 1979: The entrainment mechanism in Colorado cumuli. J. Atmos. Sci., 36, 24672478.

Petersen, W. A., R. C. Cifelli, S. A. Rutledge, B. S. Ferrier, and B. F. Smull, 1999: Shipborne dual-Doppler operations and observations during TOGA COARE. Bull. Amer. Meteor. Soc., 80, 81-97.

Pielke, R. A., and Coauthors, 1992: A comprehensive meteorological modeling system-RAMS. Meteor. Atmos. Phys., 49, 69-91.

Posselt, D. J., S. C. van den Heever, and G. L. Stephens, 2008: Trimodal cloudiness and tropical stable layers in simulations of radiative convective equilibrium. Geophys. Res. Lett., 35, L08802, doi:10.1029/2007GL033029.

-------, S. C. van den Heever, G. L. Stephens, and M. R. Igel, 2012: Changes in the interaction between tropical convection, radiation, and the large-scale circulation in a warming environment. J. Climate, 25, 557-571.

Raymond, D., and A. M. Blyth, 1986: A stochastic model for nonprecipitating cumulus clouds. $J$. Atmos. Sci., 43, 2708-2718.

Riehl, H., and J. S. Malkus, 1958: On the heat balance in the equatorial trough zone. Geophysica, 6, 503-538.

Romps, D. M., Z. Kuang, 2010: Do Undiluted Convective Plumes Exist in the Upper Tropical Troposphere?. J. Atmos. Sci., 67, 468-484.

-------, Z. Kuang, 2011: A transilient matrix for moist convection. J. Atmos. Sci., 68, 2009-2025.

Saleeby, S.M., and S.C. van den Heever, 2013: Developments in the CSU-RAMS Aerosol Model: Emissions, Nucleation, Regeneration, Deposition, and Radiation. Accepted pending revision at J. Appl. Meteor. Climatol.

Schumacher, Courtney, Robert A. Houze, Ian Kraucunas, 2004: The Tropical Dynamical Response to Latent Heating Estimates Derived from the TRMM Precipitation Radar. J. Atmos. Sci., 61, 1341-1358.

Schutgens, N. A. J., 2008: Simulated Doppler Radar Observations of Inhomogeneous Clouds: Application to the EarthCARE Space Mission. J. Atmos. Oceanic Technol., 25, 26-42.

Seigel, Robert B., Susan C. van den Heever, 2012: Dust Lofting and Ingestion by Supercell Storms. J. Atmos. Sci., 69, 1453-1473. 
Siebesma, A. P., and Coauthors, 2003: A large eddy simulation intercomparison study of shallow cumulus convection. J. Atmos. Sci., 60, 1201-1219.

Smagorinsky, J., 1963: General circulation experiments with the primitive equations. I. The basic experiment. Mon. Wea. Rev., 91, 99-164.

Stephens, G. L., S. C. van den Heever, L. Pakula, 2008: Radiative-Convective Feedbacks in Idealized States of Radiative-Convective Equilibrium. J. Atmos. Sci., 65, 3899-3916.

Stith, J. L., J. E. Dye, A. Bansemer, A. J. Heymsfield, C. A. Grainger, W. A. Petersen, R. Cifelli, 2002: Microphysical Observations of Tropical Clouds. J. Appl. Meteor., 41, 97-117.

Stommel, H., 1947: Entrainment of air into a cumulus cloud. J. Atmos. Sci., 4, 91-94.

Storer, Rachel L., Susan C. van den Heever, 2013: Microphysical Processes Evident in Aerosol Forcing of Tropical Deep Convective Clouds. J. Atmos. Sci., 70, 430-446.

Tao, W.-K., and Coauthors, 2001: Retrieved vertical profiles of latent heat release using TRMM rainfall products for February 1998. J. Appl. Meteor., 40, 957-982.

Tompkins, A. M. and G. C. Craig, 1998a: Radiative-convective equilibrium in a threedimensional cloud ensemble model, Q. J. R. Meteorol. Soc., 124, 2073-2097.

Tripoli, G. J., and W. R. Cotton, 1981: The use of ice-liquid water potential temperature as a thermodynamic variable in deep atmospheric models. Mon. Wea. Rev., 109, 1094-1102.

van den Heever, S.C., and W.R. Cotton, 2004: The impact of hail size on simulated supercell storms. J. Atmos. Sci., 61, 1596-1609.

van den Heever, S. C., G. L. Stephens, N. B. Wood, 2011: Aerosol Indirect Effects on Tropical Convection Characteristics under Conditions of Radiative-Convective Equilibrium. J. Atmos. Sci., 68, 699-718.

Yanai, M., S. Esbensen, and J.-H. Chu, 1973: Determination of bulk properties of tropical cloud clusters from large-scale heat and moisture budgets. J. Atmos. Sci., 30, 611-627.

Yeo, K., D. M. Romps, 2013: Measurement of Convective Entrainment Using Lagrangian Particles. J. Atmos. Sci., 70, 266-277.

Yuter, S. E., and R. A. Houze, Jr., 1995a: Three-dimensional kinematic and microphysical evolution of Florida cumulonimbus. Part I: Spatial distribution of updrafts, downdrafts, and precipitation. Mon. Wea. Rev., 123, 1921-1940.

, and R. A. Houze, Jr., 1995b: Three-dimensional kinematic and microphysical evolution of Florida cumulonimbus. Part II: Frequency distribution of vertical velocity, reflectivity, and 
differential reflectivity. Mon. Wea. Rev., 123, 1941-1963.

-------, and R. A. Houze, Jr., 1995c: Three-dimensional kinematic and microphysical evolution of Florida cumulonimbus. Part III: Vertical mass transport, mass divergence, and synthesis. Mon. Wea. Rev., 123, 1964-1983.

Zipser, E. J., 1977: Mesoscale and Convective-Scale Downdrafts as Distinct Components of Squall-Line Structure. Mon. Wea. Rev., 105, 1568-1589.

------, 2003: Some views on "hot towers" after 50 years of tropical field programs and two years of TRMM data. Cloud Systems, Hurricanes, and the Tropical Rainfall Measuring Mission (TRMM), Meteor. Monogr., No. 51, 49-58.

------, M. A. LeMone, 1980: Cumulonimbus Vertical Velocity Events in GATE. Part II: Synthesis and Model Core Structure. J. Atmos. Sci., 37, 2458-2469. 